\title{
Implementing practice guidelines: A workshop on guidelines dissemination and implementation with a focus on asthma and COPD
}

\author{
Louis-Philippe Boulet MD FRCPC (Chair) ${ }^{1}$, Allan Becker MD FRCPC ${ }^{2}$, Dennis Bowie MD FRCPC ${ }^{3}$, \\ Paul Hernandez MD FRCPC ${ }^{3}$, Andrew Mclvor MD FRCPC ${ }^{3}$, Michel Rouleau MD 4
}

\begin{abstract}
Contributing authors
Jean Bourbeau MD MSc FRCPC, Ian D Graham PhD, Jo Logan RN PhD, France Légaré MD PhD CCFP FCFP, Thomas F Ward MD FRCPC, Robert L Cowie MD MSc FCP(SA), Denis Drouin MD FRCP, Stewart B Harris MD MPH FCFP FACPM, Robyn Tamblyn PhD,

Pierre Ernst MD FRCPC, Wan C Tan MD FRCPC, Martyn R Partridge MD FRCP, Philippe Godard MD, Carla T Herrerias BS MPH, John W Wilson MD, Liz Stirling, Emily-Brynn Rozitis, Nancy Garvey RRCP/RRT CAE, Diane Lougheed MD MSc FRCPC, Manon Labrecque MD FRCPC, Renata Rea RRCP CAE, Martin C Holroyde MSc PhD, Danielle Fagnan MSc, Eileen Dorval (BPharm), Lisa Pogany, Alan Kaplan MD CCFP(EM), Lisa Cicutto RN PhD ACNP CAE, Mary L Allen MA, Serge Moraca BSc, J Mark FitzGerald MB MD FACCP FRCPC FRCP, Francine Borduas MD
\end{abstract}

\begin{abstract}
L-P Boulet, A Becker, D Bowie, P Hernandez, A McIvor, M Rouleau. Implementing practice guidelines: A workshop on guidelines dissemination and implementation with a focus on asthma and COPD. Can Respir J 2006;13(Suppl A):5A-47A.
\end{abstract}

The present supplement summarizes the proceedings of the symposium "Implementing practice guidelines: A workshop on guidelines dissemination and implementation with a focus on asthma and COPD", which took place in Quebec City, Quebec, from April 14 to 16, 2005. This international symposium was a joint initiative of the Laval University Office of Continuing Medical Education (Bureau de la Formation Médicale Continue), the Canadian Thoracic Society and the Canadian Network for Asthma Care, and was supported by many other organizations and by industrial partners. The objectives of this meeting were to examine the optimal implementation of practice guidelines, review current initiatives for the implementation of asthma and chronic obstructive pulmonary disease (COPD) guidelines in Canada and in the rest of the world, and develop an optimal strategy for future guideline implementation. An impressive group of scientists, physicians and other health care providers, as well as policy makers and representatives of patients' associations, the pharmaceutical industry, research and health networks, and communications specialists, conveyed their perspectives on how to achieve these goals.

This important event provided a unique opportunity for all participants to discuss key issues in improving the care of patients with asthma and COPD. These two diseases are responsible for an enormous human and socioeconomic burden around the world. Many reports have indicated that current evidence-based guidelines are underused by physicians and others, and that there are many barriers to an effective translation of recommendations into day-to-day care. There is therefore a need to develop more effective ways to communicate key information to both caregivers and patients, and to promote appropriate health behaviours. This symposium contributed to the initiation of what could become the "Canadian Asthma and COPD Campaign", aimed at improving care and, hence, the quality of life of those suffering from these diseases.

It is hoped that this event will be followed by other meetings that focus on how to improve the transfer of key recommendations from evidence-based guidelines into current care, and how to stimulate research to accomplish this.

Key Words: Asthma; COPD; Evidence-based medicine; Guidelines implementation; Practice guidelines

\section{Symposium sur la diffusion et l'application des lignes directrices en pratique clinique, en particulier sur l'asthme et la MPOC}

Le présent supplément résume le compte rendu du symposium intitulé Implementing practice guidelines: A workshop on guidelines dissemination and implementation with a focus on asthma and COPD qui a eu lieu à Québec entre le 14 et le 16 avril 2005. Ce symposium international était un projet conjoint du bureau de la formation médicale continue de l'Université Laval, de la Société canadienne de thoracologie et du Réseau canadien pour le traitement de l'asthme et était appuyé par de multiples autres organismes et par des partenaires de l'industrie. Cette rencontre visait à examiner l'application optimale de directives de pratique clinique, à analyser les projets en cours visant l'application des directives en matière d'asthme et de maladie pulmonaire obstructive chronique (MPOC) au Canada et dans le reste du monde et à élaborer une stratégie optimale en

The present report was an initiative of the Canadian Thoracic Society and the Canadian Network for Asthma Care in collaboration with the Continuing Medical Eductation Bureau of the Faculté de Médecine de l'Université Laval, Québec, Québec. Chair: Dr Louis-Philippe Boulet ${ }^{1}$ Centre de Pneumologie, Institut universitaire de cardiologie et de pneumologie de l'Université Laval, Hôpital Laval, Québec, Québec;

${ }^{2}$ Allergy 83 Clinical Immunology, Department of Pediatrics 83 Child Health, Children's Hospital of Winnipeg, Winnipeg, Manitoba;

${ }^{3}$ Division of Respirology, Queen Elizabeth II Health Sciences Centre, Dalhousie University, Halifax, Nova Scotia; ${ }^{4}$ Centre de Pneumologie, Hôpital Saint-Sacrement, Québec, Québec

Correspondence and reprints: Dr Louis-Philippe Boulet, Hôpital Laval, 2725 Chemin Sainte-Foy, Québec, Québec G1V 4 G5.

Telephone 418-656-4747, fax 418-656-4762, e-mail lpboulet@med.ulaval.ca 
prévision de l'application des prochaines directives. Un groupe impressionnant de scientifiques, de médecins et d'autres dispensateurs de soins ainsi que des décideurs et des représentants d'associations de patients, l'industrie pharmaceutique, les réseaux de recherche et de la santé et des spécialistes des communications ont partagé leurs visions respectives sur la manière d'atteindre ces objectifs.

Cet événement d'importance a constitué pour tous les participants une occasion idéale de discuter d'enjeux essentiels pour améliorer les soins des patients atteints d'asthme et de MPOC. Ces deux maladies sont responsables d'un énorme fardeau humain et socioéconomique de par le monde. D'après de nombreux comptes rendus, les directives probantes actuelles sont sousutilisées par les médecins et d'autres intervenants, et il existe de nombreux obstacles à une application efficace des recommandations dans les soins quotidiens. Il faut donc mettre en œuvre des moyens plus efficaces de communiquer l'information clé à la fois aux dispensateurs de soins et aux patients et de promouvoir des comportements pertinents en matière de santé. Ce symposium a contribué à la mise sur pied de ce qui pourrait devenir la « campagne canadienne sur l'asthme et le MPOC » afin d'améliorer les soins et, par conséquent, la qualité de vie des personnes atteintes de ces maladies.

Il est à espérer que ce symposium sera suivi d'autres rencontres dont le but sera d'examiner comment on peut faire appliquer plus adéquatement dans les soins courants les principales recommandations des guides de pratique basés sur les données probantes et de stimuler la recherche sur les méthodes requises pour y parvenir.

\section{Care gaps in asthma management}

\author{
Louis-Philippe Boulet MD FRCPC
}

Centre de Pneumologie, Institut universitaire de cardiologie et de pneumologie de I'Université Laval, Hôpital Laval, Québec, Québec

Key Words: Asthma; Asthma management; Asthma treatment; Care gaps; Health care

A sthma is the most common chronic respiratory disorder in Canada, affecting approximately $10 \%$ of the population $(1,2)$. Despite numerous initiatives to improve asthma care, such as the Canadian Asthma Consensus Guidelines (CACG) (3), the prevalence of the disease in this country continues to increase $(2,4,5)$, and the level of control has not sufficiently improved. A 2001 survey (6) reported that $76 \%$ of asthmatic patients treated by primary care practitioners had not achieved the control criteria set out in the CACG. Asthma reduces the daily activities and quality of life of a large number of Canadians, and adds considerably to the nation's health care burden $(2,7-9)$. Factors related to care by physicians and to patients contribute to the lack of progress on this significant health care issue.

\section{FACTORS RELATED TO CARE}

Many barriers to implementation of the CACG appear to reside at the physician level (10). Primary care physicians are the main target of the CACG, yet most remain unfamiliar with the guidelines (11). These guidelines, like many others, are often considered by primary care physicians to be too lengthy, complex and not always easy to integrate into daily practice. Furthermore, the physicians who actively seek to implement the recommendations into their patient care often find that they have insufficient time, personnel and equipment to do so. For example, the limited availability of asthma educators and of spirometry may make it difficult for physicians to measure airway function and to provide adequate education; thus, variable airway obstruction is often not measured objectively (11) and proper asthma control assessment may be missing (12). The 2001 survey (6) also revealed that while $91 \%$ of patients thought that their asthma was well controlled, according to current criteria, the true figure was $24 \%$ (5). More recent surveys have shown that the situation still remains far from optimal $(13,14)$.

The result is that many patients are not accurately diagnosed and/or their asthma is improperly treated. For example, patients with a chronic cough due to postnasal discharge, or gastroesophageal or nonspecific respiratory symptoms, may be misdiagnosed with asthma (15). Moreover, contrary to the CACG recommendations, short-acting bronchodilators are frequently overused and inhaled corticosteroids (ICS) are frequently underused, resulting in significant asthma-related morbidity (16). Introduction of ICS may also be delayed, despite the fact that even patients with recently diagnosed, mild asthma benefit from early corticosteroid treatment $(17,18)$. Furthermore, patients whose symptoms are not controlled by low to moderate doses of ICS may be given high doses of ICS, despite recommendations to add another medication such as a long-acting, inhaled beta-2-agonist when symptoms are insufficiently controlled by a low dose of ICS (19). Moreover, 'controllers' such as ICS are still underused $(20,21)$, regular assessments of the lowest efficacious doses of medications are often not conducted, action plans for the management of exacerbations are often not used, and patient compliance and disease control are infrequently assessed (22-25).

Education provided by knowledgeable health care professionals - primarily family physicians, asthma specialists and asthma educators - is also critical for optimizing patient compliance and, hence, treatment success $(3,26)$. A Cochrane meta-analysis has shown that discussion of the written action plan and regular review can significantly reduce asthma-related morbidity (27). However, there remains insufficient education and referral to specialized asthma educators. Although most general practitioners regard asthma education as important, many feel they are too busy to integrate education into all or most patient visits. Most also fail to refer patients to asthma educators (28), often because of the nonintegration of formal education into current care or the lack of availability of such educators in many parts of the country (29-31).

Inadequate attention to education can result in suboptimal communication of the rationale behind suggested interventions and of ways to optimize compliance. Among important questions that patients should be asked, but rarely are asked, are whether they understand the role and potential side effects of their medication, and how they plan to implement the environmental measures their doctors have recommended $(3,32,33)$. A large study found that $30 \%$ of asthmatic patients were dissatisfied with their asthma treatment and that poor communication was one of the main contributors to this dissatisfaction (34). Many communication problems could be alleviated and care improved by referring patients to specially trained asthma educators $(35,36)$.

Regular follow-up is another key component of asthma care $(3,37)$. Unfortunately, many asthmatic patients are treated at walk-in clinics or emergency departments and, hence, do not receive regular follow-up from medical professionals. Thus, their education is woefully inadequate and their compliance with treatment is usually very poor $(38,39)$. 


\section{FACTORS RELATED TO PATIENTS}

More than one-third of asthmatic patients expect their doctor to cure them (34), despite the fact that medical science has not yet made such an option available. Other factors complicating the efforts of health care professionals to treat asthma are the patients' potential denial of having the disease, their gathering of significant misinformation from the Internet and other media, and patient misinterpretation of their asthmatic symptoms $(40,41)$. One result is that patients often disregard some of their symptoms and think that their asthma is under control when it is not. Another result is that patients may not use 'controller' inhalers or monitoring devices frequently enough, while physicians may not ask questions that would allow these problems to be detected and possibly rectified $(42,43)$.

Patients may also have fears and misconceptions about asthma, arising from their particular ethnic, religious and/or educational backgrounds. Many people are also reluctant to ask specific questions for fear of asking a 'stupid' question or of taking up too much of the physician's time. Hence, many patients do not ask physicians about the impact the disease may have on their lifestyle, and about other aspects of disease management and monitoring that they do not fully understand.

Other patient factors that mitigate against achievement of adequate asthma control include the following: lack of social support; reluctance to follow environmental measures such as reduction of exposure to pets (44); poor compliance to medication for various reasons, including insufficient understanding of the role and potential side effects of the medication, the complexity of the medication regimen and/or the cost involved $(24,25)$; reluctance to stop smoking or to reduce exposure to secondhand smoke $(45,46)$; and sedentary lifestyle, obesity and unrecognized or untreated comorbidities (47-49).

\section{CLOSING THE GAPS}

This is a complex issue. We have addressed some means to improve asthma control and reduce care gaps (Table 1). Among the most urgent actions required to achieve these goals are improvement of the dissemination and adoption of the CACG through more effective continuing medical education programs and asthma management aids, as well as education and incentives to empower patients to better manage their disease. There is a particular need to develop and/or adapt interventions for previously underserved groups such as adolescents, elderly patients and patients with low socioeconomic status. Highquality education of patients and caregivers, and particularly, referral to asthma educators must be increased.

\section{SUMMARY}

Numerous care gaps still exist which, if closed, would likely significantly reduce the morbidity associated with asthma. Physicians, particularly those in primary care, need to continue to be supported in their efforts to deliver optimal care and enable positive health behaviours among their patients through improved communication and education efforts surrounding the CACG.

\section{REFERENCES}

1. Sears MR. Natural history and epidemiology. In: FitzGerald JM, O'Byrne PM, Boulet L-P, Ernst P, eds. Evidence-based Asthma Management, 1st edn. Hamilton: BC Decker Inc, 2001:1-12.

2. Canadian Institute for Health Information, Canadian Lung Association, Health Canada, Statistics Canada. Respiratory

\section{TABLE 1}

Measures for improving asthma care

- Improve dissemination and implementation of guidelines

- Develop continuing medical education programs targeted to identified care gaps

- Develop aids to practice

- Facilitate access to resources (eg, educators and specialists)

- Improve access to therapies

- Adapt/develop specific interventions for the following groups:

- Adolescents

- Elderly patients

- Patients with high asthma-related morbidity/health care use

- Patients with low socioeconomic status

- Patients with psychosocial problems

Measures for improving patient care and self-management

- Provide educational interventions

- Provide good communication with caregivers

- Apply preventive measures

- Reduce relevant environmental exposures (eg, allergens and tobacco)

- Encourage patients to use medication adequately

- Encourage patients to comply adequately with other treatments and adequate management

- Enact appropriate changes in action plans on management of exacerbations

- Properly assess asthma control and recognize symptoms

- Increase use of peak expiratory flow measures

Disease in Canada, 1st edn. Ottawa: Health Canada, 2001:1-102.

3. Boulet LP, Becker A, Berube D, Beveridge R, Ernst P; Canadian Asthma Consensus Group. Canadian Asthma Consensus Report, 1999. CMAJ 1999;161(Suppl 11):S1-S61.

4. Sly RM. Changing prevalence of allergic rhinitis and asthma. Ann Allergy Asthma Immunol 1999;82:233-52.

5. Britton J. Asthma's changing prevalence. BMJ 1992;304:857-8.

6. Chapman KR, Ernst P, Grenville A, Dewland P, Zimmerman S. Control of asthma in Canada: Failure to achieve guideline targets. Can Respir J 2001;8(Suppl A):35A-40A.

7. Redd SC. Asthma in the United States: Burden and current theories. Environ Health Perspect 2002;110(Suppl 4):557-60.

8. Blainey AD, Beale A, Lomas D, Partridge MR. The cost of acute asthma. How much is preventable? Health Trends 1991;22:151-3.

9. Weiss KB, Sullivan SD, Lyttle CS. Trends in the cost of illness for asthma in the United States, 1985-1994. J Allergy Clin Immunol 2000;106:493-9.

10. Davis D. Clinical practice guidelines and the translation of knowledge: The science of continuing medical education. CMAJ 2000;163:1278-9.

11. Jin R, Choi BC, Chan BT, et al. Physician asthma management practices in Canada. Can Respir J 2000;7:456-65.

12. Boulet LP, Phillips R, O’Byrne P, Becker A. Evaluation of asthma control by physicians and patients: Comparison with current guidelines. Can Respir J 2002;9:417-23.

13. Chapman KR, Boulet LP, FitzGerald MJ, McIvor RA, Zimmerman S Patient factors associated with suboptimal asthma control in Canada: Results from the Reality of Asthma Control Study. Am J Respir Crit Care Med 2005;2:A678. (Abst)

14. Bousquet J, Knani J, Henry C, et al. Undertreatment in a nonselected population of adult patients with asthma. J Allergy Clin Immunol 1996;98:514-21.

15. Irwin RS, Boulet LP, Cloutier MM, et al. Managing cough as a defense mechanism and as a symptom. A consensus panel report of the American College of Chest Physicians. Chest 1998;114(Suppl 2):133S-81S.

16. Blais R, Gregoire JP, Rouleau R, Cartier A, Bouchard J, 
Boulet LP; Comite de revue de l'utilisation des medicaments. Ambulatory use of inhaled $\beta_{2}$-agonists for the treatment of asthma in Quebec: A population-based utilization review. Chest 2001;119:1316-21.

17. Selroos O, Lofroos AB, Pietinalho A, Riska H. Asthma control and steroid doses 5 years after early or delayed introduction of inhaled corticosteroids in asthma: A real-life study. Respir Med 2004;98:254-62

18. Pauwels RA, Pedersen S, Busse WW, et al; START Investigators Group. Early intervention with budesonide in mild persistent asthma: A randomised, double-blind trial. Lancet 2003;361:1071-6.

19. Kelly HW. What is new with the $\beta_{2}$-agonists: Issues in the management of asthma. Ann Pharmacother 2005;39:931-8.

20. O'Byrne PM. Inhaled corticosteroid therapy in newly detected mild asthma. Drugs 1999;58(Suppl 4):17-24.

21. Laforest L, Pacheco Y, Bousquet J, Kocevar VS, Yin D, Van Ganse E. How appropriate is asthma therapy in general practice? Fundam Clin Pharmacol 2005;19:107-15.

22. Boulet LP, Thivierge RL, Bellera C, Dorval E, Collet JP. Physicians' assessment of asthma control in low vs high asthma-related morbidity regions. J Asthma 2004:41:813-24.

23. Weinstein AG. Should patients with persistent severe asthma be monitored for medication adherence? Ann Allergy Asthma Immunol 2005;94:251-7.

24. Lacasse Y, Archibald H, Ernst P, Boulet LP. Patterns and determinants of compliance with inhaled steroids in adults with asthma. Can Respir J 2005;12:211-7.

25. Matheson M, Wicking J, Raven J, et al. Asthma management: How effective is it in the community? Intern Med J 2002;32:451-6.

26. Gibson P, Boulet LP. Asthma education. In: FitzGerald JM, O'Byrne PM, Boulet L-P, Ernst P, eds. Evidence-based Asthma Management, 1st edn. Hamilton: BC Decker Inc, 2001:275-90.

27. Gibson PG, Powell H, Coughlan J, et al. Self-management education and regular practitioner review for adults with asthma. Cochrane Database Syst Rev 2003:CD001117.

28. Chapman KR, FitzGerald MJ, Boulet LP, McIvor RA, Rufino S. Certified asthma educators are underutilized: The reality of asthma control study. Am J Respir Crit Care Med 2005;2:A678. (Abst)

29. Cowie RL, Cicutto L, Boulet LP; Patient Education Program Committee, Canadian Network for Asthma Care. Asthma education and management programs in Canada. Can Respir J 2001;8:416-20. (Erratum in 2002;9:37).

30. Boulet LP. Asthma guidelines and outcomes. In: Adkinson MF Jr, Yunginger JW, Busse WW, Bochner BS, Holgate ST, Simons FER, eds. Middleton's Allergy Principles and Practice, 6th edn. Philadelphia: Mosby, 2003:1283-301.

31. Robichaud P, Côté J, Battisti L, Parent JG, Boulet LP. Application of the PRECEDE model and educational intervention aiming at increased self efficacy of asthmatic consulting at the emergency department (ED). Am J Respir Crit Care Med 2000;161:A54. (Abst)

32. Gillissen A. Managing asthma in the real world. Int J Clin Pract 2004:58:592-603.

33. Boulet LP. Perception of the role and potential side effects of inhaled corticosteroids among asthmatic patients. Chest 1998;113:587-92.

34. Mancuso CA, Rincon M, Robbins L, Charlson ME. Patients' expectations of asthma treatment. J Asthma 2003;40:873-81.

35. Boulet LP. Asthma education: What has been its impact? Can Respir J 1998;5(Suppl A):91A-6A.

36. Navaie-Waliser M, Misener M, Mersman C, Lincoln P. Evaluating the needs of children with asthma in home care: The vital role of nurses as caregivers and educators. Public Health Nurs 2004;21:306-15.

37. Lemiere C, Bai T, Balter M, et al. Adult Asthma Consensus Guidelines Update 2003. Can Respir J 2004;11(Suppl A):9A-18A

38. Krishnan JA, Riekert KA, McCoy JV, et al. Corticosteroid use after hospital discharge among high-risk adults with asthma. Am J Respir Crit Care Med 2004;170:1281-5.

39. Heisler M, Blumenthal DS, Rust G, Dubois AM. The Second Annual Primary Care Conference - Programming to eliminate health disparities among ethnic minority populations: An introduction to proceedings. Ethn Dis 2003;13(Suppl 3):S1-S5.
40. Farr RS. Coping styles in asthma. J Allergy Clin Immunol 1999;103:29-35.

41. Boulet LP, Leblanc P, Turcotte H. Perception scoring of induced bronchoconstriction as an index of awareness of asthma symptoms. Chest 1994;105:1430-3.

42. Giraud V, Roche N. Misuse of corticosteroid metered-dose inhaler is associated with decreased asthma stability. Eur Respir J 2002;19:246-51

43. Coté J, Cartier A, Malo JL, Rouleau M, Boulet LP. Compliance with peak expiratory flow monitoring in home management of asthma. Chest 1998;113:968-72.

44. Coté J, Cartier A, Robichaud P, et al. Influence of asthma education on asthma severity, quality of life and environmental control. Can Respir J 2000;7:395-400.

45. Sawyer SM. Action plans, self-monitoring and adherence: Changing behaviour to promote better self-management. Med J Aust 2002;177(Suppl):S72-S4

46. Lemiere C, Boulet LP. Cigarette smoking and asthma: A dangerous mix. Can Respir J 2005;12:79-80.

47. Tantisira KG, Weiss ST. Complex interactions in complex traits: Obesity and asthma. Thorax 2001;56(Suppl 2):S64-S73.

48. Simard B, Turcotte H, Marceau P, et al. Asthma and sleep apnea in patients with morbid obesity: Outcome after bariatric surgery. Obes Surg 2004;14:1381-8.

49. Weisgerber MC, Guill M, Weisgerber JM, Butler H. Benefits of swimming in asthma: Effect of a session of swimming lessons on symptoms and PFTs with review of the literature. J Asthma 2003;40:453-64

Correspondence: Dr Louis-Philippe Boulet, Hôpital Laval, 2725 Chemin Sainte-Foy, Québec, Québec G1V 4G5. Telephone 418-656-4747, fax 418-656-4762, e-mail lpboulet@med.ulaval.ca

\section{Care gaps in chronic obstructive pulmonary disease management}

Jean Bourbeau MD MSc FRCPC1, Paul Hernandez MDCM FRCPC 2

${ }^{1}$ Respiratory Epidemiology and Clinical Research Unit, Montreal Chest Institute, McGill University Health Centre,

Montreal, Quebec; ${ }^{2}$ Respirology Divsion, Queen Elizabeth II Health Sciences Centre, Dalhousie University, Halifax, Nova Scotia

Key Words: Care gaps; Chronic bronchitis; COPD; COPD management; COPD treatment; Emphysema; Health care

Chronic obstructive pulmonary disease (COPD) is one of the most common causes of chronic disease, disability and mortality affecting adults around the world (1). In Canada, COPD accounts for a huge disease burden, with consequences for individuals, families, the health care system and society (2). The prevalence of COPD increases with age for both men and women. The increased proportion of people older than 65 years of age will produce an increased number of COPD-related deaths. Furthermore, COPD is expected to become the fifth leading cause of premature death and disability in the coming decade, behind ischemic heart disease, depression, accidents and stroke (1). In addition to a major impact on patients' health status, patients with COPD often experience a decline in personal independence and require a wide variety of care and services. Many international and national guidelines (3-5) have been developed to improve the diagnosis and the management of COPD, but relatively little is known about real-life practice.

\section{CORRECT LABELLING}

Correct labelling of COPD needs to be improved. In a recent survey (6), only $20 \%$ of participants reported having COPD, 
while most of the subjects were using the terms 'chronic bronchitis' and 'emphysema'. Ensuring the correct use of the term 'COPD' by health professionals and patients alike would likely help to increase awareness among the public, the health community and the decision-makers.

\section{MAKING THE DIAGNOSIS}

A barrier to the optimal management of COPD is underdiagnosis of the disease. Population-based studies have shown that the true prevalence of COPD is largely underestimated (7-9). In one study (7), it was shown that $70 \%$ of the population with a low level of lung function (as indicated by a forced expiratory volume in $1 \mathrm{~s}\left[\mathrm{FEV}_{1}\right] /$ forced vital capacity [FVC] ratio of less than 0.70) did not have a current diagnosis of COPD (7). The diagnosis is often made only when the disease has reached an advanced stage.

Studies of COPD have not looked at the causes of underdiagnosis, specifically whether it is primarily the physician or the patient at the root of the problem. For asthma, it has been shown that underdiagnosis may be in large part due to the patient not reporting symptoms and only in a small part due to factors related to the physician (10). Poor perception and minimization of symptoms by patients could partly explain the reason that patients do not present to a physician. For COPD, it is well known that the relationship between dyspnea or disability and air flow obstruction is weak $(11,12)$. Therefore, awareness of COPD has to be increased and specific criteria developed in clinical practice to help physicians make an early diagnosis of the disease.

The Canadian Thoracic Society (CTS) Guidelines (4) have recommended that people 40 years of age or older who are current or ex-smokers and suffer from typical respiratory complaints (eg, cough and phlegm, activity-related breathlessness and recurrent respiratory tract infections) are at high risk for having COPD, and that they should be targeted for confirmation of the suspected clinical diagnosis by spirometry. The CTS recommended that "objective demonstration of air flow obstruction by spirometry is essential for the diagnosis of COPD. A postbronchodilator $\mathrm{FEV}_{1}$ of less than $80 \%$ of the predicted normal value and a ratio $\mathrm{FEV}_{1} / \mathrm{FVC}<0.70$ are both required for COPD to be diagnosed" (4).

However, a simple test, like spirometry, is not widely accessible or used in primary care. There is also a lack of familiarity with the interpretation of pulmonary function tests among primary care practitioners. In the daily routine of a general practice, screening the general population for COPD is not a realistic option. Thus, a targeted case-finding strategy based on specific criteria is desirable if one wishes to detect patients with COPD. In a 2002 study (13) of a random group of smokers visiting their physician, one patient at risk of COPD ( $\mathrm{FEV}_{1}$ less than $80 \%$ predicted normal value) was found for every five to six smokers tested. The positive predictive value of $18 \%$ was increased to $27 \%$ when this was restricted to coughing smokers; it was increased only to $29 \%$ when symptoms included coughing, wheezing and dyspnea. The mean time needed for adequately performed spirometry was $4 \mathrm{~min}$ to $5 \mathrm{~min}$. It has been shown with modern spirometry equipment that after a one-half day training session, $84 \%$ of the spirometry curves obtained were of sufficient quality to determine the $\mathrm{FEV}_{1}$ (13). More research has to be conducted to find answers to the ongoing debate regarding the possibility of improving the early diagnosis of COPD in primary care, and the accuracy and impact of such a diagnosis on patient outcomes.

\section{MANAGING COPD}

Special attention is needed in primary care where the majority of patients are treated. Poor symptom control and frequent acute exacerbations are likely to be key drivers of unscheduled clinic visits and hospitalizations. Surprisingly, little is known about the condition beyond its epidemiology, clinical and physiological nature, and disease impacts.

\section{Smoking cessation}

Smoking cessation remains the only therapy proven to slow the accelerated rate of decline in lung function that is characteristic of COPD $(14,15)$. Physicians have a primary role in counselling patients, whenever possible, for smoking cessation. Even brief counselling sessions have been shown to be effective. More intensive interventions such as group or individual counselling or pharmacotherapy (eg, nicotine replacement therapy or bupropion) result in greater quit rates. Unfortunately, variable access to such intensive interventions across Canada remains a barrier to providing optimal help to smokers who are trying to quit.

\section{Pharmacotherapy management}

The primary treatment goal in patients with symptomatic COPD is the improvement of dyspnea and exercise tolerance, and a reduction in the frequency and severity of exacerbations. Recently, the results of an important survey (the Confronting COPD Survey) (16) in North America and Europe has highlighted some important gaps in the care of patients with COPD. The survey was conducted as a telephone interview. The criteria for inclusion of patients in the survey were as follows: at least 45 years of age; smoking history of at least 10 years; and previous diagnosis of COPD, emphysema or chronic bronchitis, or chronic bronchitis defined by persistent coughing with phlegm or sputum from the chest for the past two years or more. Patients were questioned using a validated questionnaire such as the American Thoracic Society questionnaire and the Medical Research Council scale as a measure of the severity of COPD symptoms. Additional questions were included to collect information on patient demographics, activity limitation due to COPD, health care contacts and the use of respiratory therapy.

The results of the Canadian survey indicated that many patients with COPD, despite having symptoms of dyspnea, were not being treated (17). Although patients were visiting a health professional for treatment, $50 \%$ of patients reported that their symptoms were only somewhat controlled, poorly controlled or not at all controlled. Almost $40 \%$ of patients surveyed had not received an influenza vaccination in the past year. Physicians who were questioned as part of the survey revealed a need for further education on the effectiveness of varying approaches to the management of COPD. Most COPD guidelines (3-5) recommend bronchodilators as the mainstay of pharmacotherapy for COPD and not ICS (unlike in asthma where they are the first-line treatment). In the survey, the most commonly prescribed drug classes were ICS, followed by bronchodilators. The undertreatment seen in the survey suggests the persistence of a significant care gap in clinical practice. There is not enough information from the survey to establish whether medications were appropriately prescribed according to the disease severity, as recommended in the current CTS COPD Guidelines (4). 


\section{Nonpharmacological interventions}

The care gap in the management of COPD is not limited to pharmacotherapy. The CTS Guidelines (4) have strongly positioned nonpharmacological treatment for COPD:

"A management strategy consisting of combined pharmacotherapy and nonpharmacological interventions can effectively improve symptoms, activity levels and quality of life, even in patients with severe COPD".

Pulmonary rehabilitation has been proven to be effective in improving dyspnea, exercise tolerance and health-related quality of life (18). The CTS Guidelines (4) make a strong recommendation that patients with COPD should have earlier access to this modality of treatment. In Canada, it was estimated that there were only 44 pulmonary rehabilitation programs in 1999; therefore, among the 500,000 to one million Canadians with COPD, fewer than 5000 patients can access a pulmonary rehabilitation program every year (4).

In primary care, attention continues to focus on initiating treatment with drug prescriptions only. In a 2001 study (19), it was shown that time spent with patients with diabetes or other chronic conditions was only slightly more than with acute disease (average visit lengths of $10.5 \mathrm{~min}$ to $11 \mathrm{~min}$ versus $9.7 \mathrm{~min}$, respectively). Visits with patients with chronic conditions included slightly more time for lifestyle and medication counselling than did acute illness visits. The care of chronic diseases, such as COPD, is often based on the reaction to acute episodes of disease worsening, as reported by the patients. In contrast, effective chronic disease management should ensure that the patient is able to manage her/his disease on a day-to-day basis. This self-management approach requires that patients have the confidence and the specific skills to control their disease in collaboration with a health care team. Currently, there is an insufficient number of health care professionals trained as COPD educators in Canada. Self-management applied to patients with COPD has been shown to be beneficial in reducing hospital admissions and patient well-being $(20,21)$. There are indications that the current health care system of episodic and acute disease-focused care is not adapted to meet the global needs of patients with COPD. More research is needed on new methods of delivering health care.

\section{SUMMARY}

Although we have greatly improved our knowledge of the effectiveness of specific pharmacological and nonpharmacological treatments in managing COPD, less is known on how to effectively transfer this knowledge into clinical practice. From what we currently know, it seems that there is a large gap between evidence-based recommendations and 'real world' practice. More studies are needed to evaluate the care gaps in COPD and to develop strategies to improve adherence to clinical practice guidelines. Another challenge is the need to adapt health care delivery systems to better address the needs of patients living with chronic illnesses, such as COPD. Finally, access to evidence-based pharmacological and nonpharmacological treatments within our publicly funded system of health care requires improvement. Public policy makers and health care professionals have to work more closely to identify and narrow care gaps of COPD in Canada.

\section{REFERENCES}

1. Murray CJ, Lopez AD, eds. In: The Global Burden of Disease:

A Comprehensive Assessment of Mortality and Disability from
Diseases, Injuries and Risk Factors in 1990 and Projected to 2020. Cambridge: Harvard University Press, 1996.

2. The Centre for Chronic Disease Prevention and Control, Health Canada, Canadian Institute for Health Information. Editorial Board Respiratory Disease in Canada. Ottawa: Health Canada, 2003.

3. Global Initiative for Chronic Obstructive Lung Disease. Global Strategy for the Diagnosis, Management, and Prevention of Chronic Obstructive Pulmonary Disease. Updated 2004. $<$ http://www.goldcopd.com> (Version current at September 8, 2004).

4. O'Donnell DE, Aaron S, Bourbeau J, et al; Canadian Thoracic Society recommendations for management of chronic obstructive pulmonary disease - 2003. Can Respir J 2003;10(Suppl A):11A-65A.

5. Celli BR, MacNee W; ATS/ERS Task Force. Standards for the diagnosis and treatment of patients with COPD: A summary of the ATS/ERS position paper. Eur Respir J 2004;23:932-46. (Erratum in 2006;27:242).

6. Rennard S, Decramer M, Calverley PM, et al. Impact of COPD in North America and Europe in 2000: Subjects' perspective of Confronting COPD International Survey. Eur Respir J 2002;20:799-805.

7. Petty T, Rennard SI. Introduction: Mechanisms of COPD. Chest 2000;117(Suppl 1):219S-23S.

8. Siafakas NM, Vermeire P, Pride NB, et al. Optimal assessment and management of chronic obstructive pulmonary disease (COPD). The European Respiratory Society Task Force. Eur Respir J 1995;8:1398-420.

9. Vrijhoef HJ, Diederiks JP, Wesseling GJ, van Schayck CP, Spreeuwenberg C. Undiagnosed patients and patients at risk for COPD in primary health care: Early detection with the support of non-physicians. J Clin Nurs 2003;12:366-73.

10. van Schayck CP, van Der Heijden FM, van Den Boom G, Tirimanna PR, van Herwaarden CL. Underdiagnosis of asthma: Is the doctor or the patient to blame? The DIMCA project. Thorax 2000;55:562-5.

11. Bestall JC, Paul EA, Garrod R, Garnham R, Jones PW, Wedzicha JA. Usefulness of the Medical Research Council (MRC) dyspnoea scale as a measure of disability in patients with chronic obstructive pulmonary disease. Thorax 1999;54:581-6.

12. Hajiro T, Nishimura K, Tsukino M, Ikeda A, Koyama H, Izumi T. Analysis of clinical methods used to evaluate dyspnea in patients with chronic obstructive pulmonary disease. Am J Respir Crit Care Med 1998;158:1185-9.

13. Van Schayck CP, Loozen JM, Wagena E, Akkermans RP, Wesseling GJ. Detecting patients at a high risk of developing chronic obstructive pulmonary disease in general practice: Cross sectional case finding study. BMJ 2002;324:1370.

14. Fletcher C, Peto R. The natural history of chronic airflow obstruction. Br Med J 1977;1:1645-8.

15. Anthonisen NR, Connett JE, Murray RP. Smoking and lung function of Lung Health Study participants after 11 years. Am J Respir Crit Care Med 2002;166:675-9.

16. Halpern MT, Musin A, Sondhi S. Economic analysis of the Confronting COPD survey: Methodology. Respir Med 2003;97(Suppl C):S15-S22.

17. Chapman KR, Bourbeau J, Rance L. The burden of COPD in Canada: Results from the Confronting COPD survey. Respir Med 2003;97(Suppl C):S23-S31.

18. Lacasse Y, Wong E, Guyatt GH, King D, Cook DJ, Goldstein RS. Meta-analysis of respiratory rehabilitation in chronic obstructive pulmonary disease. Lancet 1996;348:1115-9.

19. Yawn B, Zyzanski SJ, Goodwin MA, Gotler RS, Stange KC. Is diabetes treated as an acute or chronic illness in community family practice? Diabetes Care 2001;24:1390-6.

20. Bourbeau J, Julien M, Maltais F, et al; Chronic Obstructive Pulmonary Disease axis of the Respiratory Network Fonds de la Recherche en Sante du Quebec. Reduction of hospital utilization in patients with chronic obstructive pulmonary disease: A disease-specific self-management intervention. Arch Intern Med 2003;163:585-91.

21. Bourbeau J, Nault D, Dang-Tan T. Self-management and behaviour modification in COPD. Patient Educ Couns 2004;52:271-7.

Correspondence: Dr Jean Bourbeau, Montreal Chest Institute, McGill University Health Centre, 3650 St Urbain, Montréal, Québec H2X 2P4. Telephone 514-934-1934 ext 32185, fax 514-843-2083, e-mail jean.bourbeau@mcgill.ca 


\section{How to influence medical practice: A conceptual framework}

\author{
Ian D Graham PhD1, Jo Logan RN PhD²
}

${ }^{1}$ Clinical Epidemiology Program, Ottawa Health Research Institute; School of Nursing and Department of Epidemiology \& Community Medicine; ${ }^{2}$ School of Nursing, University of Ottawa, Ottawa, Ontario

$T^{\text {he }}$ Ond Cttawa Model of Research Use offers a comprehensive, interdisciplinary framework of elements that comprise the process of the transfer of health care knowledge. It is derived from theories of change, published literature and reflection. In the case of guideline implementation, these elements are as follows: the practice guidelines that are to be disseminated and adopted in clinical practice; the potential adopters; the practice environment of the potential adopters; the various interventions that will be used to disseminate the guidelines and promote their adoption in clinical practice; the adoption and sustained use of the guidelines; and physician, patient and economic outcomes resulting from implementation of the guidelines. A particular advantage of the model is that it may be applied at any level in the delivery of care (ie, to an individual professional, a health care team, an organization or even an entire health care system).

The model considers guideline implementation to be an interactive, multistep, synergistic process between many individuals rather than a sequential process involving only one individual or group of individuals at a time (1). Although presented as a linear diagram (Figure 1), all the model elements influence and are influenced by each other, reflecting the complexity of the knowledge transfer process. This is depicted by double arrows that create multiple loops in Figure 1.

Furthermore, the model assumes that patients/clients, as well as the societal and health care environments, play key roles in all aspects of the process.

The purpose of the model is to provide research implementors (in this case, health care providers who will implement practice guidelines) with information on what issues to focus on and what activities to undertake. In brief, the model directs implementors to conduct an assessment of factors that may hinder or support the uptake of the guidelines, including the content and presentation of the guidelines, and factors at the level of the potential adopters and their practice environments.

This information is used to select and tailor interventions that can overcome the anticipated barriers and/or enhance the supports. The introduction of the interventions is then monitored to ensure that all potential adopters actually learn about the guidelines and the behaviours/actions that they should be doing. Moreover, monitoring the adoption of the guidelines during the implementation phase can help to determine whether the dose of intervention has been sufficient to bring about the desired change in practice, or whether more of the same or new interventions may be required. Finally, the impact of the implementation process on outcomes is evaluated to determine whether the uptake of the guidelines is having the intended effect and whether there are any unintended consequences of adopting the guidelines. The iterative process then begins again.

Detailed descriptions about how to use the model can be found elsewhere (2-7).

\section{SUMMARY}

Influencing medical practice is a complex process. Although there are a number of knowledge transfer theories/models, the

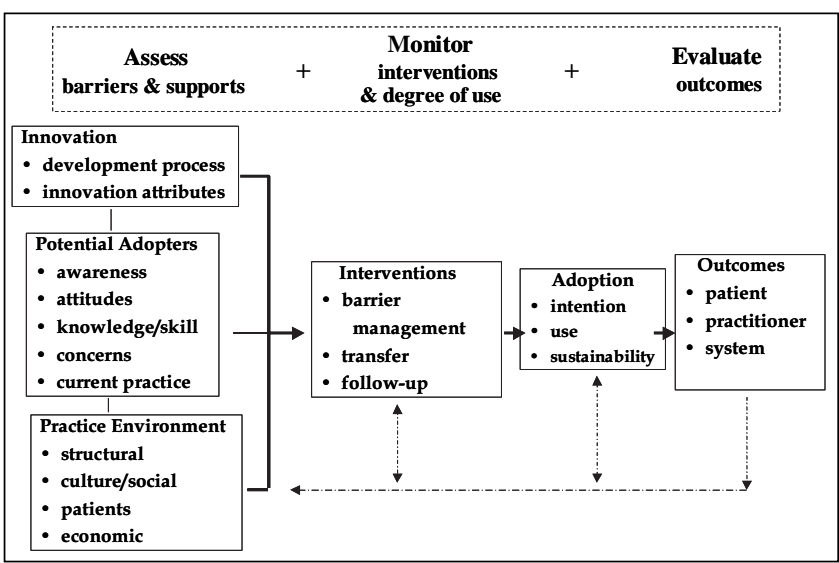

Figure 1) Ottawa Model of Research Use. Adapted with permission from reference 7

use of these frameworks to guide implementation activities is not yet commonplace. If the health care system and patients/clients are to benefit from the use of practice guidelines, researchers and implementors need to become better versed in the knowledge transfer literature, experiment with these frameworks when implementing guidelines and begin to test their usefulness with different guidelines in different contexts.

Dr Ian Graham is a Canadian Institutes of Health Research New Investigator.

\section{REFERENCES}

1. Buxton M, Hanney S. How can payback from health services research be assessed? J Health Serv Res Policy 1996;1:35-43.

2. Logan J, Graham ID. Toward a comprehensive interdisciplinary model of health care research use. Sci Commun 1998;20:227-46.

3. Logan J, Harrison MB, Graham ID, Dunn K, Bissonnette J. Evidence-based pressure-ulcer practice: The Ottawa Model of Research Use. Can J Nurs Res 1999;31:37-52.

4. Graham K, Logan J. Using the Ottawa Model of Research Use to implement a skin care program. J Nurs Care Qual 2004;19:18-24.

5. Harrison M, Logan J, Joseph L, Graham ID. Quality improvement, research and evidence-based practice: 5 years experience with pressure ulcers. Evid Based Nurs 1998;1:108-10.

6. Hogan DL, Logan J. The Ottawa Model of Research Use: A guide to clinical innovation in the NICU. Clin Nurse Spec 2004;18:255-61.

7. Graham ID, Logan J. Innovations in knowledge transfer and continuity of care. Can J Nurs Res 2004;36:89-103.

Correspondence: Dr Ian Graham, Clinical Epidemiology Program Ottawa Health Research Institute, 1053 Carling Avenue, Ottawa, Ontario K1Y 4E9. Telephone 613-798-5555 ext 18273,

fax 613-761-5402, e-mail igraham@ohri.ca

\section{Optimizing the limited resources available for implementing evidence-based practices}

France Légaré MD PhD CCFP FCFP

Department of Family Medicine, Centre hospitalier universitaire de Québec, Hôpital St-François d'Assise, Ville de Québec, Québec

ajor difficulties arise when introducing best evidence, I including clinical practice guidelines, into routine daily practice (1). Data show that approximately $30 \%$ to $40 \%$ of patients do not receive appropriate care and that approximately 


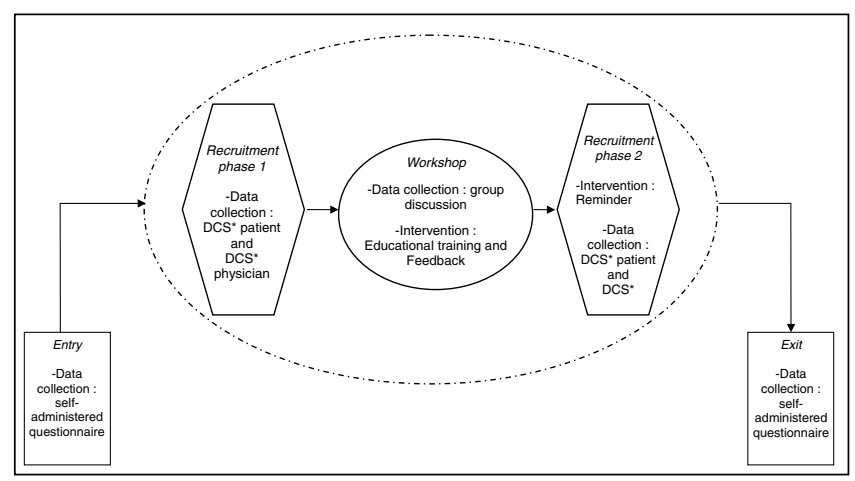

Figure 2) Study design. DCS Decisional Conflict Scale

$20 \%$ to $25 \%$ receive unnecessary or harmful care (1). These statistics explain a growing interest in rigorous studies on how to implement evidence-based practice.

Implementation research refers to a scientific approach to identify and intervene in the underlying mechanisms that can change clinical practice (2). Similar to studies of drug efficacy, such research produces evidence that can be used to modify an undesirable clinical practice. However, implementation studies impose constraints that must be kept in mind. In the present section, we briefly report on an implementation trial of the Ottawa Decision Support Framework (ODSF), and summarize some of the constraints encountered during the trial and how they were addressed. Based on what we learned in this trial, we then suggest strategies to improve future implementation trials of clinical practice guidelines.

\section{THE ODSF}

The ODSF provides a process and clinical tools that are evidencebased. Compared with usual care, the ODSF improves patients' knowledge and creates more realistic patient expectations (3-7), reduces decisional conflict $(3,4)$ and the number of individuals who do not make a decision (4), and also increases satisfaction with the decision-making process (7).

Given the paucity of evidence regarding the implementation of the ODSF in clinical practice, a 'before and after' study was deemed appropriate to explore the factors influencing such implementation and to pilot one implementation intervention (8).

A total of 120 family physicians agreed to participate $(\mathrm{RR}=75 \%)$. To make the most of the few resources that could be allocated to this trial, three main strategies of inquiry were embedded in this trial (Figure 2). These strategies are as follows: discussion groups on perceived help and hindrance to the implementation of the ODSF; theory-based assessment and monitoring of the intention of practitioners to implement the ODSF in their practices; and assessment of the impact of the ODSF on the agreement between the practitioners' and patients' levels of decisional conflict. Data collection involved both qualitative and quantitative methods.

Based on Cochrane systematic reviews (the best level of evidence available at that time), the implementation intervention comprised the following three components: an interactive workshop (9); feedback on the agreement between physicians' and their patients' levels of decisional conflict observed during the phase 1 recruitment period (10); and a reminder of the ODSF during the phase 2 recruitment period (11-13). Given the importance of the local environment in implementing change, the interactive workshop was developed with experts in medical education from the local university (14). Cotrainers were recruited from each clinical site. The interactive workshop included sufficient time for group discussion. To elicit participants' views on using the process and tools provided by the ODSF, a video with a simulated clinical scenario was presented. Participants were then asked about the barriers to and facilitators for implementing this approach in their own clinical practices.

Based on strategies used for medical audits, feedback on the level of agreement reached during the phase 1 recruitment period was provided in the following manner. Physicians received a personalized letter in a sealed envelope. In this letter, each physician's level of agreement on the decisional conflict scores with his or her first five patients was provided. Physicians were also informed about their group performance. During the phase 2 recruitment period, a reminder was given in person by research assistants to physicians. The reminder was provided on one side of a letter-sized sheet of paper and contained a summary of the key elements of the ODSF.

\section{CONSTRAINTS}

The first constraint that needed to be addressed in the trial was the lack of a theory. Indeed, the lack of a theory-based approach has been identified as one of the main reasons why the development of effective interventions to implement evidencebased practice has been hampered (1). For this study, we used the theory of planned behaviour (15) to identify which mechanisms were underpinning the intention of clinicians to adopt the ODSF in their practices. The theory also served to monitor the change in their intention during the study.

Therefore, the entry and exit questionnaires included the validated scales of this theory. Results showed that the strength of exposure to the implementation intervention (ie, the number of components practitioners were exposed to) was associated with the change in their intention to implement the ODSF in their practices. In other words, we observed a dose-response effect. Physicians exposed to all three components showed greater intention to implement the ODSF in their clinical practices than physicians exposed to fewer than three components. In turn, those exposed to fewer than three components showed greater intention than those exposed to none. Moreover, this change in intention was only associated with a change in the physicians' perceived ability to counteract the barriers to implementation. These results are important because they suggest that throughout this study, the full implementation intervention had a more positive influence on the practitioners than an incomplete one.

We also speculate that participants' intentions were changed because the intervention had a positive influence on their perceived ability to counteract the barriers to implementing the ODSF in their practices. Therefore, the results tend to support the need for combining many strategies when implementing clinical practice guidelines in practice. They also tend to support the need for specific activities that identify perceived barriers to the implementation of clinical practice guidelines.

A second constraint relates to recruiting busy clinicians to commit to a longitudinal study. Previous implementation studies have shown how difficult this is (16). Therefore, the interactive workshop that formed one component of the intervention was also used to conduct a group discussion. A 
trained anthropologist used nonparticipant observation methods to collect data in the 13 workshops included in this study (17). The collected data were analyzed for content by two independent assessors (18). Data matrixes were used to identify saturation of themes concerning the perceived help and hindrances to the implementation of the ODSF (19). The following themes were the most frequently identified: familiarity with the model; agreement with the model or a portion of the model; belief that the ODSF would improve patients' outcomes; self-efficacy; motivation; and other external factors. These results indicate that combining medical education activities with data collection on barriers to implementation is possible, is well-received by participants and is a worthy strategy to pursue when implementing clinical practice guidelines.

A third and more important constraint concerned collecting data from both practitioners and patients with decisional conflict scales after clinical encounters. The study design required that practitioners each recruit five patients with whom a decision had been made in each of the two recruitment periods. Each patient was invited to meet with a research assistant who explained the study and presented the consent form and a postclinical encounter questionnaire. Using his or her own words, the patient described, in writing, the decision that had been made with the physician. The patient completed the decisional conflict scale referring to this decision. The research assistant entered the decision that had been identified by the patient on the physician postclinical encounter questionnaire. He or she then handed the questionnaire to the physician who, without knowing the answers on the patient questionnaire, completed it. To carry this out, six research assistants were hired to provide maximum coverage at the five clinical sites five days and two evenings a week over a nine-month period. Surprisingly, we estimated that, overall, only approximately $2 \%$ of the clinical encounters that occurred at these clinical sites during the study were entered in the data set.

\section{IMPLICATIONS FOR FUTURE IMPLEMENTATION RESEARCH ON CLINICAL PRACTICE GUIDELINES}

Throughout this trial, the use of theory provided a systematic approach $(20,21)$. Theory also provided insight into the underlying mechanisms by which change occurred in behavioural intention. This is important because it provided the investigators with the empirical basis to draw inferences about which portions of the intervention had influenced the physicians' intention to implement the ODSF into their practices. In turn, this could enable investigators to compare the results with those from similar studies and, thus, to help identify which underlying mechanisms need to be addressed to implement change into clinical practices. This study also demonstrated that it is possible to use an interactive workshop for two purposes: for data collection on barriers that need to be addressed and as an intervention. However, although maximum coverage of the clinicians' working schedule was put into place, this study showed that if feedback is to be provided to physicians, then new methods need to be developed to support data collection from both practitioners and patients at the point of care.

\section{REFERENCES}

1. Grol R, Grimshaw J. From best evidence to best practice:

Effective implementation of change in patients' care. Lancet 2003;362:1225-30.
2. De Maeseneer JM, van Driel ML, Green LA, van Weel C. The need for research in primary care. Lancet 2003;362:1314-9

3. O'Connor AM, Tugwell P, Wells GA, et al. Randomized trial of a portable, self-administered decision aid for postmenopausal women considering long-term preventive hormone therapy. Med Decis Making 1998;18:295-303.

4. Man-Son-Hing M, Laupacis A, O'Connor AM, et al. A patient decision aid regarding antithrombotic therapy for stroke prevention in atrial fibrillation: A randomized controlled trial. JAMA 1999;282:737-43.

5. Dodin S, Legare F, Daudelin G, Tetroe J, O'Connor A. [Making a decision about hormone replacement therapy. A randomized controlled trial.] Can Fam Physician 2001;47:1586-93.

6. Rostom A, O'Connor A, Tugwell P, Wells G. A randomized trial of a computerized versus an audio-booklet decision aid for women considering post-menopausal hormone replacement therapy. Patient Educ Couns 2002;46:67-74.

7. Laupacis A, O'Connor AM, Drake ER, et al. A decision aid for autologous pre-donation in cardiac surgery - A randomized trial. Patient Educ Couns 2005 [Epub ahead of print]

8. Campbell M, Fitzpatrick R, Haines A, et al. Framework for design and evaluation of complex interventions to improve health. BMJ 2000;321:694-6.

9. Thomson O'Brien MA, Freemantle N, Oxman AD, Wolf F, Davis DA, Herrin J. Continuing education meetings and workshops: Effects on professional practice and health care outcomes. Cochrane Database Syst Rev 2000:CD003030.

10. Thomson O'Brien MA, Oxman AD, Davis DA, Haynes RB, Freemantle N, Harvey EL. Audit and feedback versus alternative strategies: Effects on professional practice and health care outcomes. Cochrane Database Syst Rev 2000:CD000260.

11. Rowe R, Wyatt J, Grimshaw J, et al. Manual paper reminders: Effects on professional practice and health care outcomes [protocol]. Cochrane Database Syst Rev 2004:2;CD001174.

12. Grimshaw JM, Thomas RE, MacLennan G, et al. Effectiveness and efficiency of guideline dissemination and implementation strategies. Health Technol Assess 2004;8:iii-iv,1-72.

13. Hulscher M, Wensing M, van der Weijden T, Grol R. Interventions to implement prevention in primary care. Cochrane Database Syst Rev 2001:CD000362.

14. Lomas J. Diffusion, dissemination, and implementation: Who should do what? Ann N Y Acad Sci 1993;703:226-35.

15. Ajzen I. Attitudes, Personality and Behavior, 1st edn. Maidenhead: Open University Press, 1988.

16. Beaulieu MD, Rivard M, Hudon E, Beaudoin C, Saucier D, Remondin M. Comparative trial of a short workshop designed to enhance appropriate use of screening tests by family physicians. CMAJ 2002;167:1241-6.

17. Mays N, Pope C. Qualitative research: Observational methods in health care settings. BMJ 1995;311:182-4.

18. Mays N, Pope C. Rigour and qualitative research. BMJ 1995;311:109-12.

19. Miles MB, Huberman AM. Qualitative Data Analysis: An Expanded Sourcebook, 2nd edn. Thousand Oaks: Sage Publications, 1994.

20. Slotnick HB, Shershneva MB. Use of theory to interpret elements of change. J Contin Educ Health Prof 2002;22:197-204.

21. Saillour-Glenisson F, Michel P. [Individual and collective facilitators of and barriers to the use of clinical practice guidelines by physicians: A literature review.] Rev Epidemiol Sante Publique 2003;51:65-80.

Correspondence: Dr France Légaré, Department of Family Medicine, Centre hospitalier universitaire de Québec, Hôpital St-François

d'Assise, 10 rue Espinay, Ville de Québec, Québec G1L 3 L5.

Telephone 418-525-4437, fax 418-525-4194, e-mail

france.legare@mfa.ulaval.ca

\section{Should guidelines influence the making of policies and laws?}

Thomas F Ward MD FRCPC

The Ward Group, Victoria, British Columbia

Should there be public policies and laws for the clinical management of chronic diseases? Should guidelines for clinical management influence the making of these policies and laws? 
At first glance, the answer seems clear: of course guidelines should influence public policy, but there is no need to legislate. Or is there? Should government intervene as part of the effort to sustain the health care system? After all, as reported by Tompkins et al (1), Medicare costs are expected to significantly decrease if the natural history of chronic disease is altered by systematic early intervention to lower morbidity, improve quality and avoid unnecessary utilization.

\section{SCOPE OF THE PROBLEM}

It is useful to begin with some terminology. Although the term 'public policy' eludes specific definition, it is frequently understood to be "a course of action or inaction chosen by public authorities to address a given problem or interrelated set of problems" (2). To date, public policy for the clinical management of chronic diseases in this country has been inaction, although British Columbia is embarking on the design of frameworks for some long-term conditions. Health laws, which are simply health policies that have been rendered into legislation, are few, and they refer to infectious disease and other matters of public health (3). This is not a surprise because government policies have focused more on safety of the general public and less on that of the individual.

However, chronic disease management has gained the attention of multiple levels of government in Canada, if for no other reason than the stark realities of economics. The World Health Organization has reported that the growing burden of chronic diseases is the biggest problem facing all national health care systems (4). For example, the cost of chronic disease care in Nova Scotia has been estimated to be $60 \%$ of total medical care expenditures, using 1998 data (5). The percentage is likely only slightly higher in the rest in the country. Moreover, American data suggest that $45 \%$ of those with chronic disease are likely to have more than one chronic condition - and for those older than 65 years of age, this figure rises to nearly $70 \%$ (6). In Great Britain, approximately $25 \%$ of people with a long-standing condition have three or more diseases (7).

\section{INHIBITORS TO CREATION OF PUBLIC POLICY}

Chronic diseases may have precipitated the creation of public policy and legislation - most notably, laws and regulations aimed at reducing tobacco use - but their clinical management has not. Clinical practice guidelines or chronic disease management frameworks could (and should) influence policy at a regional or provincial/territorial level, as they have in other jurisdictions in the world. Why has there not been more policy development related to chronic disease management?

Certainly an overarching conundrum for policy makers is that chronic disease management is not acute care and, thus, is not imbedded in the foundation of our health care system. As such, components of care - interdisciplinary teams, communitybased care, partnerships with family caregivers and information technology support - are not components of more familiar acute care traditions, nor is disease prevention such a component.

Three factors are principal inhibitors to policy creation. The first is the absence of a system-wide electronic health record with built-in decision support systems. Patient information and diagnosis are the core of the electronic health record, while clinical practice guidelines can be integrated into decision support tools for care teams. Unfortunately, progress toward an electronic health record has been slow in Canada. The recent target completion date of 2020 set by Canada Health Infoway is unacceptable and must be reconsidered.

The second factor is the tension between professional autonomy and adherence to clinical guidelines or chronic disease management framework. This is exaggerated in the context of putative legislation because evaluation of performance would rest outside of the profession, likely with regional health authorities or provincial governments.

Historically, the concept of clinical autonomy has been central to the occupational status of the medical profession. However, there are signals of change. In the United Kingdom, Harrison and Dowswell (8) investigated the impact of current government policies, new institutions and governance arrangements relating to clinical practice on the ability of physicians to set their own limits and to judge the quality of their own work. They found that general practitioners accepted the need to discharge 'bureaucratic accountability' and, in particular, to maintain records of clinical decisions. These results indicate that physicians are willing to accept some sharing of oversight of their medical work. Indeed, the study, in reviewing the results of policies set by a central government, provides further evidence of the intermediary or contingent, rather than independent, character of professional autonomy.

The third challenge in translating any clinical guidelines into policy is achieving consensus within the professional community on the recommendations and then having them adopted appropriately by everyone. Success in achieving an evidence-based, best practice guideline has been uneven at best in Canada, according to an article in the Canadian Medical Association Journal (9). With more than a touch of irony, Dr Steven Lewis suggests that the inability to reach agreement only strengthens the need for single, national guidelines: "If practitioners are going to ignore [clinical practice guidelines], they might as well ignore the best" (10).

\section{REFERENCES}

1. Tompkins CP, Bhalotra S, Trisolini M, Wallack SS, Rasgon S, Yeoh H. Applying disease management strategies to Medicare. Milbank $Q$ 1999;77:461-84.

2. Pal LA. Beyond Policy Analysis: Public Issue Management in Turbulent Times, 1st edn. Toronto: ITP Nelson, 1997.

3. Downie J, Caulfield T, Flood C, eds. Canadian Health Law and Policy, 2nd edn. Toronto: Butterworths, 2002.

4. World Health Organization - Motion on a Global Strategy for the Prevention of Non-Communicable Diseases, World Health Assembly, 2002.

5. Colman R. The Cost of Chronic Disease in Nova Scotia. Nova Scotia: Genuine Progress Index for Atlantic Canada, 2002.

6. Hyatt JD. Integrating care for chronic conditions: The promise for an aging population. 27th Annual National Wellness Conference. Stevens Point, July 13 to 18, 2002.

7. United Kingdom Department of Health. Chronic Disease Management: A Compendium of Information. London: United Kingdom Department of Health, 2004.

8. Harrison S, Dowswell G. Autonomy and bureaucratic accountability in primary care: What British practitioners say. Sociol Health Illn 2002;24:208-26.

9. Graham ID, Beardall S, Carter AO, et al. What is the quality of drug therapy clinical practice guidelines in Canada? CMAJ 2001;165:157-63.

10. Lewis SJ. Further disquiet on the guidelines front. CMAJ 2001;165:180-1.

Correspondence: Dr Thomas Ward, Broadmead RPO, PO Box 53549, Victoria, British Columbia V8X 5K2. Telephone 250-744-1416, e-mail thomas.ward@shaw.ca 


\section{Evaluating the impact of guidelines}

\author{
Robert L Cowie MD MSc FCP(SA)
}

Departments of Medicine and Community Health Sciences, Division of Respiratory Medicine, University of Calgary, Calgary, Alberta

U ltimately, the purpose of asthma guidelines is to decrease the impact of the disease on those who suffer from it. The Canadian Asthma Consensus Conference of 1996 (1), the 1999 CACG (2) and the Canadian Adult Asthma Consensus Guidelines Update 2003 (3) have provided successively refined recommendations regarding asthma diagnosis, assessment and management, and have defined disease control as the preferred end point. The Calgary COPD and Asthma Program, and the Alberta Strategy to Help Manage Asthma developed two methods to evaluate the impact of these asthma guidelines $(4,5)$.

The first method directly addresses the end point of disease control by using a questionnaire. Individuals 12 years of age or older with a doctor's diagnosis of asthma who visit a pharmacy to fill a prescription for an asthma medication are asked to complete a questionnaire about their disease. The questionnaire includes direct questions about asthma control, asthma management and exposure to asthma triggers. The questionnaire has been validated in approximately 4000 patients (6).

The questionnaire was first used in a study in 1997 (4). The goal was to assess the impact of an intensive publicity and education program about the 1996 Canadian asthma consensus conference report in three rural communities in southern Alberta. In the study, three rural communities were provided with three different levels of asthma education and publicity. These ranged from basic continuing medical education for local physicians to an intensive, multifaceted campaign aimed at health professionals, as well as town leaders and, via the local media and public presentations on asthma, the general public. The questionnaire was distributed to pharmacies in these three communities one year after completion of the education and publicity activities. It was used to assess the impact of the intervention on the level of asthma control in the populations. No discernible impact was demonstrated.

In 2002, the pharmacy-based questionnaire was used again, this time to examine the impact of the national dissemination and implementation of the 1999 CACG (2). The results from this survey were compared with the first pharmacy questionnaire study (7). The survey showed that there had been no improvement in the proportion of the population with asthma control (approximately 30\%) and that the results were similar to those observed in two national random dialling surveys $(8,9)$. In a third study, which was an extension of the 2002 questionnaire survey, questionnaires were placed in family physicians' offices and in walk-in clinics, and the responses were compared with those in pharmacy populations (10).

The second method involves the extraction of information from family physicians' patient charts. With the consent of each participating physician, officials at the Alberta Health Care Insurance Plan were asked to send physicians a list of their patients for whom the physicians had submitted a diagnosis of asthma on at least two occasions. The list was then used to make these patients' charts available to a trained and experienced health records analyst. This method was used in a study that examined the extent to which family physicians adhered to the recommendations of the 1999 and 2003 guidelines (11). The study corroborated the findings of the questionnaire-based studies by showing a lack of documentation of asthma control, as well as underutilization of spirometry, asthma education and patient self-management plans.

Both the self-administered questionnaire and the family practice chart review have proven to be practical and feasible methods to assess and reassess the status of asthma control in the community in the context of asthma guidelines. The questionnaire technique appears to have several advantages, including allowing a direct assessment of asthma management and control in the population, being transparent and acceptable to all the patients, and being less expensive and generating less controversy on ethical review than the patient chart review. Furthermore, the validity of the questionnaire as an instrument to assess asthma in the community is supported by the similarity between the information obtained using this technique and that obtained from the two random, telephonedialling national surveys (7-9).

\section{REFERENCES}

1. Ernst P, FitzGerald JM, Spier S. Canadian Asthma Consensus Conference: Summary of recommendations. Can Respir J 1996;3:89-100.

2. Boulet LP, Becker A, Berube D, Beveridge R, Ernst P; Canadian Asthma Consensus Group. Canadian Asthma Consensus Report, 1999. CMAJ 1999;161(Suppl 11):S1-S61.

3. Lemiere C, Bai T, Balter M, et al. Adult Asthma Consensus Guidelines Update 2003. Can Respir J 2004;11(Suppl A):9A-18A.

4. Cowie RL, Underwood MF, Mack S. The impact of asthma management guideline dissemination on the control of asthma in the community. Can Respir J 2001;8(Suppl A):41A-5A.

5. Sin DD, Man SF, Cowie RL, et al; Alberta Strategy to Help Manage Asthma (ASTHMA) Investigators. Recruitment for a provincial asthma study. Participation of network and non-network primary care physicians. Can Fam Physician 2004;50:1251-4.

6. Cowie RL, Underwood MF, Revitt SG, Field SK. Predicting emergency room utilization in adults with asthma: A cohort study. J Asthma 2001;38:179-84.

7. Cowie R, Underwood MF, Man SF, Sin D, Sharpe H. Asthma in the community: 2002 compared with 1997. Can Fam Physician 2006. (In press)

8. Chapman KR, Ernst P, Grenville A, Dewland P, Zimmerman S. Control of asthma in Canada: Failure to achieve guideline targets. Can Respir J 2001;8(Suppl A):35A-40A.

9. Joyce DP, McIvor RA. Use of inhaled medications and urgent care services. Study of Canadian asthma patients. Can Fam Physician 1999;45:1707-13.

10. Cowie RL, Man SFP, Sin DD, Sharpe H. Asthma in the community: Treatment and control. Am J Respir Crit Care Med 2003;167:A115. (Abst)

11. Tsuyuki RT, Sin DD, Sharpe HM, Cowie RL, Nilsson C, Man SF; Alberta Strategy to Help Manage Asthma (ASTHMA) Investigators. Management of asthma among community-based primary care physicians. J Asthma 2005;42:163-7.

Correspondence: Dr Robert L Cowie, 3330 Hospital Drive Northwest, Calgary, Alberta T2N 4N1. Telephone 403-220-8981,

fax 403-270-8928, e-mail cowie@ucalgary.ca 


\section{Implementation of clinical practice guidelines: The Canadian Hypertension Education Program experience}

\author{
Denis Drouin MD FRCP
}

Continuing Professional Development Centre, Faculty of Medicine, Laval University, Ville de Québec, Québec

$\mathrm{T}_{\mathrm{h}}^{\mathrm{h}}$ he Canadian Hypertension Education Program (CHEP) was formed through a partnership of several important Canadian organizations: the Canadian Hypertension Society, Blood Pressure Canada, the Heart and Stroke Foundation of Canada, the Canadian Pharmacists Association and the College of Family Physicians of Canada.

Since 1998, the CHEP has initiated an annual review of its recommendations on hypertension following an evidence-based methodology, and has initiated an outcomes task force for dissemination and implementation of these recommendations (1).

\section{DEFINITIONS}

- Clinical practice guidelines: A review and evaluation of the scientific literature that results in the production of a set of evidence- and expert opinion-based recommendations.

- Dissemination of guidelines: A series of interventions aimed at influencing and improving knowledge, attitudes, beliefs and understanding of and about clinical practice guidelines. These interventions include distribution of the guidelines, as well as continuing medical education activities.

- Implementation of guidelines: Translation and application of the information in the guidelines into changes in physician and patient behaviours and attitudes.

Dissemination and implementation are two elements of a continuum. They should form a smooth sequence of events to ensure that the results of research optimize the quality of professional practice and patient care via the use of timely, credible and relevant information. The overall goal is to overcome

\section{TABLE 2}

\section{Steps for dissemination and implementation of clinical} practice guidelines

- Production of an evidence-based report

- Publication in peer-reviewed and nonpeer-reviewed journals

- Passage from a passive mode to an active mode for publication/dissemination

- Professional education

- Production of executive summaries, key messages and slide sets

- Production of practice aids: charts, algorithms, desktop assistants and pocket cards

- Activation of a network of local key opinion leaders as messengers and educators

- An Internet-based resource centre: www.hypertension.ca

- Public education

- Individualized tailored interventions for addressing barriers to dissemination and implementation as many as possible of the barriers to implementation that reside in health care professional and patient communities.

Recently, vocabulary that originated from educational organizations is being shifted to medicine - including terms such as professional education and knowledge transfer or knowledge translation (KT).

- KT: The process of turning best evidence into best practices (2).

$\mathrm{KT}$ is a mysterious process that implies a translation of scientific language into expert language, which, in the case of clinical guidelines, is user-friendly for the majority of end-users, namely, health care providers, the general public and policy-makers.

Canadian physicians have told us their preferences for the vehicle and format for obtaining clinical information. For example, in a survey published in 1997 (3), the vast majority of physician respondents stated that they rely on credible sources endorsed by their peer organizations. They also expressed a need for short summaries and decision aid tools such as pocket cards. We know from other research that unsolicited mailing of recommendations does not impact practice, at least on a shortterm basis (4). Thus, the first step for the CHEP in KT to physicians, pharmacists, nurses, dietitians and exercise physiologists or kinesiologists is to produce a set of evidence-based recommendations and to publish them in a peer-reviewed journal. The CHEP will then publish the guidelines in other peer-reviewed and some nonpeer-reviewed journals (5). Repeated publication of the same set of recommendations is important to ensure consistency and that the CHEP is recognized as a credible source of information in the field of hypertension - and as 'the reference' for all those involved in caregiving and care management.

These and the other annual activities surrounding the dissemination of the updated recommendations, under the auspices of the Implementation Task Force, are summarized in Table 2. Executive summaries and examples of pocket cards are posted on the CHEP Web site and may be downloaded free of charge. Furthermore, because professional education is an important component of any implementation program, a PowerPoint slide set designed for medical education, updated every year, is also available for download free of charge from the CHEP Web site. The CHEP and Blood Pressure Canada (formerly the Coalition for Prevention and Control of Hypertension) also sponsor a national survey to assess Canadians' attitudes and beliefs about hypertension. Furthermore, the groups disseminate information from this survey to the general population through press conferences. The CHEP is looking forward to expanding its strategies, which includes the following: fostering adoption of hypertensionrelated protocols (6) in organizations such as hospitals; helping nurses, dietitians and pharmacists be involved in the management of hypertension through a patient-centred approach; and developing community initiatives and initiatives to encourage self-management of hypertension by patients.

\section{OUTCOMES MEASUREMENT}

Although the CHEP is not able to show a direct cause and effect relationship between its initiatives and the level of blood pressure control in Canada, preliminary data extracted from prescription databases and from provincial databases are encouraging. For example, one such study indicated that since 1998, there has been a significant increase in the number of prescriptions for pharmacological agents such as calcium channel blockers used to treat hypertension in Canada (7). This is 
in line with the CHEP's recommendation of the use of nondihydropyridine calcium channel blockers as the first line of treatment for isolated systolic hypertension. This trend runs counter to that in the United States, where there has been a decrease in the use of calcium channel blockers due to the publication of a meta-analysis that suggested that calcium channel blockers have deleterious effects. Thus, the CHEP's recommendations hold more sway with Canadian physicians than does information originating in the United States. Moreover, surprisingly, there has also been an increase in the number of prescriptions for diuretics - these are generics and, hence, the CHEP recommendations have not been accompanied by commercial marketing for these products.

Another study corroborates these findings. Tu et al (8) found that among a cohort of 196,451 people newly started on antihypertensive therapy at various times between 1994 and 2002, the population-adjusted rate of new antihypertensive prescriptions increased by $30 \%$. Furthermore, the proportion of patients prescribed multiple antihypertensives concurrently within two years of diagnosis increased from $21 \%$ to $40 \%$ $(\mathrm{P}<0.0001)$, while the discontinuation rate within two years decreased from $36 \%$ to $21 \%(\mathrm{P}<0.0001)$. Tu et al $(8)$ concluded that "these data provide evidence that the physician management of hypertension in elderly Canadians became more aggressive between 1994 and 2002".

The results are in line with the CHEP's recommendations and, thus, are encouraging. It is anticipated that a national survey and physical measures (eg, blood pressure and body mass index) scheduled for 2006, will show that these trends are continuing.

\section{CONCLUSIONS}

$\mathrm{KT}$ in hypertension is the result of a comprehensive and longterm program supported by a group of key organizations and dedicated people. Because many other variables influence prescribing - including clinical trials, and local and provincial initiatives - more extensive evaluation is required to assess outcomes of the CHEP implementation and dissemination program.

\section{REFERENCES}

1. Campbell NR, Nagpal S, Drouin D; Heart and Stroke Foundation in Canada. Implementing hypertension recommendations. Can J Cardiol 2001;17:851-6.

2. Tremblay GJ, Drouin D, Parker J, Monette C, Cote DF, Reid RD. The Canadian Cardiovascular Society and knowledge translation: Turning best evidence into best practice. Can J Cardiol 2004:20:1195-8.

3. Hayward RS, Guyatt GH, Moore KA, McKibbon KA, Carter AO. Canadian physicians' attitudes about and preferences regarding clinical practice guidelines. CMAJ 1997;156:1715-23.

4. Hunskaar S, Hannestad YS, Backe B, Matheson I. Direct mailing of consensus recommendations did not alter GPs' knowledge and prescription of oestrogen in the menopause. Scand J Prim Health Care 1996;14:203-8.

5. Hemmelgarn BR, McAllister FA, Myers MG; Canadian Hypertension Education Program. The 2005 Canadian Hypertension Education Program recommendations for the management of hypertension: Part 1 - Blood pressure measurement, diagnosis and assessment of risk. Can J Cardiol 2005;21:645-56.

6. Fonarow GC, Gawlinski A, Moughrabi S, Tillisch JH. Improved treatment of coronary heart disease by implementation of a Cardiac Hospitalization Atherosclerosis Management Program (CHAMP). Am J Cardiol 2001;87:819-22.

7. Campbell NR, McAlister FA, Brant R, et al; Canadian Hypertension Education Process and Evaluation Committee. Temporal trends in antihypertensive drug prescriptions in Canada before and after introduction of the Canadian Hypertension Education Program. J Hypertens 2003;21:1591-7.
8. Tu K, Campbell NR, Duong-Hua M, McAlister FA. Hypertension management in the elderly has improved: Ontario prescribing trends, 1994 to 2002. Hypertension 2005;45:1113-8.

Correspondence: Dr Denis Drouin, Department of Family Medicine, Centre hospitalier universitaire de Québec (CHUQ), Hôpital St-François d'Assise, 10 rue de Espinay, Québec, Québec G1L 3 L5. Telephone 418-656-2131 ext 5958, fax 418-656-2465, e-mail denis.drouin@fmc.ulaval.ca

\section{Development of the Canadian diabetes guidelines: Lessons learned}

\section{Stewart B Harris MD MPH FCFP FACPM}

Department of Family Medicine, Schulich School of Medicine, University of Western Ontario, London, Ontario

In 2003, the Canadian Diabetes Association (CDA) published its third set of clinical practice guidelines (1). Fundamental to the creation of those guidelines was, at the outset, the elucidation of clear goals and guiding principles. Given the vast literature on the disease, these goals and principles helped to focus the committees and set the parameters for the document.

The key goals were as follows: to translate evidence into clinically relevant recommendations to reduce variation in clinical practice; to improve the quality of care and, hence, to reduce diabetes-related morbidity and mortality and the associated costs; and to identify areas of needed research. Furthermore, whenever possible, recommendations were harmonized with other major evidence-based guidelines such as those for hypertension and lipids; targets and terminology were simplified and standardized; and clinically directive algorithms were included. These features were used in direct response to physician frustration and confusion created by the 'guideline industry', which has led to a plethora of guidelines that often recommend different clinical targets and therapeutic strategies.

\section{METHODOLOGY}

The basic methodological principle was that each recommendation had to address a clinically important question directly related to the prevention, detection or management of diabetes and its sequelae. The strength of the evidence behind each recommendation also had to be noted. The criteria for ranking the strength of evidence behind the recommendations were specified in advance, and any recommendations based on biological or mechanistic reasoning, expert opinion or consensus had to be explicitly identified and graded as such.

Because good clinical evidence is, in some cases, impossible to generate due to cost or ethical considerations, many important recommendations - such as those for diabetes screening - were assigned 'grade D'. This grade denotes consensus ranking on the basis of clinical experience, case series, indirect trials, physiological evidence and current concepts of disease pathophysiology. The process for reaching consensus was explicitly defined at the outset of the process. The actual wording of any grade D recommendation was extensively debated and $100 \%$ agreement was required from the steering committee members.

\section{PERSONNEL AND DOCUMENT STYLE}

The structure of the CDA committee that developed these guidelines reflected the CDA's desire to include a broad range 
of stakeholders. This was considered essential to optimizing eventual uptake of the guidelines. In all, 60 volunteers with expertise in the 32 identified topic areas contributed. Another key to success in the process was the inclusion of a medical writer/editor from the outset.

The editorial goal was to consolidate the material submitted by over 60 individuals into one cohesive document with a consistent style and chapter format. The document itself was designed for maximum usability. The chapters were as concise as possible; there was extensive use of tables and algorithms because experience from the 1998 guidelines showed that these were the most cited, requested and reproduced features of the guidelines; appendixes included clinical tools and handouts; and at the end of each chapter, there was a list of relevant Web sites.

\section{REVIEW PROCESS}

An essential component of the finalization of the guidelines was a broad-based consultation with the diabetes community at large and the ultimate end-users. This was achieved in a four-phase process that began in October 2002. At that time, draft recommendations from several key chapters were presented at the joint professional conference of the CDA and the Canadian Society of Endocrinology and Metabolism. Comments generated at this meeting were considered and addressed, as appropriate, in the document.

In March 2003, draft guidelines were distributed for external review to 100 people. The reviewers were chosen from members of multidisciplinary, professional organizations in Canada and other countries. This process generated over 5000 comments, all of which were reviewed and considered.

In May and June 2003, the recommendations underwent a comprehensive, evidence-based review by a committee of three independent methodologists. They reviewed all of the references supporting the recommendations to ensure accuracy in grading and wording of the recommendations.

Finally, the document was peer-reviewed before publication in the Canadian Journal of Diabetes. The review process was important for the following reasons: it ensured that the diabetes community had some input into the document, it served as a safeguard against bias, and it identified controversial areas and helped to refine dissemination strategies around those issues.

\section{HARD COPY DISTRIBUTION AND CREATION OF THE WEB SITE}

The formal dissemination strategy included targeted distribution to key audiences. Beyond the mailing of the printed document to Canadian family physicians and selected specialists, summary articles were published in both professional and lay publications. Furthermore, a quick-reference sheet was created for consumers, as were a slide kit and four brochures for family physicians. The physician materials highlighted key topics in the guidelines.

An Internet-based version of the document ('e-guidelines') was also created. Several specific features are built into the Web site to enable visitors to peruse the guidelines with ease. In the browse section, the visitor can directly access any chapter, figure, table or subheading within a given chapter. This provides a more efficient search method than a simple key word text search; the latter may return hundreds of irrelevant matches. Furthermore, in the frequently asked questions section, users are presented with all of the guideline recommendations pertaining to common clinical questions.
The search for guidelines section is the most innovative and unique feature of the Web site. It allows users to build a customized clinical question based on criteria they select. The system returns only those guidelines relevant to the clinical scenario created by the user. Because the guidelines include 152 recommendations, the function allows users to find relevant recommendations without having to browse the entire document. Finally, the downloads section offers users the opportunity to download the document in its entirety, or as individual chapters and appendixes.

A formal evaluation of the use of the Web site confirmed that the Internet can significantly extend the reach offered by traditional dissemination methods. The evaluation revealed that within the first nine months of the availability of the e-guidelines, there were 145,543 Web site visits and 784,658 page views. Moreover, while the Web site was designed for health care professionals, fully $32 \%$ of visitors who completed an on-line survey were people with diabetes. Of the survey respondents, $95 \%$ anticipated viewing the Web site again, and $62 \%$ said it would change the way they care for themselves or their patients.

\section{CONCLUSIONS}

The set of guideline implementation measures undertaken by the CDA may serve as a model for other associations and individuals seeking to enhance the impact of clinical guidelines on daily practice. Internet-based dissemination of guidelines provides one of the most exciting methods for affecting positive change in this arena.

\section{REFERENCES}

1. Canadian Diabetes Association Clinical Practice Guidelines Expert Committee. 2003 Canadian Diabetes Association Clinical Practice

Guidelines for the Prevention and Management of Diabetes in

Canada. Can J Diabetes 2003;27(Suppl 2):S1-S152.

Correspondence: Dr Stewart B Harris, Department of Family Medicine, Schulich School of Medicine, University of Western Ontario, 245 - 100 Collip Circle, London, Ontario N6G 4X8. Telephone 519-858-5028, fax 519-858-5029, e-mail sharris1@uwo.ca

\section{Information technologies and guideline implementation for asthma}

\footnotetext{
Robyn Tamblyn PhD ${ }^{1}$, Pierre Ernst MD FRCPC ${ }^{2}$

${ }^{1}$ Department of Epidemiology and Biostatistics; ${ }^{2}$ Department of Medicine, McGill University, Montreal, Quebec

$T_{\mathrm{k}}^{\mathrm{h}}$ he most powerful way of acquiring and retaining new knowledge in medicine is in the context of solving actual clinical problems (1). In the case of practicing physicians, this means in the context of caring for their patients. This is probably why computer-based decision support systems are effective; they provide 'just-in-time' knowledge relevant to patientspecific decisions (2-4).

In community-based care, nurses, pharmacists, dietitians and other health professionals are typically geographically distributed in community clinics, public health offices and retail pharmacies. In this context, there is consensus that different models of primary care management of chronic disease are needed, and that information technologies are essential for the implementation of a system of integrated chronic disease management across
} 
a geographically distributed network of health professionals (5-8). Information technology is expected to provide solutions in two areas that are relevant to chronic disease management: integration of new knowledge into practice through computer-based decision support $(4,9)$; and sharing of clinical information and treatment goals among health professionals through secure electronic messaging of clinical information or shared electronic health records $(10,11)$. Computerized decision support systems have provided a new set of tools for enabling evidence-based guidelines to be incorporated into practice by providing physicians with reminders and alerts for evidence-based preventive care and disease management $(4,12-26)$. Three types of computer-based decision support have been used: first, standalone computer-based registries that track information on patient care, such as preventive screening, and generate reminders for follow-up care that are inserted into the patient chart; second, stand-alone, interactive computer programs that can be used to generate disease risk and/or treatment recommendations after the clinician has entered relevant patient information; and third, integrated clinical information systems that retrieve electronically stored patient information (eg, laboratories, pathology and drugs). These systems generate recommendations for screening or treatment that are presented to the clinician through an order-entry system or full electronic health record.

While computer-based registries that generate chart reminders have been shown to be effective in increasing adherence to preventive care screening $(4,12,13,15)$, the provision of decision support through integrated clinical information systems has produced the most substantial decreases in treatment errors $(21,27,28)$, as well as increases in adherence to evidence-based treatment recommendations $(4,22-25)$. This is likely because integrated systems have the capacity to provide patient-specific recommendations and just-in-time treatment recommendations at the time that decisions are being made, without the requirement that extensive information about the patient be entered by the clinician before he or she receives treatment advice.

Unfortunately, few studies have assessed whether computerbased decision support or other models for improving care actually achieve the expected change in patient outcome $(4,29,30)$. This omission needs to be addressed to ultimately determine the cost-effectiveness of innovative interventions. Furthermore, very few computer-based decision support systems have been tested in primary care, particularly in nonacademic private office settings $(4,12-15,17,31,32)$. This is due to a lack of infrastructure supporting computerization of primary care office practices, as well as difficulty in integrating prescription, laboratory and other sources of electronic clinical information that would provide value-added benefit to the busy practicing family physician (7,31). The United Kingdom, Australia and some other countries have made a considerable investment in computerizing primary care office practices (31), and early pioneering studies in integrated computer-based decision support are beginning to emerge from these initiatives $(17,32)$.

Of particular relevance are two randomized controlled trials of computer-based decision support systems for the management of asthma and angina (32) and hypertension (17) in primary care. The studies failed to show improvement in guideline adherence or patient outcome with the use of decision support. In the study on asthma and angina, the lack of benefit is most likely explained by the very low levels of use of the computerbased decision support system, due to incomplete and awkward integration of decision support within the electronic health record (32). The hypertension study distinguishes itself from other integrated computerized decision support studies in that no patient-specific treatment recommendations were provided for reducing blood pressure or other cardiovascular risk factors. These are attributes of decision support systems that have been present in all successful studies (4,22-25).

In contrast, a Canadian trial (33) has shown significant reductions in inappropriate prescribing with computer-based decision support in primary care. Unlike the studies in the United Kingdom, Canadian physicians made regular use of the computer-based system. It provided them with comprehensive information on dispensed prescriptions for their elderly patients by integration of information on dispensed prescriptions from the provincial drug insurance plan, as well as treatment recommendations for prescription drug difficulties.

To successfully deploy computer-based decision support, physicians need to be educated about the value-added benefits of computerization (31). In primary care, one of the main areas of potential benefit is the possible time savings for prescription drug management (34-36), particularly if the computerized system is integrated with retail pharmacies for transmission of electronic prescriptions and retrieval of information on drugs dispensed (36). Indeed, a prescription drug management system is the backbone of almost all efforts to implement electronic health records in primary care (31). It is also an established Canadian priority for a national electronic health record system (37). However, to date, no fully integrated prescription drug management system has been established.

Our current Canadian Institutes of Health Research (CIHR)-funded clinical trial is evaluating a prototype of a computer-based decision support system for asthma management in primary care that is integrated with a prescription drug management system. The study also will assess the system's impact on asthma-related morbidity.

\section{REFERENCES}

1. Barrows HS, Tamblyn RM. Problem-Based Learning: An Approach to Medical Education. New York: Springer Publishing Co, 1980.

2. Greco PJ, Eisenberg JM. Changing physicians' practices. N Engl J Med 1993;329:1271-3.

3. Davis DA, Thomson MA, Oxman AD, Haynes RB. Changing physician performance. A systematic review of the effect of continuing medical education strategies. JAMA 1995;274:700-5.

4. Hunt DL, Haynes RB, Hanna SE, Smith K. Effects of computer-based clinical decision support systems on physician performance and patient outcomes: A systematic review. JAMA 1998;280:1339-46.

5. Stead WW, Miller RA, Musen MA, Hersh WR. Integration and beyond: Linking information from disparate sources into workflow. J Am Med Inform Assoc 2000;7:135-45.

6. Westberg EE, Miller RA. The basis for using the Internet to support the information needs of primary care. J Am Med Inform Assoc 1999;6:6-25.

7. Lobach DF, Low R, Arbanas JA, Rabold JS, Tatum JL, Epstein SD.

Defining and supporting the diverse information needs of community-based care using the web and hand-held devices. Proc AMIA Symp 2001:398-402.

8. Noffsinger R, Chin S. Improving the delivery of care and reducing healthcare costs with the digitization of information. J Healthc Inf Manag 2000;14:23-30.

9. Johnston ME, Langton KB, Haynes RB, Mathieu A. Effects of computer-based clinical decision support systems on clinician performance and patient outcome. A critical appraisal of research. Ann Intern Med 1994;20:135-42.

10. Sicotte C, Denis JL, Lehoux P, Champagne F. The computer-based patient record challenges towards timeless and spaceless medical practice. J Med Syst 1998;22:237-56.

11. Monane M, Matthias DM, Nagle BA, Kelly MA. Improving prescribing patterns for the elderly through an online drug utilization 
review intervention: A system linking the physician, pharmacist, and computer. JAMA 1998;280:1249-52.

12. Burack RC, Gimotty PA, George J, Stengle W, Warbasse L, Moncrease A. Promoting screening mammography in inner-city settings: A randomized controlled trial of computerized reminders as a component of a program to facilitate mammography. Med Care 1994;32:609-24.

13. Frame PS, Zimmer JG, Werth PL, Hall WJ, Eberly SW. Computer-based vs manual health maintenance tracking. A controlled trial. Arch Fam Med 1994;3:581-8.

14. McPhee SJ, Bird JA, Fordham D, Rodnick JE, Osborn EH. Promoting cancer prevention activities by primary care physicians. Results of a randomized, controlled trial. JAMA 1991;266:538-44.

15. Turner RC, Peden JG Jr, O'Brien K. Patient-carried card prompts vs computer-generated prompts to remind private practice physicians to perform health maintenance measures. Arch Intern Med 1994;154:1957-60.

16. Rind DM, Safran C, Phillips RS, et al. Effect of computer-based alerts on the treatment and outcomes of hospitalized patients. Arch Intern Med 1994;154:1511-7.

17. Montgomery AA, Fahey T, Peters TJ, MacIntosh C, Sharp DJ. Evaluation of computer based clinical decision support system and risk chart for management of hypertension in primary care: Randomised controlled trial. BMJ 2000;320:686-90.

18. Vadher B, Patterson DL, Leaning M. Evaluation of a decision support system for initiation and control of oral anticoagulation in a randomised trial. BMJ 1997;314:1252-6.

19. Poller L, Wright D, Rowlands M. Prospective comparative study of computer programs used for management of warfarin. J Clin Pathol 1993;46:299-303.

20. Mungall DR, Anbe D, Forrester PL, et al. A prospective randomized comparison of the accuracy of computer-assisted versus GUSTO nomogram-directed heparin therapy. Clin Pharmacol Ther 1994:55:591-6.

21. Bates DW, Leape LL, Cullen DJ, et al. Effect of computerized physician order entry and a team intervention on prevention of serious medication errors. JAMA 1998;280:1311-6.

22. Pestotnik SL, Classen DC, Evans RS, Burke JP. Implementing antibiotic practice guidelines through computer-assisted decision support: Clinical and financial outcomes. Ann Intern Med 1996;124:884-90.

23. Evans RS, Pestotnik SL, Classen DC, et al. A computer-assisted management program for antibiotics and other antiinfective agents. N Engl J Med 1998;338:232-8.

24. Dexter PR, Wolinsky FD, Gramelspacher GP, et al. Effectiveness of computer-generated reminders for increasing discussions about advance directives and completion of advance directive forms. A randomized, controlled trial. Ann Intern Med 1998;128:102-10.

25. Overhage JM, Tierney WM, Zhou XH, McDonald CJ. A randomized trial of "corollary orders" to prevent errors of omission. J Am Med Inform Assoc 1997;4:364-75.

26. Overhage JM, Tierney WM, McDonald CJ. Computer reminders to implement preventive care guidelines for hospitalized patients. Arch Intern Med 1996;156:1551-6.

27. Teich JM, Merchia PR, Schmiz JL, Kuperman GJ, Spurr CD, Bates DW. Effects of computerized physician order entry on prescribing practices. Arch Intern Med 2000;160:2741-7.

28. Bates DW, Cohen M, Leape LL, Overhage JM, Shabot MM, Sheridan T. Reducing the frequency of errors in medicine using information technology. J Am Med Inform Assoc 2001;8:299-308.

29. Renders CM, Valk GD, Griffin SJ, Wagner EH, Eijk Van JT, Assendelft WJ. Interventions to improve the management of diabetes in primary care, outpatient, and community settings: A systematic review. Diabetes Care 2001;24:1821-33.

30. Griffin S. Diabetes care in general practice: Meta-analysis of randomized control trials. BMJ 1998;317:390-6.

31. Bates DW, Ebell M, Gotlieb E, Zapp J, Mullins HC. A proposal for electronic medical records in US primary care. J Am Med Inform Assoc 2003;10:1-10.

32. Eccles M, McColl E, Steen N, et al. Effect of computerised evidence based guidelines on management of asthma and angina in adults in primary care: Cluster randomised controlled trial. BMJ 2002;325:941-4.

33. Tamblyn R, Huang A, Perrault R, et al. The medical office of the 21st century (MOXXI): Effectiveness of computerized decision-making support in reducing inappropriate prescribing in primary care. CMAJ 2003;169:549-56.

34. Institute of Medicine. Crossing the Quality Chasm: A New Health System for the 21st Century. Washington: National Academy Press, 2001.
35. Papshev D, Peterson AM. Electronic prescribing in ambulatory practice: Promises, pitfalls, and potential solutions. Am J Manag Care 2001;7:725-36.

36. Kilbridge P, Gladysheva K. E-prescribing. Oakland: California HealthCare Foundation, 2001:1-43.

37. Canada Health Infoway Inc. Presentation of Business Plan, 2002.

Correspondence: Dr Pierre Ernst, Division of Clinical Epidemiology, Royal Victoria Hospital, R4.29, 687 Pine Avenue West, Montreal, Quebec H3A 1A1. E-mail pierre.ernst@mcgill.ca

\section{Dissemination and implementation of the Global Initiative for Asthma (GINA) guidelines}

\author{
Wan C Tan MD FRCPC \\ iCAPTURE Centre, University of British Columbia, St Paul's \\ Hospital, Vancouver, British Columbia
}

Pespite advances in drug treatment, outcomes in asthma - 1 remain unsatisfactory and fall well short of those targeted by asthma guidelines worldwide $(1,2)$. The main reasons for this poor control of asthma are failure to recognize asthma, nonimplementation of asthma guidelines and patient noncompliance. The difficulty in implementing asthma guidelines is largely due to potentially correctable barriers existing at the level of health care provision.

From a global perspective, asthma guideline implementation faces three key types of challenges (3):

- The challenge inherent in local adaptation of the recommendations for asthma care in the face of the great diversity of health care systems and variations in the availability of asthma therapies;

- The challenge of providing accurate and timely information to the public health officials of the different countries on costs of asthma care, on how to effectively manage asthma as a chronic disease and on the best methods to develop asthma care services and programs that are responsive to the needs and circumstances within their countries; and

- The challenge of overcoming the many barriers to the implementation of asthma in developing countries in which resources are limited.

\section{THE GINA DISSEMINATION/ IMPLEMENTATION PROGRAM}

The GINA program was initiated in 1991 with the publication of the GINA workshop report on asthma management guidelines (4). Over the years, the GINA guidelines have been translated into many languages and widely disseminated. In recent years, to facilitate the uptake of the guidelines, innovative and interactive measures have been introduced. As a result, the GINA program now consists of multifaceted strategies that aim to reduce mortality and morbidity from asthma worldwide.

\section{GUIDELINES AND REPORTS}

The GINA global strategy for asthma management and prevention is detailed in four documents: the comprehensive workshop report, the physician's office guide, the health professionals' guide, and the patient and family pocket book. 
These documents are kept current by the GINA Science Committee. This group has developed a sophisticated set of procedures to review the world's literature on asthma management and to update the GINA guidelines to reflect this stateof-the-art information. The updates, as well as educational material for patients and the public, are highlighted for quick retrieval on the GINA Web site at www.ginasthma.org. The Web site, which has become one of the most visited health sites on the Internet, also provides updates about GINA's activities, and information about GINA collaborating groups and contacts throughout the world.

Two additional recent reports are key to the GINA dissemination program and are available from the GINA Web site. The report on the Global Burden of Asthma provides a valuable resource to identify the barriers to asthma care and the actions required for overcoming these barriers to reduce the overall burden of the disease worldwide (3). The GINA Dissemination and Implementation report reviews the status of implementation and provides the blueprint for the new GINA implementation strategies (4).

\section{WORLD ASTHMA DAY}

GINA organizes the annual World Asthma Day - initiated in 1998 and held on the first Tuesday in May - in collaboration with health care groups and asthma educators throughout the world. Since its initiation in 1998, it has become the world's most important asthma awareness and education event.

\section{REGIONAL INITIATIVES}

The goals of GINA span the globe; however, for implementation to occur, they have to be embraced at the local/regional level. The formation of networks facilitates the process of guideline implementation. Two pilot GINA networks called 'clusters' were initiated in the Mesoamerican and Mediterranean regions in October 2004 and January 2005, respectively. These are full-scale collaborations between GINA and local groups. Each country in each region has a GINA advisory leader who supervises the dissemination and implementation efforts. There is also a regional committee in each area, the chair of which is automatically a member of the GINA Executive Committee. This person provides the link by which GINA's Executive, Science and Dissemination Committees work with the regional leaders in a range of implementation efforts.

\section{GINA AND THE WORLD HEALTH ORGANIZATION}

Another new initiative for implementation of GINA is the collaboration between the World Health Organization and primary care and other respiratory organizations to form the Global Alliance Against Chronic Respiratory Diseases. The goal of this effort is to improve collaboration between already existing governmental and nongovernmental programs that combat chronic respiratory diseases. The resulting improved coordination will help to increase the efficiency of resource use and avoid duplication of efforts in countries where competing chronic respiratory diseases such as COPD and tuberculosis are common. This includes focusing on a symptom-driven rather than a disease-driven approach to asthma management, and focusing on primary care practices.

Ultimately, the participants will develop a comprehensive global approach to the prevention and control of chronic respiratory diseases, with a special emphasis on developing countries. The Global Alliance Against Chronic Respiratory Diseases initiative will be officially launched later this year.

\section{GINA SYMPOSIA: GOVERNMENTAL, EXPERT} AND PRIMARY CARE OUTREACH

More than 85 GINA symposia have been held throughout the world as part of GINA's efforts to connect with governments, asthma experts, primary care physicians and professional organizations.

\section{GINA ASSEMBLY}

To maximize interaction with global asthma practitioners, the GINA Assembly was initiated in January 2005. It provides a forum for face-to-face dialogue and the sharing of scientific information on asthma guideline implementation among asthma practitioners and members of the GINA committees. The GINA Assembly will meet twice a year: in May, to coincide with the annual meeting of the American Thoracic Society, and in September, to coincide with the annual meeting of the European Respiratory Society.

At GINA Assembly meetings, members of the Executive and Science Committees will have the opportunity to provide an update of the scientific data that have resulted in changes to the GINA guidelines. However, the major agenda will be sharing of information among the participants about programs on asthma health education, and on asthma management and prevention.

\section{REFERENCES}

1. Bergquist P, Crompton GK. Clinical management of asthma in 1999: The Asthma Insights and Reality in Europe (AIRE) study. Eur Respir J 2001;18:248.

2. Rabe KF, Vermeire PA, Soriano JB, Maier WC. Clinical management of asthma in 1999: The Asthma Insights and Reality in Europe (AIRE) study. Eur Respir J 2000;16:802-7.

3. Masoli M, Fabian D, Holt S, Beasley R. The Global Burden of Asthma Report. <http:/www.ginasthma.com/ReportItem.asp?l1= $2 \& 12=2 \&$ intId=94> (Version current at September 13, 2005).

4. GINA Dissemination Committee. Dissemination and Implementation of Asthma Guidelines. January 2002.

<http://www.ginasthma.com/ReportItem.asp?intId=96> (Version current at September 13, 2005).

Correspondence: Dr Wan C Tan, iCAPTURE Centre, University of British Columbia, St Paul's Hospital, Vancouver, British Columbia. Telephone 604-806-8570, fax 604-806-9274, e-mail wtan@mrl.ubc.ca

\section{Dissemination and implementation of respiratory guidelines: The United Kingdom experience}

\author{
Martyn R Partridge MD FRCP
}

Respiratory Health Services Research Group, National Heart and Lung Institute, Imperial College, London, England

The he United Kingdom respiratory guidelines are disease-specific and also relate to services and techniques (Table 3).

The first British guidelines on asthma in adults were published in $1990(1,2)$ and have been regularly revised. In 2003, a new version of the guidelines was produced jointly by the British Thoracic Society (BTS) and the Scottish Intercollegiate 
TABLE 3

United Kingdom respiratory guidelines

\begin{tabular}{ll}
\hline Disease & Services and techniques \\
\hline Asthma & Nebulizer therapy \\
$\begin{array}{l}\text { Chronic obstructive pulmonary } \\
\text { disease }\end{array}$ & Bronchoscopy \\
Lung cancer & Smoking cessation services \\
Community-acquired pneumonia & Services for those with lung cancer \\
Pleural conditions and & Assessment of the fitness of those \\
pneumothorax & with lung disease for diving \\
Sleep-related breathing disorders & Assessment of the fitness of those \\
& with lung disease for air travel \\
Pulmonary thromboembolism & \\
Diffuse parenchymal lung disease & \\
Tuberculosis & \\
\hline
\end{tabular}

Guidelines Network (SIGN) (3). The National Health Service's National Institute for Clinical Excellence has also produced guidelines on COPD (4) and on lung cancer. The BTS and SIGN guidelines are updated at least every two years. All BTS guidelines, including those produced in conjunction with SIGN, as well as the National Institute for Clinical Excellence's COPD Guidelines, can be downloaded for free from the BTS Web site (5).

\section{DISSEMINATION AND IMPLEMENTATION OF THE BRITISH ASTHMA GUIDELINES}

A BTS/SIGN dissemination committee was launched in 1995 in anticipation of the publication of revised guidelines in 1997 (6); the activities of the committee have been followed in the literature $(7,8)$. In 1997, the committee mailed the Thorax supplement containing the new guidelines to 60,000 health care professionals in primary and secondary care. This mailing included a form for requests for summary charts of the management of asthma in primary and secondary care in emergency departments and in hospital wards. Just under one in 10 recipients $(9.3 \%)$ requested these charts. Members of the BTS were also offered a set of slides summarizing the guidelines' major recommendations, and $37.1 \%$ of physicians requested these materials. A follow-up mailing was made six weeks later to 45,500 general practitioners. It contained a four-page summary of the guidelines, and $7.3 \%$ of these recipients also ordered summary charts.

The committee organized 19 regional meetings on the content and implementation of the guidelines. At each meeting, an adult respiratory physician and a respiratory pediatrician gave a presentation, followed by a question and answer session chaired by a local public health physician. These meetings were attended by a total of 1197 general practitioners.

The mailings and meetings were accompanied by the dissemination of key messages in the medical and general media on the importance of the 'stepwise approach', the new role for long-acting, inhaled beta-agonists and three other themes.

After these activities took place, a survey of 400 general practitioners and 100 practice nurses showed that $86 \%$ of practice nurses and $94 \%$ of general practitioners were aware that the guidelines had been revised. However, when the respondents were asked to spontaneously mention key features of the new guidelines, their recall was poor.
In an effort to improve dissemination activities, a new committee was created before the BTS/SIGN Guideline on the Management of Asthma was launched in the February 2003 issue of Thorax (3). This time, the BTS Web site was used as the main dissemination point. The full guidelines, a 17-page summary, summary posters, PowerPoint slides and five case histories - including facilitators' notes and cross-referencing to the PowerPoint slides and the full guidelines - were all available for download from the Web site.

In total, more than 120,000 copies of the guidelines were disseminated, most of which were downloaded from the Web site. This is double the number of 1997 guidelines received by health care professionals. Moreover, a review of Web site statistics showed that more than 18,000 copies of the asthma guidelines were downloaded during January 2005. This is nearly four times higher than the number of pneumonia guidelines that were downloaded from the BTS Web site, six times higher than the number of downloaded tuberculosis guidelines and nine times higher than the number of downloads of the pulmonary embolism guidelines (BTS, personal communication).

\section{DISSEMINATION AND IMPLEMENTATION OF THE COPD GUIDELINES}

In 1997, after the first BTS guidelines for the management of COPD were published (9), a BTS COPD consortium involving the BTS, pharmaceutical companies, equipment manufacturers and the British Lung Foundation was established. The group conducted a number of opinion polls among medical professionals; these confirmed that awareness of COPD was much lower than that of asthma.

In 2004, the National Institute for Clinical Excellence produced the "National clinical guideline on the management of COPD in adults in primary and secondary care" (4). The BTS COPD consortium undertook activities to disseminate the guidelines. During 2004, the consortium produced 70,000 wall charts and 40,000 booklets on the new guidelines, and 50,000 booklets on spirometry. The group also has undertaken a major spirometry awareness and training program. The value of these activities is currently being examined in a survey of health care professionals.

\section{EFFECTS OF THE UNITED KINGDOM RESPIRATORY GUIDELINES ON CLINICAL PRACTICE}

Unfortunately, it is extremely difficult to ascertain what impact the guidelines have had on health professionals' behaviour and, hence, on patient outcomes. There has been a decline in hospital admissions and mortality from asthma in the United Kingdom; however, most of the decline occurred before the guidelines were released (10). Furthermore, reliance on other measures, such as patient self-report of morbidity, is confounded by the fact that patients usually overestimate the control of their symptoms (11).

Can we turn to primary care prescribing databases to detect changes in the use of agents such as high-dose inhaled steroids or long-acting beta-agonists that could reflect increased implementation of the guidelines? Again, this is an imperfect approach. Physicians are more likely to recall guidelines' pharmaceutical recommendations than the nondrug recommendations (7), and implementation is poor. For example, one recent study (12) found that only $3 \%$ of adults and children had a written asthma action plan, even though according to 
another study, $62 \%$ of patients would be willing to follow such a plan (11).

\section{WHAT OTHER INFLUENCES AFFECT IMPLEMENTATION?}

The introduction of guidelines from 1990 onward has been accompanied by well-organized activities by the patient support organization Asthma UK (formerly known as the National Asthma Campaign). There also has been considerable effort to train primary care nurses through the National Respiratory Training Centre. Moreover, the greatest force influencing physicians to implement the asthma guidelines in the United Kingdom is the pharmaceutical industry, through advertising, promotion and formal continuing medical education.

Government initiatives also have played a significant role in this arena. For example, in 1990, a program was initiated that gives general practitioners very small financial rewards for running disease management programs for chronic conditions such as asthma. This initiative resulted in a significant increase in employment and training of nurses working in primary care.

Furthermore, a new government program began last year that, anecdotally at least, has increased the awareness of COPD and asthma, as well as the need for spirometry. A general medical services contract provides financial incentives to general practitioners for meeting targets for the percentage of patients with COPD who have had the diagnosis confirmed with spirometry, and for the proportion of asthmatic patients receiving a review every 15 months.

\section{SUMMARY}

In the United Kingdom, great effort has gone into the production of high-quality, evidence-based guidelines, using increasingly rigorous and transparent methodology. Guidelines for the treatment of common respiratory diseases, asthma and COPD have been rigorously disseminated. However, the amount of activity that professional societies can initiate is limited, and initiatives by nonprofit organizations, the government and pharmaceutical companies have helped to fill the resultant gap. Indeed, the high awareness of and regard for the content of major respiratory guidelines among all health care professionals has proven to be an effective substrate for such synergistic activities. However, there is still significantly less implementation of the nonpharmacological aspects of the guidelines than those relating to medication use. Governmentbacked financial incentives aimed at primary care practitioners appear to be rectifying this imbalance.

\section{REFERENCES}

1. Guidelines for management of asthma in adults: I - Chronic persistent asthma. Statement by the British Thoracic Society, Research Unit of the Royal College of Physicians of London, King's Fund Centre, National Asthma Campaign. BMJ 1990;301:651-3. (Erratum in 1990;301:924).

2. Guidelines for management of asthma in adults: II - Acute severe asthma. Statement by the British Thoracic Society, Research Unit of the Royal College of Physicians of London, King's Fund Centre, National Asthma Campaign. BMJ 1990;301:797-800. (Erratum in 1990;301:1272).

3. British Thoracic Society and Scottish Inter-Collegiate Guidelines Network. British Guideline on the Management of Asthma. Thorax 2003;58(Suppl 1):i1-94.

4. National Collaborating Centre for Chronic Conditions. Chronic obstructive pulmonary disease. National clinical guideline on management of chronic obstructive pulmonary disease in adults in primary and secondary care. Thorax 2004;59(Suppl 1):S1-S232.

5. The British Thoracic Society. Guidelines, Reports \& Audit Tools. $<$ http://www.brit-thoracic.org.uk/iqs/sid.0076695038578200902310/ guidelines.html> (Version current at August 26, 2005).

6. British Thoracic Society, the National Asthma Campaign, the Royal College of Physicians of London, the General Practitioner in Asthma Group, the British Assoc of Accident and Emergency Medicine, the British Paediatric Respiratory Group and the Royal College of Paediatrics and Child Health. The British Guidelines on Asthma Management. 1995 Review and Position Statement. Thorax 1997;52:S1-S21.

7. Partridge MR, Harrison BD, Rudolph M, Bellamy D, Silverman M The British Asthma Guidelines - their production, dissemination and implementation. British Asthma Guidelines Co-ordinating Committee. Respir Med 1998;92:1046-52.

8. Dennis SM, Edwards S, Partridge MR, Pinnock HJ, Qureshi SJ. The dissemination of the British Guidelines on the Management of Asthma 2003. Respir Med 2004;98:832-7.

9. BTS guidelines for the management of chronic obstructive pulmonary disease. The COPD Guidelines Group of the Standards of Care Committee of the BTS. Thorax 1997;52(Suppl 5):S1-S28.

10. Lung and Asthma Information Agency. Trends in hospital admissions and deaths from Asthma. <http://www.laia.ac.uk> (Version current at January 26, 2006).

11. Haughney J, Barnes G, Partridge M, Cleland J. The Living and Breathing Study: A study of patients' views of asthma and its treatment. Prim Care Respir J 2004;13:28-35.

12. National Asthma Campaign. Needs of People with Asthma Survey. Asthma J 2000;5:133-7.

Correspondence: Dr Martyn R Partridge, Charing Cross Hospital, St Dunstan's Road, London, England W6 8RP.

Telephone 011-44-20-8846-7181, fax 011-44-20-8846-7999, e-mail m.partridge@imperial.ac.uk

\section{Dissemination and implementation of guidelines in France}

\author{
Philippe Godard MD
}

Hôpital Arnaud de Villeneuve, Montpellier, France

In France, there are approximately 3.5 million individuals with asthma, of whom 200,000 need to visit an emergency department each year. Asthma is responsible for 63,000 hospitalizations and the loss of seven million working days annually. The overall economic burden of asthma is estimated at 1.5 billion euros (1).

The mortality rate from asthma was estimated to be between 2.8 and 3.9 deaths per 100,000 inhabitants of France in 1999. This has not changed markedly since 1986, when the mortality rate was estimated at four deaths per 100,000 people (2). Care provision for asthmatic patients in emergency departments appears to be suboptimal, as shown by the use of peak expiratory flow rate in only $70 \%$ of patients, a $54 \%$ rate of hospitalization and a $42 \%$ rate of prescribing corticosteroids (3).

The results of the Asthma Insights and Reality in Europe (AIRE) study in France are comparable with those obtained in Western countries (4). These show that asthma control in the general population is not optimal, with many patients having regular attacks, consulting health care providers in an inappropriate way and being limited in their activities of daily living. 
Similar conclusions have been drawn from a national survey of asthmatic patients seen by general practitioners, of whom $70 \%$ were not adequately controlled and more than one-half were unaware of their symptoms (5). For patients followed in university hospitals, a recent study (6) evaluated the influence of asthma severity on the probability of obtaining good control. The results showed a low proportion of wellcontrolled patients in spite of the fact that these patients consulted asthma clinics regularly.

The prescription of antiasthma drugs has also been examined. In one study (7), 54.7\% of patients reimbursed by social security for asthma treatments had only one prescription reimbursed in the previous year, and 30\% of these prescriptions were for inhaled glucocorticoids only. Another study (8) evaluated the patterns of asthma management by general practitioners from 1995 to 1998. It showed that although antibiotics, expectorants, antihistamines, antitussives and nasal corticosteroids were commonly prescribed, asthma control therapies (ie, inhaled corticosteroids and long-acting beta-agonists) were underused.

\section{THE FRENCH GUIDELINES: 1996 TO 2005}

A large number of recommendations to improve this situation have been published over the past 15 years. The first were published in Australia, followed by Canada, the United Kingdom, the United States and, finally, on a worldwide level by the World Health Organization. In France, the first guidelines were published in 1996 (9). The French Language Society of Chest Physicians subsequently set up a continuing medical education program based on these recommendations (10). More recently, the French national agency for the evaluation of health, l'Agence Nationale d'Accréditation et d'Évaluation en Santé, published a series of documents concerning health care education for adults and children, and recommended follow-up for asthmatic patients (11).

\section{HOW CAN THESE GUIDELINES BE IMPLEMENTED?}

Many programs have been put in place in France to facilitate implementation of the recommendations. The most significant of these was the drafting, at the request of the health authorities, of the Asthma Plan in 2002 (12). This program has five objectives: first, the development of information on asthma for asthmatic patients and the general public; second, the improvement of the treatment of acute, severe asthma, the follow-up of patients with chronic asthma, and the detection and management of new cases of pediatric asthma in the school environment; third, the development of health care education; fourth, the improvement of the detection and management of occupational asthma; and fifth, the establishment of a databank covering all epidemiological and economic aspects of asthma, and its use in identification of risk factors.

These dissemination and implementation activities have had an impact. The recent European Lung White Book identified only two countries in Europe where asthma has been officially recognized by their respective health authorities as a priority area for action, namely, Finland and France (13).

A conference was organized in December 2004 in the prestigious buildings of the French Senate to give an overview of the impact of the Asthma Plan. The meeting was covered widely in newspapers and professional journals, as was the publication of the resulting recommendations (14).

However, the real use of such coverage may be questioned, because the role of the traditional media is to inform rather than to educate (15). The situation may be different for the new media, particularly the Internet. For example, the AsmaNet Web site (16) has high visibility and is regularly consulted, particularly the section devoted to occupational asthma (17).

Patient associations also have an important role to play. Some of the most prominent of these groups have organized an annual national forum on asthma for the past 10 years, at which more than 1000 people per year share their experiences, and take part in training and education programs. Furthermore, at least 10 'asthma schools' have been created in recent years and a number of asthma management networks have been set up in different regions. These 'schools' are devoted to asthma education, with a multidisciplinary team providing coordinated care and support to the most difficult asthmatic patients. Finally, clinical trials have been designed to assess how it may be possible to improve the management of acute, severe asthma, and lessons from these trials are being disseminated to health care providers ( $\mathrm{S}$ Salméron, personal communication).

\section{CONCLUSIONS}

Even with increased awareness of the challenges of asthma management and the implementation of better standards of care, it will likely take more than 10 years to have a real impact on the key epidemiological markers of morbidity. One obvious area in which doctors, as well as patients and their relatives, need to be better informed and educated is on the use of ICS. In all countries where these drugs have been used for a long time, their use has clearly led to a decrease in mortality rate.

The final word can be left to Dr Tari Haahtela, who has moved mountains for the cause of asthma prevention in Finland (18):

"Several recent reports have provided evidence that the burden of asthma may have levelled off, after increasing for decades. Implementation of the national and global asthma prevention and management guidelines that have led to earlier detection and improved treatment of asthmatics, is considered to be involved in this apparent change for the better".

\section{REFERENCES}

1. Godard P, Chanez P, Siraudin L, Nicoloyannis N, Duru G. Costs of asthma are correlated with severity: A 1-yr prospective study. Eur Respir J 2002;19:61-7.

2. Delmas M-C, Zeghnoun A, Jougla E. Mortalité par asthme en France métropolitaine, 1980-1999. Bull Epidémiol Hebdo 2004;47:221-2.

3. Salmeron S, Liard R, Elkharrat D, Muir J, Neukirch F, Ellrodt A. Asthma severity and adequacy of management in accident and emergency departments in France: A prospective study. Lancet 2001;358:629-35.

4. Rabe KF, Adachi M, Lai CK, et al. Worldwide severity and control of asthma in children and adults: The global asthma insights and reality surveys. J Allergy Clin Immunol 2004;114:40-7.

5. Godard P, Huas D, Sohier B, Pribil C, Boucot I. [Asthma control in general practice: A cross-sectional survey of 16,580 patients.] Presse Méd 2005;34:1351-7.

6. Combescure C, Chanez P, Saint-Pierre P, Daures JP, Proudhon H, Godard P; Association pour la Recherche en Intelligence Artificielle 
group. Assessment of variations in control of asthma over time. Eur Respir J 2003;22:298-304.

7. Deprez P-H, Chinaud F, Clech S, et al; le groupe Médipath. Patients treated with anti-asthmatic medications in metropolitan France: The National Health Fund's 2000 data. Rev Méd l'Ass Maladie 2004;35:3-10.

8. Laforest L, Pacheco Y, Bousquet J, Kocevar VS, Yin D, Van Ganse E. How appropriate is asthma therapy in general practice? Fundam Clin Pharmacol 2005;19:107-15.

9. l'Agence Nationale d'Accréditation et d'Évaluation en Santé. Asthme: Critères de gravité, aspects diagnostiques et thérapeutique. Concours Méd 1996;41(Suppl):S1-S18.

10. Société de Pneumologie de Langue Française. FMC Asthme. $<$ http://www.splf.org/s/article.php3?id_article $=232>$ (Version current at September 13, 2005).

11. Agence Nationale d'Accréditation et d'Évaluation en Santé. Les publications par thèmes d'études. <http://www.anaes.fr> (Version current at February 20, 2006).

12. L'asthme - Programme d'action, de prévention et de prise en charge de l'asthme (2002-2005). <http://www.sante.gouv.fr/htm/pointsur/ asthme/1asth.htm> (Version current at September 13, 2005).

13. Loddenkemper R, Gibson GJ, Sibille Y. The burden of lung disease in Europe: Why a European White Book on lung disease? Eur Respir J 2003;22:869.

14. Godard Ph. Prise en charge de l'asthme. Quel bilan à la fin du plan asthme? Rev Mal Respir 2005;22(Suppl 4):S5-S57.

15. Roche N, Morel H, Martel P, Godard P. Clinical practice guidelines: Medical follow-up of patients with asthma - Adults and adolescents. Respir Med 2005;99:793-815

16. Association Asthme \& Allergies. <http://www.remcomp.fr/asmanet/> (Version current at September 13, 2005).

17. AsmaPro. <http://www.remcomp.fr/asmanet/asmapro/asmawork.htm> (Version current at September 13, 2005).

18. von Hertzen L, Haahtela T. Signs of reversing trends in prevalence of asthma. Allergy 2005;60:283-92.

Correspondence: Dr Philippe Godard, Service des maladies respiratoires, Hôpital Arnaud de Villeneuve, Avenue Doyen Giraud, 34295 Montpellier cedex, France. Telephone 00-33-467-33-61-17, fax0033-467-61-18-48, e-mail godard@montp.inserm.fr

\section{Development, dissemination and implementation of clinical practice guidelines by the American College of Chest Physicians (the two D's and an I)}

\author{
Carla T Herrerias BS MPH
}

American College of Chest Physicians, Northbrook, Illinois, USA

$\mathrm{O}$ ver the past few years, the American College of Chest Physicians (ACCP) and many other organizations have made considerable progress in developing evidence-based clinical practice guidelines and incorporating the resulting recommendations into the clinical setting. However, the problem remains that no matter how solid the data are that underpin these clinical recommendations, no procedure has yet been found that ensures full implementation of guidelines in clinical practice.

One of the first challenges in developing and implementing guidelines is to determine what constitutes an evidence-based clinical practice guideline. There are now more than 1400 guidelines in the United States National Guidelines Clearinghouse (www.guidelines.gov), and most guidelines and measures of clinical improvement claim to be evidence-based (1). Furthermore, in the United States, evidence-based policy is used frequently to promote disease management and assessment, and also is used for making decisions that guide Medicaid and Medicare resource allocation (2). However, several studies (2-4) indicate that not all clinicians are implementing evidence-based information, nor are they changing practice based on published guidelines.

The ACCP continues to study the barriers to such implementation and to develop innovative strategies that promote change in practice and, ideally, enhance patient care. The ACCP's Health and Science Policy Committee has produced valid, evidence-based clinical guidelines - addressed not only to chest physicians but to all clinicians treating chest disease - on many topics, including the appropriate use of antithrombotic therapy, and the treatment of lung cancer and cough. All ACCP guidelines can be accessed on their Web site (www.chestnet.org).

The ACCP also created a clinical resource to accompany each set of practice guidelines. This is a package that includes physician information, patient information and educational tools such as slide sets to be used for both learning and teaching. It is disseminated to each member of the ACCP in both a hard copy and $\mathrm{CD}$ format. In this way, clinicians can customize the information that they provide to their patients and individualize care.

Other innovative steps that the ACCP has taken to ensure that physicians rely on the highest quality clinical evidence in their patient care include the development of the Tobacco Cessation Toolkit and creation of specific implementationtracking measures. The widely used toolkit provides clinicians with many tools to effectively intervene with patients who wish to stop using tobacco. The implementation tracking measures have been developed by the ACCP in conjunction with the American Medical Association Physician Consortium for Performance Improvement and the National Quality Forum.

In 2004, the ACCP embarked on a survey of the approaches other organizations in the United States are using in developing and disseminating evidence-based recommendations. Although the data show that most American specialty societies are developing practice guidelines using an evidencebased method and have some type of dissemination process in place, very few formal implementation programs and evaluation tools have been created. We hope the results of this survey, which will soon be published, encourage other societies to develop processes to measure the impact of their clinical practice guidelines.

A follow-up study is planned to further explore specific issues related to the implementation and evaluation of practice guideline programs. Physician associations need to continue to refine the skills for developing evidence-based recommendations and specific implementation strategies that help to change practice behaviour and improve health outcomes.

\section{REFERENCES}

1. Steinberg EP, Luce BR. Evidence based? Caveat emptor! Health Aff (Millwood) 2005;24:80-92.

2. Atkins D, Siegel J, Slutsky J. Making policy when the evidence is in dispute. Health Aff (Millwood) 2005;24:102-13.

3. Green ML, Ruff TR. Why do residents fail to answer their clinical questions? A qualitative study of barriers to practicing evidence-based medicine. Acad Med 2005;80:176-82.

4. Solberg LI, Brekke ML, Fazio CJ, et al. Lessons from experienced guideline implementers: Attend to many factors and use multiple strategies. Jt Comm J Qual Improv 2000;26:171-88.

\section{OTHER READING}

- Landro L. Are treatment guidelines reliable? Wall Street Journal 2005, January 26:D4.

- Rastegar DA. Health care becomes an industry. Ann Fam Med 2004;2:79-83.

- Rousseau N, McColl E, Newton J, Grimshaw J, Eccles M. Practice 
based, longitudinal, qualitative interview study of computerised evidence based guidelines in primary care. BMJ 2003;326:314.

- Sim I, Sanders GD, McDonald KM. Evidence-based practice for mere mortals: The role of informatics and health services research. J Gen Intern Med 2002;17:302-8.

- Ferlie E, Fitzgerald L, Wood M. Getting evidence into clinical practice: An organizational behaviour perspective. J Health Serv Res Policy 2000;5:96-102.

Correspondence: Carla T Herrerias, American College of Chest Physicians, Educational Resources, 3300 Dundee Road, Northbrook, Illinois 60062-2348, USA. Telephone 847-498-1400, fax847-498-5460, e-mail cherrerias@chestnet.org

\section{The development and implementation of asthma guidelines in Australia}

\author{
John W Wilson MD
}

Department of Allergy, Immunology and Respiratory Medicine, The Alfred Hospital, Melbourne, Australia

$\Lambda$ ustralia and New Zealand have experienced high prevaAlence rates of asthma over the past 30 years. However, the countries recently have succeeded in reversing this trend through the dissemination of evidence-based treatment guidelines, coupled with active awareness campaigns and the introduction of new therapies in rational treatment plans. Statistics on changes in the morbidity and mortality associated with asthma attest to the power of this approach.

The first asthma guidelines were produced in 1989 by the Thoracic Society of Australia and New Zealand in response to a need by professional bodies for a unified approach to

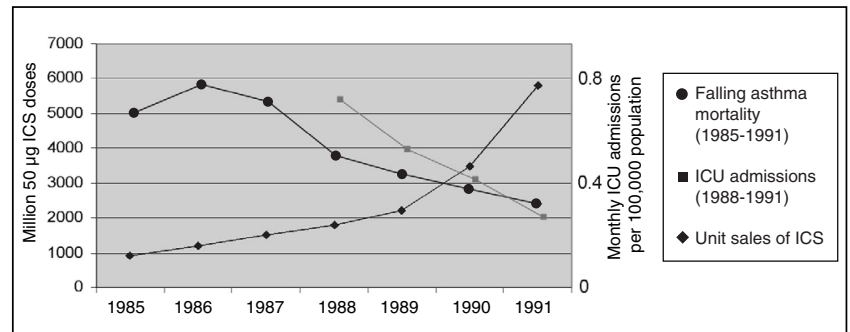

Figure 3) Increase in unit sales of inhaled corticosteroids (ICS) (the number [in millions] of $50 \mu \mathrm{g}$ beclomethasone dipropionate dose equivalents) against falling asthma mortality (1985 to 1991) and intensive care unit (ICU) admissions (1988 to 1991)

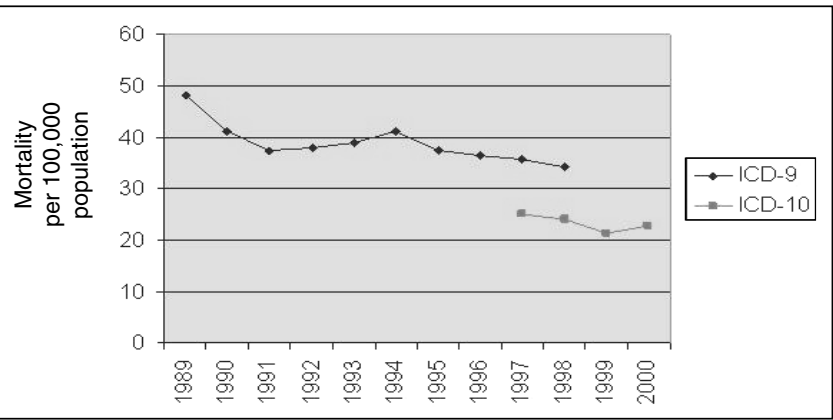

Figure 4) Asthma mortality in five- to 34-year-old Australians per 100,000 population from 1989 to 2000. International Classification of Diseases (ICD)-9 and ICD-10 coding overlapped in 1997 and 1998 reducing asthma morbidity and mortality (1). Professional bodies involving pharmacists and physicians in internal medicine and primary care joined with representatives of patient advocacy groups to adopt these recommendations. The guidelines were developed based on both local and international studies. However, the studies were limited in number and small by current standards. There also was no systematic evaluation such as a meta-analysis to define the significance of the reported findings.

In 2002, the guidelines known as the Asthma Management Handbook were developed by the National Asthma Council (NAC) (2). The NAC is the umbrella body representing The Thoracic Society of Australia and New Zealand, The Royal Australasian College of General Practitioners, The Pharmaceutical Society of Australia and the Australasian Society for Clinical Immunology and Asthma.

The NAC has played an important role in centralizing and promoting professional opinion in relation to critical areas of asthma care. Members of the body have produced position papers on primary prevention strategies, the use of complementary medicines and combination therapy consisting of ICS and long-acting beta-agonists.

The NAC functions primarily through support from the pharmaceutical industry for nonpartisan projects. There is also some government support for specific projects and collaborative ventures. The Australian College of Emergency Medicine has been closely involved in the assessment of acute asthma management plans. In addition, the Asthma Foundations of Australia, which represent consumers, have played a crucial role in determining priorities for management and raising community awareness.

\section{MEASURES OF GUIDELINE ADOPTION}

The effectiveness of any guideline should be scientifically assessed with regard to both uptake by the target audience and relevant health care outcomes. The use of the first guideline documents (1989) was examined in a survey of 286 Australian general practitioners - and two sets of important findings emerged (3). First, $92 \%$ of respondents said that they felt that evidence-based guidelines are good educational tools and $49 \%$ stated that the guidelines had caused a change in their prescribing habits. Second, fully $85 \%$ stated that guidelines are "developed by experts who don't understand general practice". This underlines the vital importance of involvement of experienced medical writers capable of understanding the needs of primary care physicians in the development phase.

A 2002 meta-analysis of 30 published surveys on the use of practice guidelines involving 11,611 health care professionals (conducted before the 2002 Asthma Management Handbook [2] was produced) found similar results (4). Three-quarters of those surveyed stated that they believed guidelines are a useful resource and $70 \%$ said such guidelines generate better clinical outcomes. However, 30\% of respondents said they thought the existing guidelines were impractical and rigid. Furthermore, $34 \%$ said the guidelines reduced autonomy and oversimplified clinical issues, $41 \%$ believed the guidelines increased the likelihood of litigation and 52\% thought they were formulated as a vehicle for cost constraint. Clearly, development and implementation of guidelines must account for these attitudes if they are to achieve maximal penetration and effectiveness. 


\section{ASTHMA MORBIDITY AND MORTALITY DECLINING}

The use of national databases to identify trends in health care outcomes is an important component of the audit process. Asthma mortality in the five- to 34-year-old age group has fallen since the introduction of the first consensus guidelines in Australia in 1989 (Figure 3) (IMS Health Australia, personal communication). This is likely due to the combined influence of increased community and professional awareness about the key points in asthma diagnosis and management, and the advent of newer asthma medications, including combination therapy.

Analysis of hospital and intensive care unit admission rates is also an important component of any review of guideline impact, particularly when examined with sales of specific medications such as ICS (D Tuxen and J Cailes, personal communication). Figure 4 shows that these trends are also in line with the adoption of asthma guidelines (5).

The author wishes to thank D Tuxen and J Cailes for the provision of intensive care unit admission data.

\section{REFERENCES}

1. Woolcock A, Rubinfeld AR, Seale JP, et al. Thoracic society of Australia and New Zealand. Asthma management plan, 1989. Med J Aust 1989;151:650-3.

2. National Asthma Council. Asthma Management Handbook, 1st edn. Melbourne: National Asthma Council, 2002.

3. Gupta L, Ward JE, Hayward RS. Clinical practice guidelines in general practice: A national survey of recall, attitudes and impact. Med J Aust 1997;166:69-72.

4. Farquhar CM, Kofa EW, Slutsky JR. Clinicians' attitudes to clinical practice guidelines: A systematic review. Med J Aust 2002;177:502-6.

5. Australian Bureau of Statistics. Causes of death: Australia. Annual Reports, 1999.

Correspondence: Dr John Wilson, Department of Allergy, Immunology and Respiratory Medicine, The Alfred Hospital, Commercial Road, Melbourne 3004, Australia. Telephone 011-61-3-9276-2315, fax 011-61-3-9207-1050, e-mail john.wilson@med.monash.edu.au

\section{KT at the CIHR}

\author{
Liz Stirling, Emily-Brynn Rozitis \\ Knowledge Translation Branch, CIHR, \\ Ottawa, Ontario
}

$\mathrm{C}^{\mathrm{In}}$ IHR is Canada's major federal funding agency for health research. CIHR's mandate includes both health research and KT. The objective of CIHR is to excel, according to internationally accepted standards of scientific excellence, in the creation of new knowledge and its translation into improved health for Canadians, more effective services and products, and a strengthened health care system (1).

Within the CIHR mandate, KT has the potential to both increase and accelerate the benefits flowing to Canadians from their investments in health research. KT can also help to establish Canada as an innovative and authoritative contributor to health-related KT.

CIHR defines KT as "the exchange, synthesis and ethicallysound application of knowledge - within a complex system of interactions among researchers and users - to accelerate the capture of the benefits of research for Canadians through improved health, more effective services and products, and a strengthened health care system". (Please see www.cihr-irsc.gc.ca/e/26574.html for a description of CIHR's KT strategy). This definition emphasizes that, for CIHR, KT involves an active exchange of information between the researchers who create new knowledge and those who use it.

\section{CIHR - KT STRATEGY 2004 TO 2009}

The KT strategic plan outlines the strategic directions for responding to CIHR's KT mandate for 2004 to 2009. CIHR's strategic direction in $\mathrm{KT}$ is guided by the document "Investing in Canada's Future: CIHR's Blueprint for Health Research and Innovation" (2) and by its Governing Council Knowledge Translation Working Group. The Knowledge Translation Branch and CIHR's 13 institutes operationalize these strategic directions by promoting $\mathrm{KT}$ programs and activities that:

- Support KT research;

- Contribute to building KT networks;

- Strengthen and expand KT at CIHR; and

- Support and recognize KT excellence.

\section{STRATEGIC DIRECTIONS}

\section{Strategic direction \#1: Support KT research}

Supporting KT research is essential to develop the science of KT. It also leads to a better understanding of the concepts and theories that underlie effective KT, and to a better determination of effective strategies for KT. This includes funding grants that support KT research into the basic science of KT, intervention development and evaluation research, and knowledge synthesis. It also requires the development of KT research capacity through open awards and competitions, and by supporting interactions among KT researchers.

Strategic direction \#2: Contribute to building KT networks CIHR supports networks of researchers and knowledge users in coming together to assess health priorities. The agency also helps these individuals to understand, prepare and disseminate evidence to improve the conditions that lead to effective and timely uptake and application of knowledge. Specific objectives are to launch new strategic initiatives (ie, competitively awarded long-term grants) and to build and/or strengthen KT networks by providing advice and/or funding initiatives in collaboration with others that maximize KT potential.

\section{Strategic direction \#3: Strengthen and expand KT at the CIHR}

CIHR is building KT expertise internally and creating learning opportunities that enable it to play a lead role in the KT community. Specific objectives include ensuring that KT opportunities and potential inform CIHR activities as appropriate, providing advice on $\mathrm{KT}$ assessment for peer-review processes, consulting and/or collaborating within CIHR on KT-related activities, and contributing to organizational learning and KT knowledge.

\section{Strategic direction \#4: Support and recognize KT} excellence externally

CIHR celebrates and supports the KT community in Canada. It recognizes and rewards excellence, and builds awareness in 
this growing field. Two of the many ways it does so is by developing and implementing a KT recognition and award initiative, as well as by collaborating with others to provide KT research expertise to Canada's health sector.

\section{CURRENT KT BRANCH PROGRAMS}

Listed below are the names and descriptions of some of CIHR's current KT Branch programs.

\section{Grants}

1.1 Open Competition -

1.2 KT Request for Applications

1.2.1 Knowledge Translation Strategies for Health Research launched December 2001, 2002 and 2003

- Increase understanding of the theory and practice of KT;

- Align KT research to CIHR institutes and their research priorities; and

- Promote research on how best to integrate KT principles and practice into training and continuing education.

1.2.2 Research Syntheses - launched June 2005

- Support research synthesis to support evidenceinformed decision-making; and

- Create more synthesis of knowledge in selected, high-priority, eligible thematic research areas related to health and health care.

1.2.3 Knowledge to Action - launched June 2005

- Build and strengthen teams engaged in KT at the community, local or regional level by funding KT activities of researchers and users of research situated in the same community or region; and

- Position recipients to accelerate the translation of knowledge to strengthen Canada's health care system and/or improve the health of Canadians.

\section{Awards - Priority Announcements}

Priority Announcements fund highly rated research applications that are relevant to CIHR's research priority areas and do not receive funding through CIHR's regular competitions.

\subsection{New Investigators and Fellowships - launched June 2005}

- It is expected that these targeted investments will lead to a better understanding of concepts and theories that underlie effective KT.

\section{Workshop and Symposium Program}

- Will partially contribute to workshops and symposia that support KT research and that contribute to building KT networks.

\section{Health Research Communications Award}

- Aims to increase the number of Canadian writers engaged in communicating the findings and implications of health research; and
- Is open to applicants who have one or more degrees related to human health.

\section{KT Award}

- Honours and supports local/regional and national/ international organizations that, through KT research and/or active evidence-based KT, make an outstanding contribution to the health of Canadians or the health care system; and

- Provides financial support to further foster excellence in KT in Canada.

\section{Partnerships for health systems improvement}

- Supports teams of researchers and decision-makers interested in conducting applied health research useful to health system managers and/or policy-makers over the next two to five years.

\section{Other initiatives}

1.0 Adverse Events in Canadian Hospitals: The Canadian Institute for Health Information and CIHR jointly funded research to determine the extent of avoidable and unavoidable adverse events in Canadian hospitals and the availability of data that could serve to monitor and help to reduce health system adverse events. A Stakeholder Forum was established to facilitate two-way communication from the outset of this important research project. This helped to position stakeholders to anticipate results and to address them in a proactive and constructive fashion.

\section{REFERENCES}

1. Canadian Institutes of Health Research Act. Section 4, Bill C-6. Ottawa: Royal Society of Canada, 2000.

2. Canadian Institutes of Health Research. Investing in Canada's Future: CIHR's Blueprint For Health Research and Innovation. <http://www.cihrirsc.gc.ca/e/20264.html> (Version current at January 30, 2006).

Correspondence: Liz Stirling, Knowledge Translation Branch, Canadian Institutes of Health Research, 160 Elgin Street, Room 97, Address Locator 4809A, Ottawa, Ontario K1A OW9. Telephone 613-941-1072, fax 613-941-0568, e-mail LStirling@cihr-irsc.gc.ca

\section{Dissemination and implementation of asthma guidelines in Canada}

Dennis M Bowie MD, Andrew Mclvor MD

Division of Respirology, Dalhousie University, Halifax, Nova Scotia

$T_{\mathrm{in}}^{\mathrm{h}}$ e Canadian Asthma Committee set up a working group in 1999 to disseminate and encourage the implementation of the CACG (1). This working group was created because of the belief that despite publication of guidelines, there was a failure to use them. This was demonstrated by the Asthma in Canada study showing that the previous guidelines, published in 1996 (2) - for which there had been no activities surrounding dissemination - had not significantly affected clinical practice. The study found that only $24 \%$ of patients met all six of the symptom-based criteria used to gauge control of the disease, 
and fully $57 \%$ failed to meet two or more of the six control measures (3). Furthermore, $51 \%$ of patients required urgent care for out-of-control asthma in the previous year. Only $54 \%$ of patients recalled ever having lung function tests, and many did not understand how to properly use their medications. Despite this, $91 \%$ of patients believed their asthma was adequately controlled. Of even greater concern, $77 \%$ of family physicians and $90 \%$ of respirologists thought that their asthmatic patients' symptoms were well controlled. Moreover, few physicians gauged asthma control by tracking more than one or two symptoms.

The dissemination working group, following publication of the guidelines in the Canadian Medical Association Journal, undertook a number of activities that included:

- Publication of a number of companion articles about the importance of the new guidelines in Canadian medical journals read by primary health care professionals;

- Mailing of copies of the guidelines to government officials, medical students and any other individuals who requested them;

- A series of four one-page direct mailings to general practitioners highlighting important points and containing tools to aid in the implementation of the guidelines, along with the address for an asthma information Web site;

- Setting up an asthma information Web site that incorporates links to the guidelines, tools for implementation, asthma information, asthma educational materials and other elements;

- Educational activities supported by pharmaceutical companies and nongovernmental organizations; and

- A survey of general practitioners regarding their familiarity with the guidelines, and the use of the mailed tools and Web site.

The two-year budget for all of these activities was approximately $\$ 280,000$, of which approximately $25 \%$ went to administration. The remainder was used for the development of tools and for direct mailing. Unfortunately, this sum prevented both the evaluation of these activities and any public education.

To enhance awareness of the new guidelines, Canada's medical media were contacted and provided with a press release. This led to the guidelines being used or mentioned in over 38 different journals, periodicals and bulletins directed at health care professionals, including family physicians, nurses, pharmacists and others. These included French and English publications, society newsletters and journals.

In addition, more than 6000 copies of the CACG were mailed after their publication in the Canadian Medical Association Journal. Three thousand of the copies were sent to francophone physicians, because this constituency often does not read the Canadian Medical Association Journal. Another 1500 copies were distributed to third-year medical students across Canada. Most of the remaining copies were sent to individuals who requested them and to officials in the provincial governments across the country, including the ministers and deputy ministers of health.
Four waves of mailings were sent personally from highprofile regional specialists to 12,000 high-prescribing family physicians. The mailings were staggered over two years as a method of providing physicians with regular reminders about the CACG. Each mailing included a short text. The text in the first mailing focused on diagnosis, the second on the use of ICS, the third on the use of long-acting beta-agonists and antileukotrienes as additional therapy, and the fourth on the role of asthma education and environmental control. Each text also included the address of the asthma information Web site <www.asthmaguidelines.com>. The Web site received more than 438,000 visits, and many of the visitors downloaded materials from the Web site.

There was also a user-friendly, leave-behind tool in each mailing. The first mailing contained a mouse pad on which was printed a figure outlining the recommended order of drug utilization in asthma. The second mailing contained a pocket slide rule with normal values for adult peak flow measurements, along with an ICS dose equivalent reminder that consisted of a list of the various ICS and their respective potencies. The third mailing contained two bilingual tear-off pads. One of the pads had an asthma treatment checklist for physicians to assess asthma control, and the other had an asthma-treatment flow chart. The fourth mailing included two sample asthma action plans, along with a number of stickers for patients' charts to assess the level of control.

The fourth and final mailing also contained a survey. Only 207 of 12,000 surveys were returned, despite respondents being automatically entered in a draw for a Palm Pilot. Ninety-three per cent of respondents indicated that they were familiar with the contents of the guidelines. One-third of respondents indicated they had read the full document and $49 \%$ said that they had only read the summary. Furthermore, $82 \%$ suggested that they found the guidelines helpful.

Regarding the content of the mailings with leave-behinds, $26 \%$ of respondents said that they had visited the asthma information Web site, 24\% indicated that they had used the pocket slide rule with the peak flow normal values and the ICS dose equivalent reminder, while $36 \%$ had used the asthmatreatment checklist or flow chart. Twenty-nine per cent said that they had used the 'level of control' stickers. When the physicians were asked about the usefulness of each of these tools, their responses indicated that the tear-off pads with the asthma-treatment checklist and flow chart were the most useful, and that the slide rule was the next most useful.

A number of educational activities surrounding the guidelines were conducted by pharmaceutical companies in the form of lectures, evening symposia and workshops. Industry also developed a number of materials for physicians to reinforce some of the guideline recommendations. Furthermore, nongovernmental agencies, including the Allergy/Asthma Information Association, the Asthma Society of Canada, the Canadian Network for Asthma Care and lung associations, tried to increase the awareness of the guidelines among their constituencies through their regular communications.

\section{RESULTS}

It appears that more work must be conducted in developing an effective strategy for implementing asthma guidelines asthma is still not well controlled. One part of the challenge is the consistently low level of control of asthmatic symptoms. A recent telephone survey of 463 physicians and 893 adult 
patients suggested that $89 \%$ of the patients had experienced asthma worsening in the previous year (4). Furthermore, $39 \%$ of patients reported urgent visits to their family physicians for asthma and $17 \%$ visited an emergency department in the previous year. Fully $97 \%$ of patients said that their asthma was well controlled, but $53 \%$ were considered uncontrolled according to the CACG criteria (5). Furthermore, despite the CACG encouraging the use of asthma written action plans, only $22 \%$ of the physicians said that they provide these to their patients (4).

Another part of the challenge is the misidentification of asthma, which leads to both significant over- and underdiagnosis of the disease. For example, one study (6) indicated that of 90 patients labelled by physicians as having asthma, 37 (41\%) showed no evidence of air flow obstruction and had a negative methacholine challenge test. Furthermore, 23 (62\%) of these patients were using medication for the treatment of asthma. The study also revealed that only $52 \%$ of the diagnosed asthmatic patients recalled ever having been tested with spirometry. It is well known that objective measurements are not used by primary care physicians, which can lead to an overdiagnosis, underdiagnosis or underappreciation of the severity of asthma.

Despite the above data, we believe the efforts surrounding implementation of the 1999 guidelines were not evaluated in a manner appropriate for the drawing of conclusions. Yet, it does appear that they had minimal impact.

These findings underline the importance of educating not only physicians, but also patients about asthma and the control of symptoms. More emphasis could be placed on asthma education for patients, including by specially trained community pharmacists (7) or other asthma educators. Newer methods of changing physician behaviour, such as the use of handheld devices (8) and treatment protocols (9), also need to be assessed.

\section{SUMMARY}

Further research is clearly required to develop and validate models to improve implementation and dissemination of guidelines. It is likely that such models will comprise both existing approaches and new strategies, along with the resources necessary to facilitate change. Furthermore, the effectiveness of the models must be scientifically evaluated using proper methods.

\section{REFERENCES}

1. Boulet LP, Becker A, Berube D, Beveridge R, Ernst P; Canadian Asthma Consensus Group. Canadian Asthma Consensus Report, 1999. CMAJ 1999;161(Suppl 11):S1-S62.

2. Ernst P, FitzGerald JM, Spier S. Canadian Asthma Consensus Conference: Summary of recommendations. Can Respir J 1996;3:101-14.

3. Chapman KR, Ernst P, Grenville A, Dewland P, Zimmerman S. Control of asthma in Canada: Failure to achieve guideline targets. Can Respir J 2001;8(Suppl A):35A-40A.

4. Chapman K, McIvor R, FitzGerald M, Boulet L, Zimmerman S. Asthma exacerbation self-management: National benchmark survey results from the Reality of Asthma Control Study. American Thoracic Society 2005. San Diego, May 20 to 25, 2005.

5. Chapman K, McIvor R, FitzGerald M, Boulet L, Zimmerman S. Patient factors associated with suboptimal asthma control in Canada: Results from the Reality of Asthma Control Study. American Thoracic Society 2005 Annual Meeting. Abstract A678.

6. LindenSmith J, Morrison D, Deveau C, Hernandez P. Overdiagnosis of asthma in the community. Can Respir J 2004;11:111-6.

7. McLean W, Gillis J, Waller R. The BC Community Pharmacy
Asthma Study: A study of clinical, economic and holistic outcomes influenced by an asthma care protocol provided by specially trained community pharmacists in British Columbia. Can Respir J 2003;10:195-202.

8. Leung GM, Johnston JM, Tin KY, et al. Randomised controlled trial of clinical decision support tools to improve learning of evidence based medicine in medical students. BMJ 2003;327:1090.

9. Morris AH. Treatment algorithms and protocolized care. Curr Opin Crit Care 2003;9:236-40.

Correspondence: Dr Dennis Bowie, Division of Respirology, Dalhousie University, Halifax, Nova Scotia B3H 3 A7.

Telephone 902-473-4024, fax 902-473-6202, e-maildennis.bowie@cdha.nshealth.ca

\section{Current status of COPD guidelines in Canada}

\author{
Paul Hernandez MDCM FRCPC
}

Respirology Division, Queen Elizabeth II Health Sciences Centre, Dalhousie University, Halifax, Nova Scotia

$T^{\mathrm{h}}$ he present section reviews the current status of COPD guidelines in Canada. Topics covered include the development of the CTS evidence-based management recommendations, and collaboration among key stakeholder groups in the guidelines dissemination and implementation strategies. Finally, the impact of guidelines is briefly evaluated.

The development of evidence-based management recommendations for COPD was undertaken in 2001 by the COPD and Pulmonary Rehabilitation Committee of the CTS, chaired by Dr Dennis O'Donnell. There have been significant changes in our understanding of the pathophysiology and management of COPD since the CTS last published COPD guidelines in the Canadian Medical Association Journal in 1992 (1). A steering committee of 12 Canadian respirologists was formed to collate and weigh the quality and strength of evidence for these recommendations according to established criteria (2). An executive summary of the COPD Guidelines was first published in a supplement to the Canadian Respiratory Journal in 2003 (3). In the same issue of the Journal, the article "Summary of Highlights for Family Physicians" was published, which distilled the lengthy guidelines document down to 15 important messages relevant to the management of COPD in a primary care setting (4). Subsequently, in 2004, a comprehensive "State of the Art" source document was published in another supplement to the Canadian Respiratory Journal (5).

Although the Global Initiative for Obstructive Lung Disease (GOLD) COPD guidelines were released in 2001, the CTS thought that Canadian COPD guidelines were still desirable (6). Clinical practice guidelines are most likely to be adopted when developed and endorsed by local stakeholders. In addition, the CTS Guidelines departed from GOLD in a number of areas. These included the following: a symptombased classification of disease severity using the Medical Research Council dyspnea scale, rather than a system-based method, on the degree of air flow obstruction as measured by spirometry; emphasis on the Canadian epidemiology of the disease burden; comprehensive evaluation of drug efficacy across the spectrum of impairment, disability and handicap; and inclusion of a chapter dealing with end-of-life issues in COPD (2-6).

Clinical practice guidelines are considered to be an important tool to reduce unnecessary variation in health care practice, 
TABLE 4

Goals of the chronic obstructive pulmonary disease (COPD) Guidelines Dissemination and Implementation Committee

- Share knowledge and learn from other groups involved in dissemination and implementation of guidelines

- Raise awareness of COPD/COPD guidelines among health care professionals and the general public

- Disseminate Canadian COPD guidelines to health care professionals

- Identify COPD care gaps in Canada

- Identify and promote key messages in the COPD guidelines

- Produce tools and educational programs to facilitate COPD guidelines implementation

- Evaluate the effectiveness of the dissemination and implementation process

minimize medical errors and encourage adoption of recent research advances into clinical practice (7). In 2003, after the publication of Canadian COPD Guidelines, the CTS struck an ad hoc committee responsible for dissemination and implementation (D\&I Committee) of the clinical practice guidelines. This committee brought together a coalition of key stakeholders with an interest in improving COPD care in Canada, including representatives from the CTS COPD Guidelines Development Steering Committee; other health care professional organizations (ie, family medicine, nursing, respiratory therapy, pharmacy and physiotherapy); organizations such as The Canadian COPD Alliance and the Canadian Lung Association; Health Canada; and the pharmaceutical industry. Importantly, the committee has engaged the services of project coordinators from its inception (Jennifer Schenkel and Laura Monette). The COPD Guidelines D\&I Committee's overall goals are to improve the prevention and management of COPD in Canada. This will be accomplished through a number of activities (Table 4).

The dissemination strategy for the COPD Guidelines D\&I Committee includes both traditional (eg, publication in health care professional journals, and presentations at symposia and conferences) and nontraditional (eg, an Internet-based resource centre and slide kits for educators) means. The guidelines will be updated and published as necessary when advances in our understanding of COPD lead to substantive changes in management recommendations. However, it is well recognized that passive diffusion and dissemination of the guidelines alone does not lead to improved COPD care. To affect real change, a more active implementation strategy is required.

A number of national needs assessments have recently been conducted that explored the care gaps in COPD between management recommendations and actual practice (8-10). These results help to give direction to the implementation strategy of the D\&I Committee. Common themes in care gaps analysis include concern about COPD prevention (eg, persistent high smoking rates across Canada), diagnosis (eg, barriers to widespread use of spirometry and the lack of a tool for targeted casefinding in primary care) and management (eg, overuse of ICS, underuse of inhaled bronchodilators, poor access to patient education and pulmonary rehabilitation programs).

Three key messages emerged from the recent guidelines (Table 5). The D\&I Committee employed the services of creative marketing and public relations firms to assist in the

\section{TABLE 5}

Key messages from the Canadian Thoracic Society's recommendations for the management of chronic obstructive pulmonary disease (COPD)

COPD is ...

- Treatable - with appropriate management. Thus, patients with COPD should expect reduced symptoms, fewer acute exacerbations and improved quality of life

- Preventable - through comprehensive tobacco control policies and increased access to smoking cessation programs

- Underdiagnosed - due to poor public awareness of the disease and underutilization of spirometry in primary care

translation of these messages into meaningful and useful formats for clinicians. No single intervention was effective in all circumstances; therefore, a multifaceted approach was used to increase the likelihood of impact on clinician behaviour and health care outcomes. All products of the committee were branded (including the logo and tagline) for a consistent look and ease of recognition among clinicians, identifying that our products come from a reputable source. A number of examples of the implementation activities of our committee follow.

Raise awareness of COPD and COPD guidelines

We collaborated with BreathWorks (a patient education program run by the Lung Association) to try to raise awareness of COPD in the general public through campaigns in various media (eg, newspapers, television and radio). In the fall of 2005 , we launched an advertising campaign in a number of professional journals to raise awareness of the COPD guidelines and our Internet-based COPD resource centre for clinicians (www.COPDguidelines.ca). We conducted research (led by Dr R Hodder) to validate a tool (the Canadian Lung Health Test) that can be used by family physicians to target individuals in their practice (case-finding) in whom spirometry should be performed to confirm a clinical diagnosis of COPD.

\section{Educate clinicians}

A slide kit has been developed to assist educators when giving lectures about COPD. In 2004, we developed a CTS-accredited continuing medical education program for specialist physicians entitled "Controversies in COPD". With sponsorship from two industry sponsors, this continuing medical education program is being delivered across the country. Members of our committee have assisted Canadian medical schools in developing academic detailing COPD projects for family physicians. We plan to target other health care professional groups in 2006/2007.

\section{Provide tools}

A number of practice-based implementation tools have been developed and distributed to physicians that act as either patient-based interventions (eg, clinic wall poster about COPD) or reminders for clinicians (eg, mouse pad with treatment algorithm or pocket-sized laminated card with summary of guidelines). In the fall of 2005, we began developing a personal digital assistant version of the guidelines. As with the slide kit, the personal digital assistant version of the guidelines will be available for free download from the Web site.

Evaluation of the impact of the COPD guidelines and the work performed by the D\&I Committee is complicated by a 
large number of factors that are difficult to control for, and that affect quality of health care, clinician behaviour and patient health care resource utilization. Market research was conducted in February and October 2004 to assess perception and awareness of the key messages in the COPD Guidelines among Canadian clinicians. Similar surveys will be repeated in 2006 to ensure that the key messages are reaching the target audiences. Ultimately, the real measure of success will be a narrowing of the gap between management recommendations and actual clinical practice, resulting in improved health outcomes among patients living with COPD in Canada.

Dr Hernandez is the Chair of the CTS COPD Guidelines, D\&I Committee, and Associate Professor of Medicine, Dalhousie University.

\section{REFERENCES}

1. Canadian Thoracic Society Workshop Group. Guidelines for the assessment and management of chronic obstructive pulmonary disease. CMAJ 1992;147:420-8.

2. MacPherson DW. Evidence-based medicine. CMAJ 1995;152:201-4.

3. O'Donnell DE, Aaron S, Bourbeau J, et al; Canadian Thoracic Society. Executive Summary: Canadian Thoracic Society recommendations for management of chronic obstructive pulmonary disease - 2003. Can Respir J 2003;10(Suppl A):11A-33A.

4. O'Donnell DE, Hernandez P, Aaron S, et al; Canadian Thoracic Society. Canadian Thoracic Society COPD Guidelines: Summary of highlights for family doctors. Can Respir J 2003;10:183-5.

5. O'Donnell DE, Aaron S, Bourbeau J, et al. State of the Art Compendium: Canadian Thoracic Society recommendations for the management of chronic obstructive pulmonary disease. Can Respir J 2004;11(Suppl B):7B-59B.

6. Global Initiative for Obstructive Lung Disease. Global Strategy for the Diagnosis, Management and Prevention of Chronic Obstructive Pulmonary Disease NHLBI/WHO Workshop Report: Executive Summary. NHI Publication No 2701A, March 2001.

7. Davis D, Taylor-Vaisey A. Translating guidelines into practice. A systematic review of theoretic concepts, practical experience and research evidence in the adoption of clinical practice guidelines. CMAJ 1997;157:408-16.

8. Rouleau MY, Hernandez P, Gagnon R, et al. Perceived solutions for better COPD guidelines implementation. Eur Respir J 2004;24(Suppl 4):156S.

9. Haye S, Cochrane L, Hernandez P, et al. Behavioural needs analysis among physicians in the care of COPD. Am J Respir Crit Care Med 2003;167:A227. (Abst)

10. Chapman KR, Bourbeau J, Rance L. The burden of COPD in Canada: Results from the Confronting COPD survey. Respir Med 2003;97(Suppl C):S23-S31.

Correspondence: Dr Paul Hernandez, Room 4458, Halifax Infirmary, 1796 Summer Street, Halifax, Nova Scotia B3H 3A7.

Telephone 902-473-3698, fax 902-473-6202,

e-mail paul.hernandez@cdha.nshealth.ca

\section{Asthma in Ontario: Ontario's Asthma Plan of Action}

\author{
Nancy Garvey RRCP/RRT CAE ${ }^{1}$, \\ Diane Lougheed MD MSc FRCPC ${ }^{2}$
}

\begin{abstract}
${ }^{1}$ Community Health Division, Ministry of Health and Long-Term Care, Toronto; ${ }^{2}$ Department of Medicine, Queen's University, Kingston, Ontario
\end{abstract}

$\mathrm{D}^{\mathrm{e}}$ spite the publication of Canadian Asthma Management Guidelines (1-4), gaps between recommended asthma management and practice are known or suspected to exist across the continuum of asthma care in Canada (5). Ontario is no exception. Morbidity and mortality rates from asthma in Ontario parallel national averages (6). In the mid-1990s, ageand sex-standardized mortality rates for asthma in Ontario were 1.39 per 100,000 population, while hospitalization rates were 126 per 100,000. Regional variations in hospitalization rates (7) and emergency department visit rates for asthma in Ontario (8) raise concerns regarding access to and quality of ambulatory and hospital-based care for asthma.

As a follow-up to recommendations from a 2000 inquest into the death of a young man with asthma, and in conjunction with the Chief Medical Officer of Health's Report entitled "Taking Action on Asthma" (9), the Ministry of Health and Long-Term Care convened an Expert Panel Steering Committee and three working groups to garner advice regarding the development of a phased provincial asthma strategy. On January 29, 2002, the Ministry of Health and Long-Term Care announced $\$ 4$ million in annual funding for phase II of the province's Asthma Plan of Action, a collaborative integrated strategy based on the Canadian Asthma Management Guidelines $(1,3)$. Phase II of the strategy promotes innovative multidisciplinary approaches that focus on health promotion, prevention, evaluation and surveillance, as well as asthma management. The ultimate goal is to reduce mortality, morbidity and health care costs for children and adults with asthma in Ontario.

The initiatives support behavioural change among patients and providers through dissemination and implementation activities related to asthma guidelines. KT activities in the form of needs assessments, multidisciplinary pathways, selfmanagement programs and small group, case-based learning have been designed to promote guideline uptake and research capacity.

A unique feature of the Asthma Plan of Action is the partnerships that have been formed to develop, implement and evaluate the initiatives. Four Ontario ministries, five public health units and municipalities, 12 school boards, nine primary care sites, 12 nongovernmental agencies, and researchers from four Ontario universities, as well as the Institute for Clinical Evaluative Sciences, have been engaged in this effort.

Initial evaluations are providing statistically significant improvements in uptake and practice, and will contribute to a provincial plan for asthma in Ontario.

\section{HEALTH PROMOTION AND PREVENTION}

The major focus of the Asthma Plan of Action projects is health promotion and prevention initiatives that result in better health outcomes for people with asthma, including prevention of exacerbations. Key projects include the following:

- The Primary Care Asthma Pilot Project - includes eight primary care sites across the province. They have contributed to the development of an asthma care program, including a primary care map, action plan, flow chart and generic program standards;

- The Public Health School Asthma Pilot Project involves 170 schools in five public health units and five municipalities. They have implemented the Roaring Adventures of Puff asthma education program for grades 3 to 5, and the Creating Asthma Friendly Schools Resource Kit to support school staff in optimizing asthma management in schools; 
- The Air Quality in the Schools Project - being developed to address the issue of indoor air quality in schools and daycares;

- A school-based asthma program led by the Ontario Physical and Health Education Association complements the Creating Asthma Friendly Schools Resource Kit, with a special focus on physical activity for children with asthma;

- The Program Training and Consultation Centre leading the Smoke-Free Homes and Asthma Project by promoting community-based campaigns to address secondhand smoke in homes and cars as a risk factor for asthma;

- Consumer health materials on asthma - developed by the Consumer Health Information Service, and are provided to the public through the Toronto Public Library and its Virtual Reference Library Web site;

- The Child and Youth Public Education project led by the Ontario Lung Association (OLA), has developed books on asthma for three- to six- and seven- to 12-year-olds (Call Me Brave Boy and Asthma Active), an environmental poster with 'trigger' stickers and a Web site endorsed by hockey player Gary Roberts;

- The Farm Safety Association, the Occupational Health Clinics for Ontario Workers and the Industrial Accident Prevention Association - raising awareness of occupational asthma in the agriculture, bakery, auto/plastics and foam industries;

- An occupational asthma problem-based, small-group learning module - developed by McMaster University's Occupational Health Clinic for provider education; and

- The OLA's Asthma Action Program - provides telephone and on-line counselling, literature and resources for individuals with asthma, caregivers, and professionals in health care and other disciplines.

\section{MANAGEMENT AND TREATMENT}

Active management and treatment of asthma exacerbations is the focus of three management and treatment initiatives:

- The Ontario Thoracic Society is leading education workshops to incorporate expert presenters and peer facilitation of small-group case discussions. The target is to expose 3000 health care professionals to the workshops over three years;

- The Ontario Hospital Association has developed a standardized emergency management pathway for adult asthma that includes preprinted physician orders, a teaching checklist and a discharge package with patient instructions. The OLA is training and supporting hospitals' use of the pathway as part of a pilot project being conducted by the Ontario Respiratory Outcomes Research Network; and

- The Patient and Family Education Project, led by the OLA, disseminates asthma action materials to pharmacists and primary care providers.

\section{RESEARCH AND SURVEILLANCE}

Each of the projects has an evaluation component. In addition, researchers from Ontario universities and other research institutions have received grants as part of the primary care, school asthma and emergency department projects to measure the projects' impact on patients, providers and health care utilization. For example, the Institute for Clinical Evaluative Sciences, an Ontario-based, independent, nonprofit research organization, is leading the Asthma Surveillance Project. This is a population-based asthma database designed to monitor the following:

- Asthma incidence and prevalence;

- Asthma-related morbidity and mortality;

- Health services use and cost; and

- Treatment and provider practice patterns.

Beginning with case verification studies for both children and adults, the first major report from the project was published in 2004. It is entitled "Burden of Childhood Asthma" (10).

As another example, the Occupational Asthma Surveillance Project is using a three-phase approach to develop, pilot-test and implement a province-wide system of occupational asthma surveillance.

\section{SUMMARY}

Ontario's Asthma Plan of Action incorporates innovative, multidisciplinary approaches to asthma guideline dissemination and implementation. The projects' initial evaluations show statistically significant improvements in health care provider practice and patient outcomes.

\section{REFERENCES}

1. Boulet LP, Becker A, Berube D, Beveridge R, Ernst P; Canadian Asthma Consensus Group. Canadian Asthma Consensus Report, 1999. CMAJ 1999;161(Suppl 11):S1-S62.

2. Boulet LP, Bérubé D, Cockcroft DW, et al. Asthma Guidelines Update 2001. Can Respir J 2001;8(Suppl 8):3A-27A.

3. Tarlo SM, Boulet LP, Cartier A, et al. Canadian Thoracic Society guidelines for occupational asthma. Can Respir ] 1998;5:289-300.

4. Lemiere C, Bai T, Balter M, et al. Adult Asthma Consensus Guidelines Update 2003. Can Respir J 2004;11(Suppl A):9A-18A.

5. Jin R, Coi BCK, Chan B, et al. Physician asthma management practices in Canada. Can Respir J 2000;7:456-65.

6. Canadian Institute for Health Information, Canadian Lung Association, Health Canada, Statistics Canada. Respiratory Disease in Canada. Ottawa: Health Canada, 2001

7. To T, Dick PT, Feldman W, Tran M. Hospitalization for childhood asthma. Pediatric health service utilization. In: Goel V, Williams JI, Anderson GM, Blackstien-Hirsch P, Fooks C, Naylor CD, eds. The ICES Practice Atlas. Ottawa: Canadian Medical Association, 1996:307-8

8. Lougheed MD, Garvey N, Chapman KR, et al. Regional variation in emergency department visits for asthma in Ontario. Am J Respir Crit Care Med 2004;169:A358. (Abst)

9. Ontario Ministry of Health and Long-Term Care. Taking Action on Asthma: Report of the Chief Medical Officer of Health. Toronto: Queen's Printer for Ontario, 2000

10. To T, Dell S, Dick P, et al. Burden of Childhood Asthma. ICES Evaluative Report. Toronto: Institute for Clinical and Evaluative Sciences, 2004

Correspondence: Nancy Garvey, Community Health Division, Ministry of Health and Long-Term Care, 393 University Avenue, Suite 2100, Toronto, Ontario M5G 1E6. Telephone 416-314-5480, fax 416-327-7550, e-mail nancy.garvey@moh.gov.on.ca 


\section{Asthma guideline implementation in Quebec}

\author{
Louis-Philippe Boulet MD FRCPC ${ }^{1}$, \\ Manon Labrecque MD FRCPC ${ }^{2}$
}

\begin{abstract}
${ }^{1}$ Institut universitaire de cardiologie et de pneumologie de I'Université Laval, Hôpital Laval, Ville de Québec; ${ }^{2}$ Service de Pneumologie, Hôpital du Sacré-Cœur, Montréal, Québec
\end{abstract}

Key Words: Asthma; Asthma management; Asthma treatment; Care gaps; Quebec

Jarious initiatives have been developed in the province of Quebec to promote the implementation of the CACG. Key programs include Towards Excellence in Asthma Management (TEAM) and Programs to Integrate Information Services and Manage Education (PRIISME).

In the province of Quebec, as elsewhere, asthma is responsible for significant morbidity and health care costs $(1,2)$. The CACG was first issued in 1989, and the groups of experts who created the last three updates were led by physicians from Quebec (3-6). Furthermore, many CACG implementation initiatives have also been developed in the province of Quebec in recent years, including workshops and other continuing medical education events at Université Laval, the University of Montreal, Université de Sherbrooke and McGill University. A significant amount of educational activity has also been aimed at members of the public suffering from asthma.

\section{TABLE 6}

Towards Excellence in Asthma Management (TEAM) program research questions

- What is the current morbidity and mortality associated with asthma in the population studied and its geographical variations?

- What is the current status of asthma care?

-What are the gaps between current and optimal global asthma care?

- What are the causes of these gaps and what strategies should be developed to address them?

- How will the proposed interventions improve care?

- How can those interventions be integrated into current care?

- How can the cost-benefit of these interventions be optimized?

- How can this information be communicated to the medical/scientific community?

- How can the continuity of the process be ensured?

TEAM strategy

- Develop innovative and cost-effective ways to gather information on current asthma care and consequences of the disease in the population

- Structure intervention programs that promote optimal care and address the care gaps identified

- Motivate stakeholders to develop innovative strategies to address care gaps and assess the strategies' effectiveness with the highest scientific standards

- Determine how the improvements in management described could be applied to the whole population at the lowest possible cost

- Ensure a continuity and synergism of the process through ongoing collaboration of the various participants
THE QUEBEC ASTHMA AND COPD NETWORK The Quebec Asthma and COPD Network (QACN) was formed in 2000 through the merger of the Quebec Asthma Education Network (Réseau Québécois pour l'enseignement sur l'asthme) and the COPD Group (7-9). Under the auspices of the QACN, a network of more than 100 asthma education centres (AECs) has been developed in hospitals and community centres. At the AECs, nurses, respiratory therapists and pharmacists provide free, high-quality educational interventions to children, adults and their families under the supervision of designated physicians. The education provided at all AECs involves a common curriculum developed by the QACN's scientific committee based on the most recent CACG recommendations. Moreover, educators receive basic training, and many enroll in the provincial training program, allowing them to attend the Canadian certification exams for asthma educators. Patients at the AECs are also given education on COPD and readaptation programs. After the educational intervention, a report is sent to the referring physician.

In addition to education, some centres also provide spirometric measurements and/or are linked with an asthma clinic. A yearly provincial meeting and numerous symposia help caregivers to remain current regarding evidence-based asthma care.

\section{TEAM}

\section{DISEASE-MANAGEMENT PROGRAMS}

TEAM/VESPA (Vers l'Excellence dans les Soins aux Personnes Asthmatiques) is a population-based, multiphase program based on the CACG recommendations. The program ran in Quebec from 1998 to 2005 (9), and its main objective was to determine how to improve asthma management, particularly in regions or groups with high asthma-related morbidity. It resulted from the joint efforts of the various intervening health care providers, researchers, the QACN, asthma patients' associations, health professionals' organizations, the pharmaceutical industry (Merck Frosst Canada and AstraZeneca Canada) and many of the province's health network institutions.

A series of projects, rolled out in four phases, identified high morbidity regions and health care gaps, and tested various innovative interventions to fill in the gaps between optimal and existing care. The projects all assessed specific outcomes that could be compared with baseline data, and involved a budget and time frame compatible with those of the overall TEAM program (Table 6).

The first phase entailed the creation of a map of regional variations in asthma-related morbidity in the province of Quebec, under the leadership of the Direction de la santé publique de Québec $(2,10,11)$. The second phase involved the recruitment of a cohort of patients and physicians to determine current patterns of asthma management and patient outcomes $(12,13)$.

Finally, the third and fourth phases consisted of a series of projects, including a specific innovative intervention associated with an evaluation of its effects (Figure 5), peer-reviewed by the Fonds de recherche en santé du Québec. These involved the testing of specific, multidisciplinary interventions targeting identified care gaps in groups and regions with high asthmarelated morbidity. For example, there were projects on the identification of optimal physician practices, testing of practice aids and environmental control. Emergency department interventions were developed for both children and adults, based on previous 
projects aimed at increasing referrals of adult patient to AECs (14). Other projects focused on ways to increase the use of spirometric measures, to optimize first-line educational interventions and to increase referrals to AECs. To be selected, these interventions had to satisfy the following criteria: they had to deal with one of the four main themes described above; they had to assess specific outcomes that could be compared with baseline data; they had to address at least one of the main deficiencies/ needs previously identified; and they had to be completed within the time frame and budget of the TEAM program (Table 6).

Descriptions of the program and the results of the initial projects have been previously published, and many other projects will soon be completed $(8,10-13)$.

\section{PRIISME}

In 1999, GlaxoSmithKline Inc developed PRIISME. This program was undertaken in collaboration with Quebec regional health authorities, QACN and hospitals. It addressed the growing health care burden caused by asthma and COPD. The objectives of the program were subsequently supported by the province of Ontario's February 2002 Disease Management Report, which found that better management of asthma, diabetes and COPD was likely to save valuable health care resources (15).

PRIISME supports three cornerstones of chronic disease health care. First, it helps health professionals to provide care for patients with asthma, diabetes and COPD. Second, it helps to provide ongoing continuing education and other initiatives to equip health care professionals to better educate patients. Finally, it supports efforts that enable patients and their families to better monitor their own health and manage their disease, thus improving their quality of life.

PRIISME now comprises more than 50 projects across Canada. A large number of Canadian health professionals and patients have been respectively trained and educated in PRIISME projects, through collaboration with the QACN. Evaluations by regional boards in Quebec showed, in keeping with our previous studies on asthma education, that people who received asthma education through PRIISME had over $40 \%$ fewer emergency room visits and hospitalizations (16). The evaluations also showed that PRIISME contributed to improved quality of life for asthmatic patients and decreased the days they missed from school and work. PRIISME facilitated the cooperation of the public and private sectors in health care, helped to improve chronic disease management and reduced patient reliance on acute care facilities.

\section{OTHER INITIATIVES}

Various initiatives have been recently developed, such as the automatic referral program to AECs for asthmatic patients consulting at the emergency department for acute asthma, under the auspices of the QACN, supported by the Health Transition Fund (Health Canada) (14). This project showed that it is possible to increase the number of patients (who most need educational intervention) enrolled in an education program, without adding significantly to the workload of the emergency departement staff.

Finally, the Quebec review board (Conseil du médicament) is a governmental organization that has developed initiatives to evaluate and promote optimal medication use. This has contributed to the dissemination of documents, such as asthma action plans and treatment algorithms, to patients and physicians. Furthermore, the group has an ongoing program to

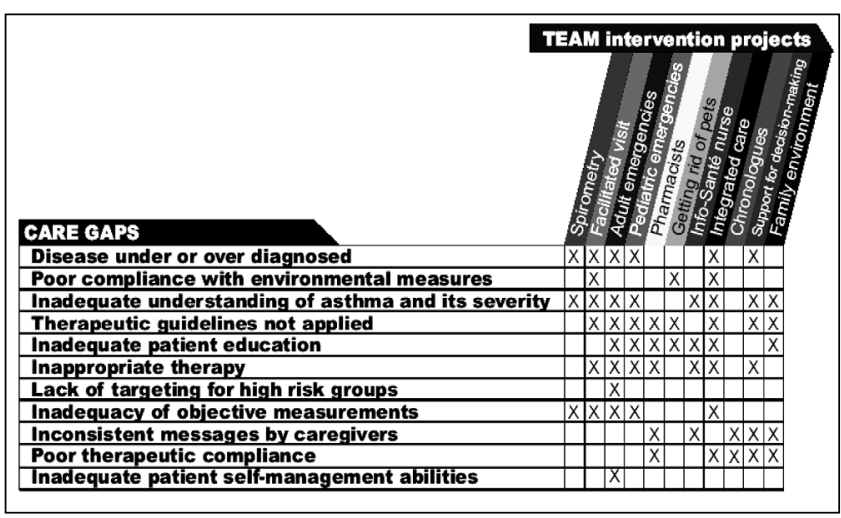

Figure 5) The Towards Excellence in Asthma Management (TEAM) program aimed at developing various interventions to address asthma care gaps and, thus, to improve asthma management

assess drug use in the province and identify means to improve adequate utilization of therapeutic options for various conditions, including asthma. In 1999, a government-funded drug review committee (Comité de revue de l'utilisation des médicaments) published the results of a survey on inhaled beta-agonist use in the treatment of asthma (17). It showed overuse of short-acting beta-agonists and underuse of ICS, in addition to suboptimal use of long-acting bronchodilators in many instances. Various initiatives have been proposed to improve the situation.

\section{REFERENCES}

1. Health Protection Branch, Respiratory Division. The burden of asthma and other chronic respiratory diseases of Canada. In: Facts and Figures, 1998. Ottawa: Health Canada, 1998:87.

2. Lajoie P, Laberge A, Lebel G, et al. Cartography of emergency department visits for asthma - Targeting high-morbidity populations. Can Respir J 2004;11:427-33.

3. Hargreave FE, Dolovich J, Newhouse MT. The assessment and treatment of asthma: A conference report. J Allergy Clin Immunol 1990;85:1098-111.

4. Ernst P, Bérubé D, Boulet LP. Consensus sur le bilan et le traitement de l'asthme. Clinicien 1996;11:122-38.

5. Boulet LP, Becker AB, Bérubé D, Beveridge R, Ernst P; the Canadian Asthma Consensus Group. Canadian Asthma Consensus Report, 1999. CMAJ 1999;161(Suppl):S1-S62.

6. Lemiere C, Bai T, Balter M, et al. Adult Asthma Consensus Guidelines Update 2003. Can Respir J 2004;11(Suppl A):9A-18A.

7. Boulet LP, Chapman KR. Asthma education: The Canadian experience. Chest 1994;106(Suppl 4):206S-10S.

8. Boulet LP. The Quebec Asthma Education Network: An update. Can Resp J 1996;3(Suppl A):21A-4A.

9. Cowie RL, Cicutto L, Boulet LP. Asthma education and management programs in Canada. Can Respir J 2001;8:416-20.

10. Boulet LP, Thivierge RL, Bellera C, Dorval E, Collet JP. Physicians' assessment of asthma control in low vs high asthma-related morbidity regions. J Asthma 2004:41:813-24.

11. Laurier C, Blais L, Kennedy W, et al. Surveillance épidémiologique de l'asthme au Québec et variations régionales, 1999-2001: Une analyse des banques de données. Université de Montréal: Montréal, Québec, 2005:264.

12. Boulet LP, Thivierge RL, Amesse A, Nunes F, Francoeur S, Collet JP. Towards excellence in asthma management (TEAM): A populational disease-management model. J Asthma 2002;39:341-50.

13. Lacasse Y, Archibald H, Ernst P, Boulet LP. Patterns and determinants of compliance to inhaled steroids in adult asthma. Am J Respir Crit Care Med 2003;167:A964. (Abst)

14. Robichaud P, Laberge A, Allen MF, et al. Evaluation of a program aimed at increasing referrals for asthma education of patients consulting at the emergency department for acute asthma. Chest 2004;126:1495-501.

15. The Change Foundation. The Disease Management Report in the Province of Ontario. Report February 2002. 
16. The PRIISME concept < www.chmonline.ca/issue/article.jsp?content= 20031031_145436_5112> (Version current at February 20, 2006).

17. Comité de revue de l'utilisation des médicaments. <www.cdm.gouv.qc.ca/ site/50.40.0.0.1.0.phtml $>$ (Version current at February 20, 2006).

Correspondence: Dr Louis-Philippe Boulet, Hôpital Laval, 2725 Chemin Sainte-Foy, Québec, Québec G1V 4G5.

Telephone 418-656-4747, fax 418-656-4762,

e-mail lpboulet@med.ulaval.ca

\section{ROUNDTABLE ON DISSEMINATION AND IMPLEMENTATION OF CLINICAL PRACTICE GUIDELINES}

Various contributors from different backgrounds were asked for their point of view on how to disseminate and implement clinical practice guidelines during a roundtable at this symposium. The following sections summarize their presentation.

\section{Implementing practice guidelines in asthma: A point of view of industry - View 1}

\author{
Renata Rea RRCP CAE 1 , Martin C Holroyde MSc PhD²
}

${ }^{1}$ GlaxoSmithKline, Mississauga; ${ }^{2}$ ALTANA Pharma, Oakville, Ontario

Behavioural change should be encouraged among primary B care physicians to improve their adoption of asthma guidelines. Several studies have been undertaken in the past 10 years to look at the state of asthma in Canada. Most recently, the Personal Practice Assessment Program stated that approximately $58 \%$ of patients are not well controlled according to guidelines (1). In addition, $52 \%$ of patients are not compliant with dosing instructions, $44 \%$ of patients finish the

\section{TABLE 7}

Steps to improve guideline implementation

- Highlight new evidence with each new iteration of guidelines

- Ensure simplicity and clarity of messages, tailored to each intended audience. In particular, guidelines aimed at a primary care audience must be reduced to one or two pages containing only the essential key messages

- Create a clear, directive call to action that will energize stakeholders

- Ensure stronger engagement and ownership of key stakeholders in the creation and implementation of guidelines (create subcommittees of key stakeholders to review relevancy and develop key messages for that stakeholder group, etc)

- Develop the dissemination/implementation plan in parallel with the development of the guidelines

- Develop a core continuing health education module, which, with the agreement of all pharmaceutical industry partners, will be delivered at all continuing health education events

- Shorten the time between the consensus meeting and publication of the guidelines

- Develop a program to measure the impact of implementation tactics on changing physician behaviour to avoid repeating fruitless activities in the future medication in a rescue inhaler in less than three months and less than 20\% have a written asthma management plan.

On the other hand, the Canadian respiratory community should congratulate itself because its efforts have had an evident impact. The level of asthma severity has declined (2). The number of deaths from asthma has also declined, along with the number of emergency room visits and the number of hospital admissions.

We have gained several key insights about patients and their care providers over this same period. We know that both patients and their caregivers overestimate levels of asthma control. Patients often tolerate lifestyle limitations because they are unaware that they can feel better and because they believe that their physicians would recommend appropriate medication changes if necessary. In contrast, caregivers appear relatively complacent and generally believe that lack of control reflects failure by patients to follow physician directions.

The view in the pharmaceutical industry is that the fundamental barrier to improving asthma management lies in the current lack of incentives for a change in physician behaviour. There are no perceived consequences for suboptimal management and no perceived rewards for improving management. This needs to change. There needs to be a strong call to action for all stakeholders, including family physicians, patients and payers. The 'active' ingredient needs to be identified! There are several steps that can be taken to improve implementation of guidelines, as shown in Table 7 .

If each of these aforementioned points is not addressed, they actually become barriers to implementation!

Implementation of the asthma guidelines must focus on a desired outcome or behaviour to be successful. There should be no more than one or two key communication points - they should have the most impact on the key audiences (family physicians and patients). We will only achieve success when there is acknowledgement and active participation in achieving optimal control of asthma by all stakeholders.

\section{REFERENCES}

1. Chapman KR, Rea RM, Boulet LP. Primary care assessment of asthma control; Discordance with guideline recommendations. AJRCCM April 2005;2:A549. (Abst)

2. Canadian Institute for Health Information, Canadian Lung Association, Health Canada, Statistics Canada. Respiratory Disease in Canada. Ottawa: Health Canada, 2001.

Correspondence: Renata Rea, GlaxoSmithKline,

7333 Mississauga Road North, Mississauga, Ontario L5N 6L4.

Telephone 905-819-3000, fax 905-819-3099,

e-mail renata.m.rea@gsk.com

\section{Implementing practice guidelines in asthma: A point of view of industry - View 2}

\author{
Danielle Fagnan MSc, Eileen Dorval (BPharm) \\ Merck Frosst Canada Ltd, Kirkland, Quebec
}

$\mathrm{M}$ erck Frosst Canada Ltd sees itself as a partner for better care and believes that it can play a role in the dissemination and implementation of asthma guidelines through health education programs and patient health programs (disease management) based on evidence-based medicine. All programs are 
developed in partnership with health care professionals and associations, academia, universities and specialty societies. They are designed based on the need of physicians to facilitate integration of guidelines into their practice. Offerings such as educational programs or validated tools to facilitate medical practice based on Canadian asthma guidelines aim to optimize the use of medication and medical care for asthmatic patients.

\section{METHODS FOR IMPLEMENTATION AND DISSEMINATION OF GUIDELINES}

\section{Patient health management}

Through the design of disease management programs, all aspects of asthma care are being addressed. First, gaps between actual asthma care and optimal care, as defined by CACG, are identified. Following this, peer-reviewed interventions addressing various gaps (ie, compliance, diagnostics, plan of action, environmental control, etc) are evaluated. At the end of the day, the impact on patient morbidity and medical knowledge/ practice are evaluated.

\section{Health education}

Through the establishment of a long-term partnership with health education providers, health education aims to design, develop and implement continuing professional development strategies. The continuum of interventions supporting these strategies will be accreditable, ethical, evidence-based and will address the physicians' learning needs and styles (1). The joint and integrated efforts of health education, patient health management and their partners will be an agent of change for practice behaviour, resulting in better patient health outcomes.

\section{Outcome measurement}

There are four levels of outcome-based continuing education: reaction/perception, learning, behaviour and results/impact (2). To ensure a successful implementation and dissemination of practice guidelines, the interventions must be well planned and the outcomes measured. For practice guidelines, the societal outcomes must be evaluated to address the following issues: the impact of the learners' change in behaviour and the effect of this change in performance on patient heath status. To resolve these issues, intervention protocols, which are peer reviewed, are designed to measure not only the impact on the application of guidelines through medical practice, but also the impact on patient morbididity.

\section{PARTNERSHIP}

Through partnership with health care providers, academia, universities and specialty societies, programs are developed to integrate consensus guidelines into medical practice. More and more, we will be looking at partnerships with multidisciplinary teams to better integrate all health professionals for better patient care.

In conclusion, the joint and integrated efforts of health education, patient health management and their partners will be an agent of change for practice behaviour, resulting in better patient health outcomes.

\section{REFERENCES}

1. Lenfant C. Shattuck lecture - Clinical research to clinical practice Lost in translation? N Engl J Med 2003;349:868-74.

2. Winfrey EC. Kirkpatrick's four levels of evaluation. In: Hoffman B, ed. Encyclopedia of Educational Technology, 1999. < http://coe.sdsu.edu/eet/ Articles/k4levels/start.htm> (Version current at March 7, 2005).
Correspondence: Danielle Fagnan/Eileen Dorval, Merck Frosst Canada Ltd, Health Education, 16711 Transcanada Highway, Kirkland, Quebec H9H 3L1. Telephone 514-428-7920, e-mail Danielle_fagnan@merck.com, Eileen_dorval@merck.com

\section{Optimal methods for the implementation of asthma and COPD clinical practice guidelines}

\author{
Lisa Pogany \\ Centre for Chronic Disease Prevention and Control, \\ Ottawa, Ontario
}

Clinical practice guidelines are systematically developed Ustatements that can assist in decision-making by both professionals and patients regarding specific clinical issues. The process of effective use of clinical practice guidelines ranges from the identification of priority clinical issues, rigorous guideline development, dissemination to all stakeholders, implementation of recommendations and evaluation of guideline effectiveness on health outcomes.

The value of clinical practice guidelines from a public health perspective includes their ability to facilitate the delivery of evidence-based care to Canadians living with chronic respiratory diseases, with the long-term goal of improving health outcomes at the population level. This is important among populations living with chronic respiratory disease where there are management strategies known to improve health outcomes. Even so, the value must be viewed in the context of whether there are effective strategies to prevent or detect the disease early and, thus, to reduce the need to ultimately intervene at all. In addition, they must also be viewed from the context that other competing strategies may be more or less cost-effective at improving the same health outcomes.

The federal government has been involved in clinical practice guideline development since the 1970s, with the establishment of the Canadian Task Force on Preventive Health Care and its subsequent release of guidelines. Since that time, however, a wide range of stakeholders have become involved in all aspects of the development, dissemination and implementation of clinical practice guidelines. Implementation of clinical care occurs at the provincial level. Therefore, contributions by the Public Health Agency of Canada may be most effective if they include initiatives at the 'systems level', such as the support of research activities that evaluate the impact of clinical practice guidelines on both professional/patient behaviours and population-level health outcomes, as well as the subsequent dissemination of such information to stakeholders, with the goal of implementation strategy evaluation and the development of further steps.

In terms of chronic respiratory disease, clinical practice guidelines have been developed and disseminated, but it is not clear whether the implementation, or uptake and use, of the guideline recommendations has been effective. The Public Health Agency of Canada has the opportunity to facilitate in the identification of barriers and enablers to the uptake of the guidelines to further facilitate changes in the strategies designed to increase uptake. Further dissemination of such health information will facilitate modification of dissemination strategies and identify areas where implementation strategies need to be re-evaluated. There is also 
an important role for the Public Health Agency of Canada that includes national level chronic disease surveillance related to disease management. Lastly, the federal role also includes support of knowledge sharing with a variety of stakeholders outside of the respiratory fields. Ultimately, this will serve to improve population-level health outcomes.

Correspondence: Lisa Pogany, Centre for Chronic Disease

Prevention and Control, 120 Colonnade Road, Ottawa, Ontario

K1A OK9. Telephone 613-957-3148, fax 613-941-549,

e-mail lisa_pogany@phac-aspc.gc.ca

\section{Guideline dissemination and implementation for primary care physicians}

\author{
Alan Kaplan MD CCFP(EM) \\ Family Physician Airways Group of Canada, \\ Richmond Hill, Ontario
}

$\mathrm{T}_{\mathrm{r}}^{\mathrm{h}}$ he guideline committee has met, the literature has been reviewed and the consultants have argued. The work is done; the guideline document is finished. All done, right?

In previous years and for an untold number of guideline documents, this was the case. Is there any wonder that guidelines are not routinely adhered to? Often, there is not even any family practice input into documents that were supposedly created to advise family physicians in their day-to-day patient management issues. I wanted to begin my exposé by thanking the respiratory community for being one of the first specialist bodies to recognize the need of family physicians to be part of the process to create guidelines. A number of other members of the Family Physician Airways Group of Canada and I have been regular contributors to respiratory guideline creation for the past six years. I have watched the growing respect that the respiratory community has developed during these interactions. We have been able to learn that our practices function differently and learn that the barriers to ideal practice may differ significantly.

We have always assumed that a knowledge gap was the problem. Far from it - it is an attitudinal gap that is the biggest barrier. Change is hard! Behavioural change is a process in which we must first assess clinicians' readiness to change. We can then assess the barriers to change and devise means of implementing change - assuming that we can disseminate this information in the first place. The most significant barrier is always time. In a perfect world, the family physician would have had the chance to review every guideline for every condition in toto, with the opportunity to get feedback from a trusted peer to reinforce this learning. This is not going to

\section{TABLE 8}

\section{Clinician types}

- Seeker
- Receptive
- Traditionalist
- Pragmatist
- Unknown - because they do not come to any continuing medical
education events!

Data from reference 1, page 19
TABLE 9

Physician barriers to new guidelines

- Lack of awareness ("What are they?")

- Lack of familiarity ("Never heard of them ...")

- Lack of agreement ("I do not agree with those guidelines")

- Lack of self-efficacy ("They won't work in my practice")

- Lack of outcome expectancy (“That won't make a difference even if I do it”)

- Inertia of previous practice ("That is much harder than the way l've been doing it up to now, and it is working for me now!")

- External barriers (resources, government, and office space and staff);

- Guideline-related barriers ("It's too hard to do ...")

- Patient-related barriers (the patients cannot or will not do it)

- Environment-related barriers (Kyoto, pollution, workplace, etc)

Data from reference 1, pages 22,23

happen, so we must create mechanisms to get the information into the clinician's hands (dissemination) and then to get them to use it (implementation).

We are all individuals, and thus, we learn differently and invoke change differently. I truly believe that physicians have their patients' best interests at heart. We do, however, know that individuals approach new information differently. A good way to describe physicians is with the model shown in Table 8 .

The seeker is seeking knowledge and just needs to be pointed in the right direction. This person rapidly assimilates new ideas. The receptive physician is very interested in knowledge transfer, but still needs a little bit of facilitation. The traditionalist is used to his or her scope of practice, but wants to improve his or her knowledge if he or she can see the benefits and rewards. Such physicians need more facilitation and evidence of rewards. The pragmatist thinks knowledge is important, but recognizes the barriers, especially their own. Strong incentives must be used to get this group's attention, and obstacles must be removed, often just for them. The last group of physicians are a big black hole when it comes to education theory and models. We do not know their needs or values because they do not come out of their offices!

Physician barriers to new guidelines are really quite simple but are also numerous (Table 9).

So how do we do it? How do we get the information to physicians? How do we make them buy into the guidelines and make them change their practice to incorporate them? If I had the answer, I would have already done it, but instead I can only offer some ideas. First, we have to consider starting earlier. Let medical students and residents be exposed to guidelines in their training to understand how they are to change in the future. Behaviour change is needed, not just information transfer. Multifaceted interventions are needed. Educational outreach processes, particularly interactive ones that allow immediate behaviour change are effective, especially when followed by reminders. Involvement of opinion leaders and respected peers work well, especially in family practice. Group meetings in which consensus can be reached are effective. Audit and feedback, when done in a nonthreatening manner, can precipitate change. We all remember a case that has gone wrong, especially if we know that we could have done it better with a little more knowledge or effort!

Didactic lectures and general mailings do not work - but we still do them anyhow, don't we! The future may well encompass electronic methods such as Palm Pilot-based programs, 
Internet programs, consultations with electronic feedback forms - and even more exciting, electronic medical records with the guidelines incorporated so that the proper process is lined up for you as you make the diagnosis. Reminders must be visual and, thus, algorithms, flow charts and pocket cards may be useful.

Medicine is exciting. We also never stop learning. We learn from our patients, our colleagues, our parents and our children. Guidelines must be useful, adoptable and authoritative. We must also attempt to assist in the behavioural changes that are needed beyond the information transfer. These barriers must be identified and broken down. We are in the information age; let us embrace it. The dissemination and implementation committees of the respiratory guidelines are working hard to try to make this happen.

\section{REFERENCES}

1. Koutsavlis A. Disseminating Practice Guidelines to Physicians. Québec: Institut national de santé publique du Québec, 2001.

Correspondence: Dr Alan Kaplan, Family Physician Airways Group of Canada, 17 Bedford Park Avenue, Richmond Hill, Ontario L4C 2N9. Telephone 905-883-1100, fax 905-884-1195, e-mail for4kids@sympatico.ca

\section{The perspective of allied health professionals}

\author{
Lisa Cicutto RN PhD ACNP CAE
}

Faculty of Nursing, University of Toronto and Asthma and Airways Centre, Toronto Western Hospital, University Health Network, Toronto, Ontario

$\mathrm{C}^{\mathrm{l}}$ inical practice guidelines are developed for the purpose of improving care for individuals living with the condition. Clinical practice guidelines pertaining to respiratory conditions are numerous and widely available, particularly in the medical community. Such guidelines are also becoming more popular and common in the other health professions. However, there is limited evidence regarding their impact on professional practice behaviours and patient outcomes $(1,2)$.

The body of knowledge regarding the effectiveness of strategies to enhance the uptake of evidence is described as 'imperfect' (3). The majority of work in this area has focused on physicians but more attention is being directed to allied health professionals. The purpose of the present section is to review the literature regarding the barriers and facilitators for implementing evidence into the practice of allied health professionals.

It is important to think about whether and how the implementation of guidelines or the uptake of evidence differs for allied health professionals compared with physicians. There are several reasons to think that differences do exist. Allied health professionals are usually employees of health care organizations and have less decision-making autonomy to change their practice than physicians. Furthermore, employment conditions vary between physicians and allied health professionals; for example, allied health professionals often work shifts, hold casual or parttime positions, and float between different health care organizations and specialty areas. The combination of these circumstances may make it more difficult to facilitate the adoption of new evidence and guidelines into practice.

\section{BARRIERS TO IMPLEMENTING \\ EVIDENCE-BASED PRACTICE}

Several studies have identified and explored barriers and facilitators to evidence-based care. In general, there are three influences on research uptake, namely, individual, organizational and research-specific factors. A systematic review conducted by Estabrooks et al (4) of nurses' research utilization behaviours suggested the following six categories of individual determinants: beliefs and attitudes; involvement in research activities; information-seeking; professional characteristics; education; and other socioeconomic factors. The most influential individual determinant factor for research use was attitude toward research. Nurses who were more research-active (ie, who were able to find and appraise the evidence, who have a keen interest in research and who value research) were more likely to experience success in implementing evidence into practice. The organizational role of the nurse was also observed to correlate consistently with research use; nurses in leadership positions (ie, clinical nurse specialists, nurse practitioners and practice leaders) and in managerial positions reported higher research use.

Other studies used qualitative methods to identify additional barriers to implementing research into practice $(5,6)$. These include the following: problems with finding, accessing, appraising, interpreting and using research products (too complex, academic and statistical); a lack of clinical credibility for research and researchers, and the failure of research to provide the level of clinical direction desired; a lack of skills and motivation of clinicians to use research; and a preference for research to be passed on to them by a third party (ie, a clinical nurse specialist). The difficulty in synthesizing and appraising research has been reported by several allied health professionals, not only nurses $(7,8)$. Often nurses and respiratory therapists enter the profession without taking a course in critically appraising research. Those who complete a baccalaureate degree are more likely to complete such a course, but this has recently changed. The literature suggests that without a basic knowledge of research, clinicians do not see research as a necessary part of everyday practice. This unfamiliarity with research and published evidence may also be linked to their preferred sources of information, which tend to place personal clinical experience and colleagues at the top of the list and formal sources of knowledge such as research articles and texts at the bottom $(4,7-9)$. Allied health professionals also tend to rely on information that is provided to them by their employers to inform practice. Despite the current era of evidencebased practice, nurses, respiratory therapists and rehabilitation therapists rely heavily on their peers for information.

The workplace provides a context that appears to be influential in the uptake of research and practice guidelines. Large-scale, multisite, multidisciplinary studies highlight a number of factors $(4,6,9,10)$. Health organizations include a range and diversity of stakeholders or players who also have differing levels of autonomy in decision-making. As a result, allied health professionals often think that they lack the authority to change practices $(4,7,9,10)$. In addition, there is often a lack of administrative support and resources in clinical settings for implementing research and guidelines (4-10). Staff report a lack of time to find, access, appraise and implement research and guidelines. This creates an unsupportive culture. A lack of feedback from managers and colleagues within and external to the discipline has also been identified as an 
important barrier $(5-7,10)$. Interprofessional barriers can also prevent integration of evidence into practice (6-10). Allied health professionals report the importance of physicians being supportive of change and the need for practice to be evidence based. Professional boundaries can inhibit the flow of information and knowledge, which could potentially affect the quality of care of patients and families.

\section{FACILITATORS TO IMPLEMENTING EVIDENCE-BASED PRACTICE}

Other investigators have identified factors that facilitate the uptake of evidence into practice. These facilitators include administrative commitment and support (such as collection and feedback of comparative data to clinicians and cueing via electronic records), favourable research attitudes, educational interventions, mentoring and financial resources $(6,8,10-12)$. To enable the integration of research into practice, it is important to have access to the evidence and the ability to appraise the evidence. Moreover, the strength of the evidence or practice recommendation needs to be sound and clear $(6,10-12)$. Studies indicate that educational-behavioural interventions can influence personal knowledge, beliefs and skills $(5,6,12)$. Implementing practice guidelines requires a variety of skills, including evidence appraisal, patient assessment, delineation of a management and monitoring plan, and patient education. To be effective, educational-behavioural interventions must be tailored to the knowledge, attitudes and skills needed for implementing the guideline. They should also address the intensity of treatment expected of the providers (clear expectations of performance), meet the special needs of patient populations, and address the context and setting in which the intervention will be provided (12). In addition, considering the context of multidisciplinary care, it is important that the practice change or initiative have a multidisciplinary focus. All parties need to have a sense of ownership in the practice change and feel that their disciplines' body of knowledge is represented $(6,7,10)$.

The role of 'change agents' appears to be significant to the implementation of evidence into practice $(5,6,8,9-12)$. Roles of change agents appear with different labels and guises. However, previous work $(5,6,8,9-12)$ suggests that having a dedicated facilitator, project leader, and/or opinion leader who works with individuals in the practice context can be a powerful enabling factor. These types of roles are often described as those of facilitators because they bridge the research and the practice contexts. Facilitators work with individuals and teams to articulate the key issues/recommendations of the guidelines, and enable the development and implementation of strategies that acknowledge and incorporate the practice setting (contextual) factors.

Previous studies $(6,8,11,12)$ have also highlighted the need for organizational fit - that is, the research needs to be translated so that the 'new practice' is perceived to fit into the organizational structures and procedures to ease uptake, because without the ability of organizational integration, the initiative is more likely to fail. Often, for research evidence to be accepted at the organizational level, some processes of local negotiation and adaptation are required. Opinion leaders can act as mediators and translators in the process of explaining the available evidence, adapting guidelines to take into account local perspectives and circumstances, and assisting with attaining general consensus. Sustained organizational adoption is largely dependent on how well it fits the specific organization (11).

\section{CONCLUSION}

Getting research into practice is complex and does not follow a logical and linear path. It is dependent on more than an individual practitioner's motivation. Indeed, there are factors at the organizational and multidisciplinary team levels that are pivotal for success. Broadly, the key elements for getting evidence into practice are individual practitioner variables, evidence (available, strong and clear), context (organizational, setting and team characteristics) and facilitation (the need for a leader and translator).

\section{REFERENCES}

1. Graham ID, Beardall S, Carter AO, Tetroe J, Davies B. The state of the science and art of practice guidelines development, dissemination and evaluation in Canada. J Eval Clin Pract 2003;9:195-202.

2. Thomas L, Cullum N, McColl E, Rousseau N, Soutter J, Steen N. Guidelines in professions allied to medicine. Cochrane Database Syst Rev 2000:CD000349.

3. Grimshaw JM, Thomas RE, MacLennan G, et al. Effectiveness and efficiency of guideline dissemination and implementation strategies. Health Technol Assess 2004;8:iii-iv, 1-72.

4. Estabrooks CA, Floyd JA, Scott-Findlay S, O'Leary KA, Gushta M. Individual determinants of research utilization: A systematic review. J Adv Nurs 2003;43:506-20.

5. Melnyk BM, Fineout-Overholt E, Feinstein NF, et al. Nurses' perceived knowledge, beliefs, skills, and needs regarding evidencebased practice: Implications for accelerating the paradigm shift. Worldviews on Evidence-Based Nursing 2004;1:185-93.

6. Rycroft-Malone J, Harvey G, Seers K, Kitson A, McCormack B, Titchen A. An exploration of the factors that influence the implementation of evidence into practice. J Clin Nurs 2004;13:913-24.

7. Mishoe SC. Critical thinking in respiratory care practice: A qualitative research study. Respir Care 2003;48:500-16.

8. Rappolt S, Tassone M. How rehabilitation therapists gather, evaluate, and implement new knowledge. J Contin Educ Health Prof 2002;22:170-80.

9. Olade RA. Strategic collaborative model for evidence-based nursing practice. Worldviews on Evidence-Based Nursing 2004;1:60-8.

10. Conway E, Schoettker PJ, Moore A, Britto MT, Kotagal UR, Rich K. Empowering respiratory therapists to take a more active role in delivering quality care for infants with bronchiolitis. Respir Care 2004;49:589-99.

11. Locock L, Dopson S, Chambers D, Gabbay J. Understanding the role of opinion leaders in improving clinical effectiveness. Soc Sci Med 2001;53:745-57

12. Ockene JK, Zapka JG. Provider education to promote implementation of clinical practice guidelines. Chest 2000;118(Suppl 2):33S-9S.

Correspondence: Dr Lisa Cicutto, Faculty of Nursing,

University of Toronto, 50 St George Street, Toronto, Ontario

M5S 3H4. Telephone 416-978-6059, fax 416-978-8222,

e-mail lisa.cicutto@utoronto.ca

\section{The point of view of patients and the public}

\author{
Mary L Allen MA
}

The Allergy/Asthma Information Association, Beaconsfield, Quebec

Datient associations play a key role in encouraging patients
to seek appropriate professional care and in helping them
to cope after diagnosis. Canada has several patient associations 
that work closely with medical professionals as they provide information, education, support, advocacy and partnership to patients, families, schools and the general public. We believe that the various associations can and should play a key role in the dissemination of new guidelines.

Patients obtain information about asthma not only from medical professionals such as family doctors, pediatricians, specialists, nurses and pharmacists, but also from friends, family, coworkers, peers, media, newspapers, Web sites and levels of government, as well as alternative practitioners and a variety of other sources. Therefore, it is very important that key points about new guidelines be disseminated to patients and the public, as well as to medical professionals. An added benefit is that medical professionals are reached indirectly when the public is targeted.

Associations can help to disseminate guidelines and basic facts about asthma care using a variety of tools at their disposal, many of which can be utilized repeatedly over a long time at a relatively low cost. Possible tools include Web sites, newsletters, brochures and other publications, phone calls, support groups, workshops, events and seminars, press releases, print-ready ads and fillers. Many groups have established partnerships with the media and with other organizations that can also be utilized.

Barriers to proper care and control of asthma include the following: lack of access to a regular physician; not knowing what control means; aversion to taking medications, especially steroids; aversion to taking more than one medication; no allergy testing; no education about environmental control; not fully understanding the benefits of treatment; a preference for 'alternative' care; difficulty in obtaining a referral to a specialist; not being ready to learn and/or being in denial; treatment goals not related to patient's own goals; poor compliance, etc. In some provinces, economics may also play a role for some families.

Messages must be consistent, clear and relevant to the patient. The process, as well as medical facts about asthma, should be given consideration (ie, how to access care/follow-up and how to pay for medications). Patients need to be aware that reflective teaching and learning takes time, and that follow-up by the same caregiver is important as the patient learns to deal with asthma effectively.

Topics relevant to patients include the need for preventative medication(s), 'out of control' signals, the importance of compliance and follow-up, handling emergencies and the essentials of proper care. Messages to patients can be framed around questions related to sleep disruption, ability to exercise, absenteeism at work and school, the importance of consistent care by a medical doctor and reassurance about the use of ICS in children and adults. Essentials of care include items such as allergy tests, environmental control, medications, action plans and follow-up. Many patients would also benefit from information about how to access and assess appropriate asthma care.

A global approach is recommended - one that targets physicians, allied health professionals, patients and the public by using carefully crafted key messages and repetition of these messages from many credible sources over the long term. While the key messages should be simple, there should be information on where to go for more in-depth information, such as a Web site.
To ensure a consistent approach, a lay version of key guidelines written in patient-friendly language should be provided to all patient associations, in French and English, and ideally, with key points in other languages. More visibility for the Canadian Network for Asthma Care and its members is recommended, along with the use of multiple logos (from professional associations, the Canadian Network for Asthma Care and patient groups) on educational materials to increase the credibility of the information.

Correspondence: Mary L Allen, Allergy/Asthma Information Association, 172 Andover Road, Beaconsfield, Quebec H9W 2Z8. Telephone 514-694-0679, fax 514-694-9814, e-mailquebec@aaia.ca

\section{The point of view of communications/professional relations firms}

\author{
Serge Moraca BSC \\ Meducom International Inc, Guelph, Ontario
}

$A s$ a result of the sheer volume of information available in A the health care community, it is not surprising that the average primary care clinician complains of being overwhelmed with information, particularly as it relates to guidelines. Moreover, they are often interpreted as confusing and at times conflicting. In Ontario alone, the Guidelines Advisory Committee endorses guidelines in over 68 therapeutic areas. Never has it been more important to have an effective dissemination and implementation strategy.

One of the important functions of practice guidelines is to provide a rigorous review and benchmark of current evidence within a therapeutic area, while providing direction for future research. Furthermore, guidelines provide a critical foundation from which a clinician can make evidence-based decisions about patient care. For clinicians who are resistant to change, guidelines can, at the very least, predispose them toward future behavioural change.

Evert Rogers (1) identifies five distinct stages to the process of behavioural change, namely, knowledge, persuasion, decision, implementation and confirmation. Knowledge implies basic awareness of the intervention, whereas persuasion is the process whereby the learner develops a favourable or an unfavourable perception of the proposed change. This process involves considering benefits versus barriers to change and may be further influenced by the complexity of the message, as well as consistency with local practice. If fellow colleagues have begun to adopt a guideline, it may help to influence a clinician during this stage. The move from decision, a stage where there is a drive to seek additional information, to implementation can be facilitated by repeated exposure to guidelines through various methods of dissemination, such as continuing medical education events and the use of practical implementation tools. Research evidence indicates that the greater the educational component of dissemination, the more likely it will be adopted into practice (2). Thus, publishing a guideline in a journal can provide knowledge. However, this may not be enough to invoke implementation and, ultimately, behavioural change in clinicians. 
Individual clinicians may also have different receptiveness to change. Rogers (1) suggests that individuals react differently to change based on a stable trait or predisposition. 'Early adopters' are respected group leaders who study a guideline (or are even involved in their development) and implement the recommendation into practice. The group labelled the 'early majority' are sensitive to peer influence and may be more cautious; they may be unwilling to risk time and resources. Furthermore, the 'late majority' are individuals who are suspect of change and may require significant persuasion before a decision can be reached. Finally, the 'laggards' are individuals who often require incentives and formal rules before implementation of any guideline recommendations or changes occur.

A significant reason for guidelines failing to invoke change is that they do not always reach the intended audience (3). The role of a communications agency is to bridge the gap between the guidelines and the target audience. Communications specialists integrate the interests and needs of each stakeholder into designing and developing education platforms that are not only practical for the target audience, but also facilitate learning and behavioural change within the intended target audience. For communication strategists, understanding the needs of the audience, elevating levels of awareness and constant innovation are primary goals. The communications industry strives to empower more clinicians as trainers and facilitators, employing a multidisciplinary approach that communicates message continuity with increased reach and frequency.

There is no simple solution to dissemination and implementation of guidelines; the ideal strategy includes a number of tactics that take into account the variability exhibited by individuals in their receptiveness to change and attempts to reach all types of individuals. As an educator and disseminator, one must have realistic expectations of a specific intervention; learning is a process and not an all-or-nothing event. Communication should be kept simple, yet remain practical and relevant to clinical practice. Strategies should also acknowledge and consider the demands of modern clinical practice.

In summary, to be effective, the process of dissemination and implementation must recognize that the motivation to learn is complex, and that clinicians have their own personal goals and objectives for learning, along with their own preferred ways to learn. As such, variable formats and strategies are required to move learners, who are at different stages in the continuum of behavioural change, to adopt new guidelines into their current practice.

\section{REFERENCES}

1. Rogers EM. Diffusion of Innovations, 4th edn. New York: Free Press, 1995.

2. Grimshaw JM, Russell IT. Achieving health gain through clinical guidelines II: Ensuring guidelines change medical practice. Qual Health Care 1994;3:45-52

3. Thomson R, Lavender M, Madhok R. How to ensure that guidelines are effective. BMJ 1995;311:237-42.

Correspondence: Serge Moraca, Meducom International Inc,

18 Macdonell Street, Suite 200, Guelph, Ontario N1H 223.

Telephone 519-767-6644 ext 225, fax 519-767-2542,

e-mailserge@meducom.ca

\section{The evaluation of the impact of asthma guidelines in Canada}

\author{
J Mark FitzGerald MB MD FACCP FRCPC FRCP \\ Respiratory Division, University of British Columbia, \\ Vancouver, British Columbia
}

\section{EPIDEMIOLOGICAL PARAMETERS}

Canada was the first country to develop and publish national evidence-based asthma guidelines (1). The dissemination and implementation of guidelines is now recognized as being a more challenging task than the development of the guidelines themselves.

There are several measures that can be used to evaluate the success of dissemination and implementation activities (Table 10), of which the most common are epidemiological parameters, and clinical and social parameters. Following the publication of the original Canadian asthma guidelines in 1990, the rate of hospitalization for acute asthma has steadily declined in Canada (Figure 6), as has mortality from asthma. The decline in hospitalizations is of particular note because it occurred during a period when the prevalence of asthma was increasing.

It could be argued that the decline in hospitalizations is being caused by a reduction in the total number of available hospital beds rather than by improved asthma control. However, this is unlikely because during the same period, the average length of hospital stay in British Columbia (a province that is representative of the rest of Canada) remained stable at 3.5 days (Dr H Platt, British Columbia Ministry of Health, personal communication). If more severely ill patients were being admitted, one would expect the length of stay to have increased. In recent years, there has also been a steady decline in another important epidemiological parameter, namely, asthma mortality (2). In the future, reductions in the severity of asthma may also be documented in Canada, as was done in the 1990s in New Zealand (3).

\section{CLINICAL AND SOCIAL PARAMETERS}

Unfortunately, the improvements in epidemiological parameters have not translated into better asthma control in the ambulatory care setting. There appears to be a significant 'iceberg' effect - hospitalizations and mortality are falling, while the level of symptom control remains unchanged. A 2001 patient survey in Canada (4) and preliminary results from a more recent study, The Reality of Asthma in Canada (TRAC) (5), indicate that key markers of asthma control, such as nocturnal awakenings, the use of rescue medication and ongoing dyspnea, remain at high levels across the spectrum of asthma severity. An additional disappointing result from the TRAC data is that both patients and physicians believe that it is acceptable for patients to have up to two emergency department visits per year.

Moreover, another study (6) has shown that only a minority of Canadian patients receive asthma action plans from their physicians, and unfortunately, most of these plans are verbal rather than written. A recently published Alberta chart audit corroborates this - just $2 \%$ of more than 3000 asthmatic patients had evidence of a written action plan (7). 
TABLE 10

Potential outcome measures to evaluate the impact of interventions to improve the dissemination and implementation of asthma guidelines

Epidemiological parameters

- Mortality

- Near-fatal asthma episodes

- Hospitalizations

- Visits to emergency department

- Unscheduled physician visits

Physiological parameters

- Spirometry

- Peak flow measurements

- Airway hyper-responsiveness

- Sputum eosinophilia

- Exhaled nitric oxide

Clinical and social parameters

- Need for rescue medication

- Nocturnal awakenings

- Interference with activities of daily living

- Asthma exacerbations

- Disease specific quality of life measurements

- Time lost from work

- Proportion of patients in different categories of disease severity

\section{DIRECTIONS FOR FUTURE RESEARCH}

It is clear that clinicians and researchers must move beyond traditional models of delivering asthma care. This task will likely be facilitated by educating physicians to be better communicators (8), by making greater use of interdisciplinary teams of health care providers, particularly educators (9), by having a greater awareness of cultural and ethnic issues (10), and by following strategies designed to address the unique challenges associated with the management of chronic diseases (11).

Furthermore, it is clear that successful dissemination interventions must be multifactorial and have at least some of their focus on primary care physicians. The effectiveness of such interventions could be evaluated by using a cluster randomized design in which several primary care practices are exposed to a particular physician-focused intervention (8) and a nonintervention practice is provided with standard printed material. The success of the intervention can then be evaluated by choosing some or all of the items from a 'menu' of epidemiological, physiological, and clinical and social parameters (Table 10). A potential name for such a study is the Canadian Asthma Dissemination Research and Evaluation (CADRE) study.

Another potentially useful putative study is the Canadian Facilitated Asthma Referral Study (CFARS). Emergency department data indicate that facilitated referral to a specialist is associated with superior patient outcomes. Furthermore, increased efficiency of referrals can be beneficial because of the shortage of both primary care and specialist physicians in this country. The CFARS could identify characteristics of patients who appear to benefit most from referral to specialist care, as well as identifying the optimal processes for expediting such referral.

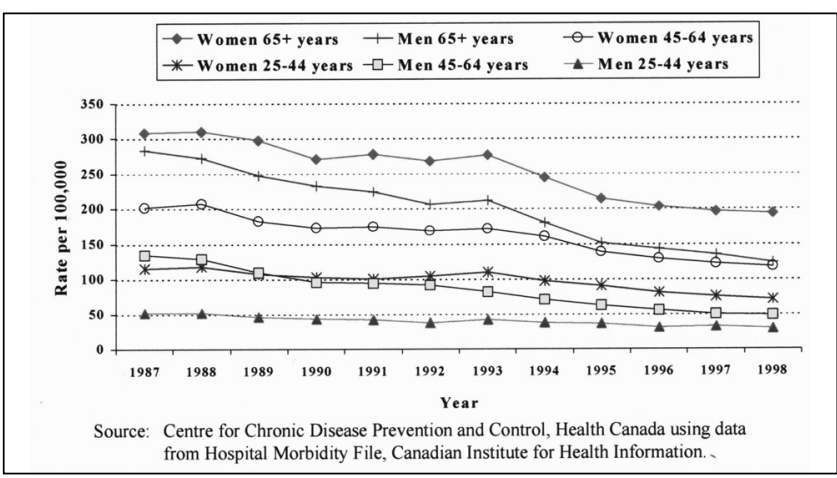

Figure 6) Asthma hospital separation rates (per 100,000) among older adults by age group and sex. Data are for Canada, excluding the territories, from 1987/1988 to 1998/1999 (standardized to 1991 Canadian population)

With the emergence of the Canadian Respiratory Clinical Research Consortium, Canadian investigators are in an ideal position to conduct such studies. There has never been a better time to design rigorous studies of evidence-based intervention strategies.

Dr FitzGerald is a recipient of a Vancouver General Hospital Scientist Award, a CIHR/BC Lung Investigator Award and a Michael Smith Foundation for Health Research Distinguished Scholar Award.

\section{REFERENCES}

1. Ernst P, FitzGerald JM, Spier S. Canadian Asthma Consensus Conference. Summary of recommendations. Can Respir J 1996;3:89-100.

2. Canadian Institute for Health Information, Canadian Lung Association, Health Canada, Statistics Canada. Respiratory Disease in Canada. September 2001. Ottawa: Health Canada, 2001.

3. Garrett J, Kolbe J, Richards G, Whitlock T, Rea H. Major reduction in asthma morbidity and continued reduction in asthma mortality in New Zealand: What lessons have been learned? Thorax 1995;50:303-11.

4. Chapman KR, Ernst P, Grenville A, Dewland P, Zimmerman S. Control of asthma in Canada: Failure to achieve guideline targets. Can Respir J 2001;8(Suppl A):35A-40A.

5. Chapman K, Boulet L-P, FitzGerald JM, McIvor A, Zimmerman S. Asthma exacerbations in Canada. The reality of asthma control. American Thoracic Society Annual Meeting 2005. San Diego, May 20 to 25, 2005.

6. Turner MO, Taylor D, Bennett R, FitzGerald JM. A randomized trial comparing peak expiratory flow and symptom self-management plans for patients with asthma attending a primary care clinic. Am J Respir Crit Care Med 1998;157;540-6.

7. Tsuyuki RT, Sin DD, Sharpe HM, Cowie RL, Nilsson C, Man SF; Alberta Strategy To Help Manage Asthma (ASTHMA) Investigators. Management of asthma among community-based primary care physicians. J Asthma 2005;42:163-7.

8. Clark NM, Gong M, Schork MA, et al. Impact of education for physicians on patient outcomes. Pediatrics 1998;101:831-6.

9. Bodenheimer T, MacGregor K. Nurses as leaders in chronic care. BMJ 2005;330:612-3.

10. Griffiths C, Kaur G, Gantley M, et al. Influences on hospital admission for asthma in south Asian and white adults: Qualitative interview study. BMJ 2001;323:926-6.

11. Managing chronic diseases. BMJ 2005;330:609-680.

Correspondence: Dr J Mark FitzGerald, Centre for Clinical Epidemiology and Evaluation, Vancouver General Hospital, Research Pavilion, 703 - 828 West 10th Avenue, Vancouver, British Columbia V5Z 1L8. Telephone 604-875-4565, fax 604-875-5179, e-mail markf@interchange.ubc.ca 


\section{Implementing practice guidelines: Do we need a Canadian national asthma campaign?}

\author{
Allan Becker MD FRCPC 1 , Dennis Bowie MD²
}

${ }^{1}$ Allergy \& Clinical Immunology, Department of Pediatrics \& Child Health, Children's Hospital of Winnipeg, Winnipeg, Manitoba;

${ }^{2}$ Queen Elizabeth II Health Sciences Centre, Halifax, Nova Scotia

$\mathrm{W}_{\mathrm{d}}^{\mathrm{h}}$ hile many guidelines have been published and widely disseminated, there has been a major gap between the dissemination and knowledge-transfer processes required in implementing guidelines. As noted in a Cochrane report, "Passive educational approaches such as the dissemination of guidelines ... are generally ineffective in changing behavior" (1). Closure of the care gap between what is known using best available data and current practice can only be accomplished through an effective implementation program. The failure to routinely translate research findings into daily practice is not caused by health care professionals being remiss in their responsibilities. Rather, as another expert notes, "health care settings are busy, complex, and occasionally chaotic [environments]" (2). There are effective approaches to changing practice, but they typically require changes within the system itself.

For example, in a report discussing the management of hypertension, the authors noted that "the real instrument of behavior change was the procedural change of delegating delivery to nursing staff" (3). Our failure to effectively implement clinical practice guidelines highlights the fact that it is critical to change the structure and process of care. This is a systems change, and is fundamental to quality improvement (4). Moreover, while changes need to be evidence-based, it is also critical that there be an interdisciplinary structure to the change $(4,5)$.

A number of recommendations for improving asthma outcomes have been put forward. For childhood asthma, a 'blueprint for policy action' has been developed (6). The policy recommendations include the following:

- Development and implementation of primary care performance measures;

- Teaching children and families self-management skills;

- Provision of case management to high-risk children and families;

- Establishment of public health grants for communities and families;

- Promotion of 'asthma-friendly' schools;

- Launching of a National Asthma Public Education campaign;

- Development of a national asthma surveillance system; and

- Development and implementation of a national agenda for asthma prevention research.

As noted by the authors, "implementing these recommendations will require coordination of activities at the national, state and local community health levels, and within and outside of the health care delivery system" (6).

\section{THE CURRENT PROBLEM}

Experts present at a workshop during the Implementing Practice Guidelines meeting came to the consensus that local implementation of guidelines is critical for effective knowledge transfer. This has been previously noted in a number of publications. For example, Heffner et al (7) stated that, "Ideally ... guidelines should be adapted ... with local ownership ... in association with an organized implementation program".

A national initiative may have more influence than local implementation initiatives (7). However, a national initiative would require a "constant drip of publicity" and "GPs' general awareness" (8). But at least one study has recognized that a national initiative has the potential to increase the quality of care in both intervention and control environments (9).

Furthermore, it is generally agreed that for a national initiative to succeed, opinion leaders need to be recruited to become the focused 'change agents' in implementing guidelines at the local level. The presence of local opinion leaders who champion the cause will enhance the initiative's effectiveness and, hence, boost the likelihood of any local 'buy-in'. This must be supported by multiple stakeholders at the local level.

A national consensus also must be present for a nationwide initiative to succeed. Unfortunately, "guideline development groups have not been routinely funded to develop an implementation strategy and no single body has held responsibility to ensure implementation [has occurred]" (9). Given this, it is even more critical that there be a nationally coordinated approach.

\section{IS A CANADIAN NATIONAL ASTHMA CAMPAIGN CRITICAL?}

Ideally, a structured Canadian National Asthma Campaign would be developed that includes all stakeholders, and that supports and coordinates local initiatives. Unfortunately, as noted, the cost of establishing such an initiative would be significant. The consensus of the working group was that local or regional campaigns would have the potential to effectively implement the asthma guidelines. In fact, local campaigns are critical to work toward local systems change most appropriate for that environment. Nevertheless, a national asthma campaign may be more important at the level of the general physician and for public awareness, and also to help coordinate the study of the effectiveness of the specific approaches and projects that are undertaken.

The general consensus arising from our implementation workshop was that local buy-in was the key, and that support from a regional and/or national program would be helpful for the process. The major impediment to establishing a Canadian National Asthma Campaign is the requirement for the appropriate funding for such an initiative.

\section{REFERENCES}

1. Freemantle N, Harvey E, Wolf F, Grimshaw J, Grilli R, Bero L. Printed educational materials to improve the behaviour of health care professionals and patient outcomes. In: The Cochrane Library, Issue 1, 1999. Chichester: John Wiley \& Sons, Ltd.

2. Grimshaw J, Eccles M, Tetroe J. Implementing clinical guidelines: Current evidence and future implications. J Con Educ Health Prof 2004;24(Suppl 1):S31-S7. 
3. Solberg LI. Guideline implementation: What the literature doesn't tell us. Jt Comm J Qual Improv 2000;26:525-37.

4. Gross PA, Greenfield S, Gretin S, et al. Optimal methods for guideline implementation: Conclusions from Leeds Castle meeting. Med Care 2001;39(Suppl 2):II85-II92.

5 . McClatchey S. Disease management as a performance improvement strategy. Top Health Inf Manage 2001;22:15-23.

6. Lara M, Rosenbaum S, Rachelefsky G, et al. Improving childhood asthma outcomes in the United States: A blueprint for policy action. Pediatrics 2002;109:919-30

7. Heffner J, Alberts WM, Irwin R, Wunderink R. Translating guidelines into clinical practice: Recommendations to the American College of Chest Physicians. Chest 2000;118(Suppl 2):70S-3S.

8. Harrison S, Dowswell G, Wright J, Russell I. General practitioners' uptake of clinical practice guidelines: A qualitative study. J Health Serv Res Policy 2003;8:149-53

9. McKinlay E, McLeod D, Dowell A, Marshall C. Clinical practice guidelines' development and use in New Zealand: An evolving process. N Z Med J 2004 Aug 6;117(1199):U999.

Correspondence: Dr Allan Becker, Allergy E Clinical Immunology, Department of Pediatrics $\mathcal{E}$ Child Health, Children's Hospital of Winnipeg, AE 101 - 840 Sherbrook Street, Winnipeg, Manitoba R3A 1S1. Telephone 204-787-2918, fax 204-787-5040, e-mail becker@ms.umanitoba.ca

\section{Implementing practice guidelines: What is the best way to implement guidelines?}

\author{
Francine Borduas MD ${ }^{1}$, Allan Becker MD FRCPC ${ }^{2}$
}

\begin{abstract}
${ }^{1}$ Continuing Professional Development, Faculty of Medicine, Université Laval, Québec, Québec; ${ }^{2}$ Children's Hospital of Winnipeg, Winnipeg, Manitoba
\end{abstract}

\begin{abstract}
breakout group from the overall workshop on implementing Apractice guidelines focused on the issue of 'best practice' for the implementation of guidelines. Participants focused on two specific aspects of this: first, the best strategies for knowledge transfer, and second, optimization of guideline dissemination and implementation.
\end{abstract}

\section{KNOWLEDGE TRANSFER STRATEGIES}

Many programs, strategies and measures can help to implement evidence and change. A number of knowledge transfer strategies that are recognized as effective to translating guidelines into clinical practice were discussed, including interactive educational workshops, expert systems, self-directed learning programs, chart audit and reflection on practice, decision aid practice tools and reminders (1-3). It was generally agreed that, at the very basic level, physician buy-in to the guidelines is critical for any effective knowledge transfer process (4).

Participants agreed that the ability of physicians to access 'e-health' programs is also critical. Ideally, this would entail the use of a computer system at the workplace that facilitates physician's assessment of every aspect of diagnosis and treatment by the use of 'just-in-time' and evidence/guidelinebased information. This can be enforced with reminders that are 'pushed' to the physician through use of the computer system.

While this form of 'expert system' would be valuable, it is uncertain how easily and how frequently it would be used by physicians. The programs would have to be flexible and adaptable to our local regions and individual clinical practices. This would allow the systems to facilitate the care of and communication with the patient by the physician (for example, by helping the physician to ask the most appropriate questions). Furthermore, targeting emerging behaviour and making such systems available to medical students, residents and fellows while they are developing skills, attitudes and clinical behaviours - would greatly facilitate the likelihood of their continuing to easily adopt evidence-based recommendations later in their careers.

Finally, workshop participants agreed that incentives are critical to help physicians buy into the process of guideline implementation (5). Financial incentives, removal of barriers to access knowledge transfer programs and availability of checklists or 'care maps' in either an electronic copy or a hard copy would allow the individual physician to adopt 'best practices'. It also may be important to consider how audits of practices can be carried out as an incentive for physicians to begin using these programs. Incentives were thought to be more helpful than penalties to facilitate the translation of knowledge into clinical practice.

\section{OPTIMIZATION OF GUIDELINE DISSEMINATION AND IMPLEMENTATION}

Focus on a clear and consistent message

Dissemination of the message is critical. The group believed that consistency of the message is important, and that the message needs to be targeted and customized to specific populations.

The focus could be put on one or two consistent messages each year; for example, in the first year, a focus on asthma control could form the basis for discussion, particularly between physicians and their patients, as well as between physicians and allied health professionals and patients. Implementation across specialties was thought to be a key to the effective evolution of this strategy.

Create a context for change and involve key opinion leaders Local buy-in and local ownership are thought to be critical to the effectiveness of implementation. Programs and measures can be undertaken to create a receptive environment, a positive attitude and a culture of change. It was clearly recognized that ongoing education to physicians, allied health professionals, patients and, ideally, caregivers is critical. However, the costs associated with extensive educational programs may limit their use. To overcome these barriers and get the message to the point of care, workplace interventions may be considered.

Multifaceted interventions are more likely to be effective than single interventions $(6,7)$. The availability of a Web site to download guidelines, documents, pocket summaries, algorithms and case studies would be helpful. Interactive educational sessions with decision aid practice tools and reminders also are effective means in disseminating and implementing the message. In addition, the availability of timely information by e-health initiatives as an active, living process should enhance the uptake of implementation.

It was thought that key opinion leaders would be needed to champion the process. Activation of a local key opinion leader network would be even more powerful. The influence of local, informal medical opinion leaders has been recognized as a 
significant factor in the diffusion and adoption of medical innovations and refinements of medical practice (8).

Assure organizational and systems conditions for change The ability for individual practitioners to take on messaging with a consistent theme was thought to be important, as was an overall change in the office environment and the office system. Organizational interventions like benefic coverage and reimbursement for guideline-based treatment protocols, and implementing clinical information systems for populationbased tracking, outcomes monitoring and bench-marking feedback may encourage guideline implementation (5). In addition, easy access through electronic means, perhaps with personal digital assistance, may help to facilitate taking on messaging.

Initiatives that attempt to establish incentives and facilitate organizational interventions should be encouraged.

\section{Create a 'call for action' at all levels}

Partnership and networking locally, regionally and nationally was thought to be important, as well as targeting multiple health care professions and the public. The roles of a national guidelines committee, government and policy-makers need clarification, but it is recognized that endorsement by key stakeholders, policy-makers and government, as well as patients' associations, have to be considered for effective implementation of guidelines.

In conclusion, we should focus on consistent messages, multifaceted interventions and partnerships, which are keys to the optimization of guideline implementation. Ongoing evaluation of this process is critical for continuous quality improvement.

\section{REFERENCES}

1. NHS Centre for Reviews and Dissemination, The University of York. Getting evidence into practice. Effective Health Care 1999;5:1-16.

2. Davis DA, Taylor-Vaisey A. Translating guidelines into practice. A systematic review of theoretic concepts, practical experience and research evidence in the adoption of clinical practice guidelines. CMAJ 1997;157:408-16.

3. DiCenso A, Virani T, Bajnok I, et al. A toolkit to facilitate the implementation of clinical practice guidelines in healthcare settings. Hosp Q 2002;5:55-60.

4. Gross PA, Greenfield S, Cretin S, et al. Optimal methods for guideline implementation: Conclusions from Leeds Castle meeting. Med Care 2001;39(Suppl 2):II89-II92.

5. Tamblyn R, Battista R. Changing clinical practice: Which interventions work? J Contin Educ Health Prof 1993;13:273-88.

6. Koutsavlis AT. Dissémination des guides de pratiques chez les médecins. Direction de la santé publique de Montréal-Centre, Institut national de santé publique du Québec, Octobre 2001.

7. Davis DA, Thomson MA, Oxman AD, Haynes RB. Changing physician performance. A systematic review of the effect of continuing medical education strategies. JAMA 1995;274:700-5.

8. Borbas C, Morris N, McLaughlin B, Asinger R, Gobel R. The role of clinical opinion leaders in guideline implementation and quality improvement. Chest 2000;118(Suppl 2):24S-32S.

Correspondence: Dr Francine Borduas, Continuing Professional Development Office, Faculty of Medicine, Pavillon Ferdinand-Vandry, Local 3316, Québec, Québec G1K 7P4. Telephone 418-656-5958, fax 418-656-2465, e-mail francine.borduas@fmc.ulvaval.ca

\section{Dissemination and implementation of guidelines on asthma and COPD in Canada: Where do we go from here?}

Louis-Philippe Boulet MD FRCPC1, Allan Becker MC FRCPC ${ }^{2}$, Dennis Bowie MD FRCPC ${ }^{3}$, Paul Hernandez MD FRCPC ${ }^{3}$, Andrew Mclvor MD FRCPC ${ }^{3}$, Michel Rouleau MD FRCPC ${ }^{4}$

${ }^{1}$ Centre de Pneumologie, Institut universitaire de cardiologie et de pneumologie de I'Université Laval, Hôpital Laval, Québec, Québec; 2Section of Allergy \& Clinical Immunology, Department of Pediatrics \& Child Health, Children's Hospital of Winnipeg, Winnipeg, Manitoba; ${ }^{3}$ Respirology Division, Queen Elizabeth II Health Sciences Centre, Dalhousie University, Halifax, Nova Scotia; ${ }^{4}$ Centre de Pneumologie, Hôpital Saint-Sacrement, Québec, Québec

Canada has been among the world leaders in the develop- 2 ment of guidelines on optimal management of chronic respiratory diseases such as asthma and COPD. Guideline development is considered a valid instrument for directing the medical community in how to practice evidence-based disease management and for identifying clinical areas that require further research.

However, while the Canadian medical community has made very significant progress in this area, there appears to have been only modest impacts on patient outcomes. Recent surveys show that the state of asthma control in the country has not changed significantly in the past decade $(1,2)$. There also continues to be significant morbidity and mortality associated with COPD (3). Key recommendations of clinical guidelines for these diseases are still not integrated into care. These include routine use of objective measures of airway obstruction, universal access to high-quality education and pulmonary rehabilitation programs, and overall optimal assessment of the control and severity of the diseases $(4,5)$. Furthermore, there continues to be limited patient access to the best pharmacological treatments, both because some physicians are not adhering to treatment algorithms and because of restriction of formularies by governments and individual health care institutions.

In these proceedings, we have reflected on the initiatives of guideline implementation in Canada and abroad in an attempt to learn from their successes and their failures. We have tried to identify the barriers that have been encountered and the factors that will facilitate better implementation of guidelines in the future.

One of the lessons we have learned in this exercise is that the main targets of these initiatives should be general practitioners and allied health professionals. After all, these are the individuals who treat most patients with respiratory ailments. Thus, the process of implementation should use proven and cost-effective methods for transmission of the details of the guideline recommendations to physicians, allied health professionals and patients. These methods cover the spectrum - from electronic and hard copy reminders, to algorithms, to data for hand-held computers. Academic detailing also can have an important role, as can complementary interventions from health educators and pharmacists.

Some of the programs also should be directed at the patients themselves and their families, as has been successfully accomplished in other countries. High-quality education and regular follow-up of patients is mandatory for empowering patients and promoting effective self-management of their disease under the guidance of professional caregivers. 
Overall, implementation of guidelines can best be accomplished by multipronged, multipartner programs. National programs should be developed, and these programs must be carefully intercalated with local treatment programs and institutions. Furthermore, the various interventions should be scrutinized to confirm their effectiveness and to continue to optimize integration of guideline recommendations into daily care. Too few studies have aimed to determine the respective influence of the previously proposed interventions.

We hope that the report of this symposium will stimulate more successful guideline implementation initiatives, and thus, significantly improve the outcomes of patients with asthma and COPD across the country.

\section{REFERENCES}

1. Chapman KR, Boulet LP, FitzGerald MJ, McIvor RA, Zimmerman S. Patient factors associated with suboptimal asthma control in Canada: Results from the reality of asthma control study. Am J Respir Crit Care Med 2005;2:A678. (Abst)

2. Boulet LP, Thivierge RL, Bellera C, Dorval E, Collet JP. Physicians' assessment of asthma control in low vs high asthma-related morbidity regions. J Asthma 2004;41:813-24.

3. Canadian Institute for Health Information, Canadian Lung Association, Health Canada, Statistics Canada. Respiratory Disease in Canada, 1st edn. Ottawa: Health Canada, 2001:1-102.

4. Anthonisen NR, Woodlrage K, Manfreda J. Use of spirometry and respiratory drugs in Manitobans over 35 years of age with obstructive lung diseases. Can Respir J 2005;12:69-74.

5. Chapman KR, Bourbeau J, Rance L. The burden of COPD in Canada: Results from the Confronting COPD survey. Respir Med 2003;97(Suppl C):S23-S31.
Correspondence: Dr Louis-Philippe Boulet, Hôpital Laval, 2725 Chemin Sainte-Foy, Ville de Québec, Québec G1V 4G5. Telephone 418-656-4747, fax 418-656-4762, e-mail lpboulet@med.ulaval.ca

ACKNOWLEDGMENTS: We are grateful to Patrice Lemay, Carole Guérin, Nadine Bédard and Sylvie Carette for their help with the organization of the symposium, and Ms Rosemary Frei for her careful revision of this report. The symposium was made possible with the contribution of our partners. Platinum: Boehringer Ingelheim, Canadian Network for Asthma Care, Canadian Thoracic Society, Faculté de Médecine de l'Université Laval, GlaxoSmithKline and Pfizer; Gold: AllerGen Network of Centres of Excellence, Altana, AstraZeneca, Public Health Agency of Canada, Merck Frosst and Novartis; Silver: Sanofi-Aventis and the CIHR Institute of Circulatory and Respiratory Health.

DISCLOSURE: LBP has been on Advisory Boards for Altana Pharma, AstraZeneca, GlaxoSmithKline, Novartis and Merck Frosst. Lecture fees were provided by 3M, Altana Pharma, AstraZeneca, GlaxoSmithKline, Merck Frosst and Schering. Sponsorship for multicentre clincial trials was provided by $3 \mathrm{M}$, Altana Pharma, Asthmatx, AstraZeneca, Boehringer Ingelheim, Dynavax, Genentech, GlaxoSmithKline, IVAX, Merck Frosst, Novartis, Pfizer, Roche, Schering and Topigen. Other support for research was provided by FRSQ, CIHR, AllerGen, IRSST, NIOSH (CDC) and QACN (TEAM). 


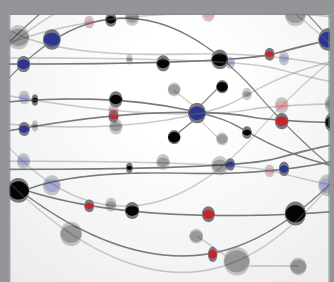

The Scientific World Journal
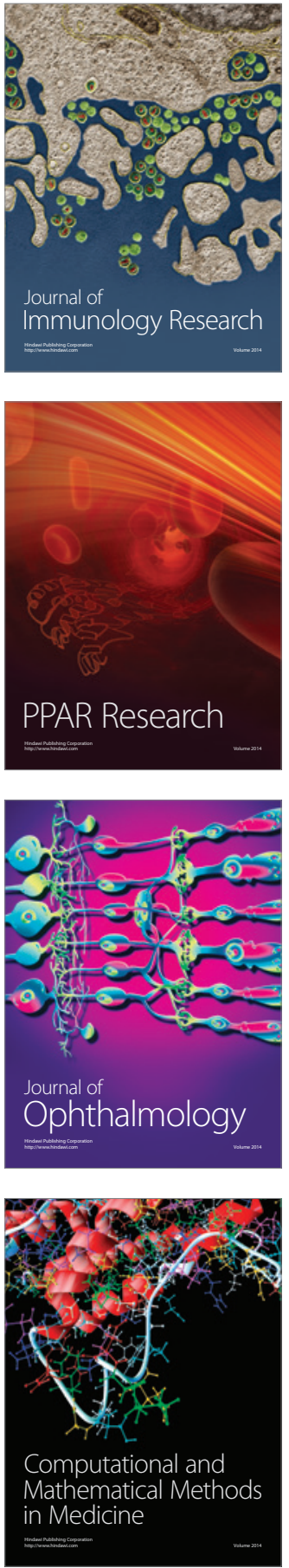

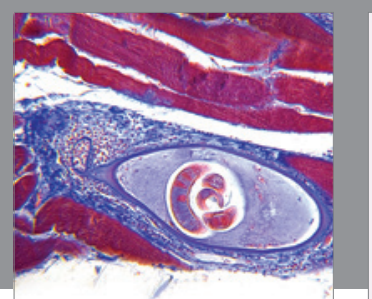

Gastroenterology Research and Practice

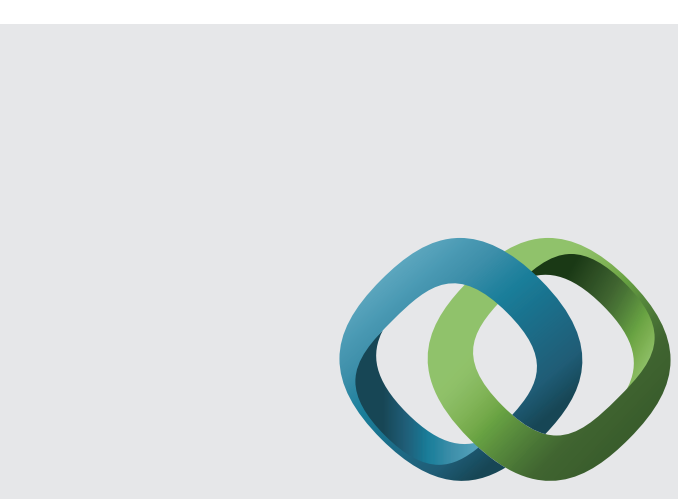

\section{Hindawi}

Submit your manuscripts at

http://www.hindawi.com
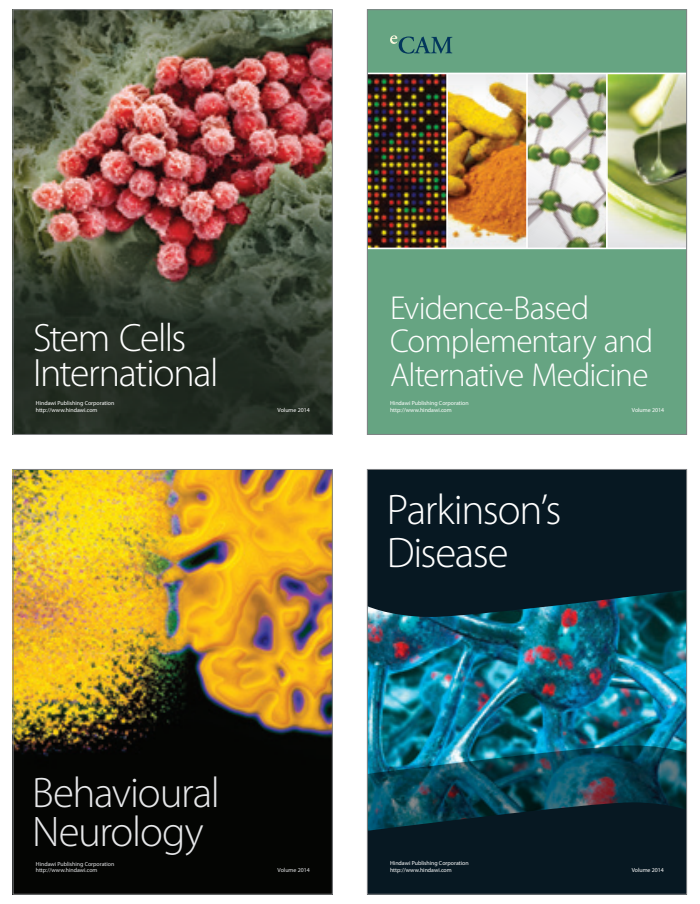
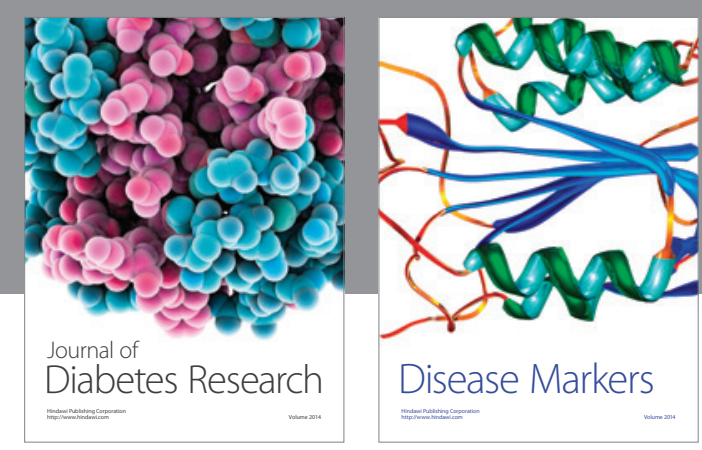

Disease Markers
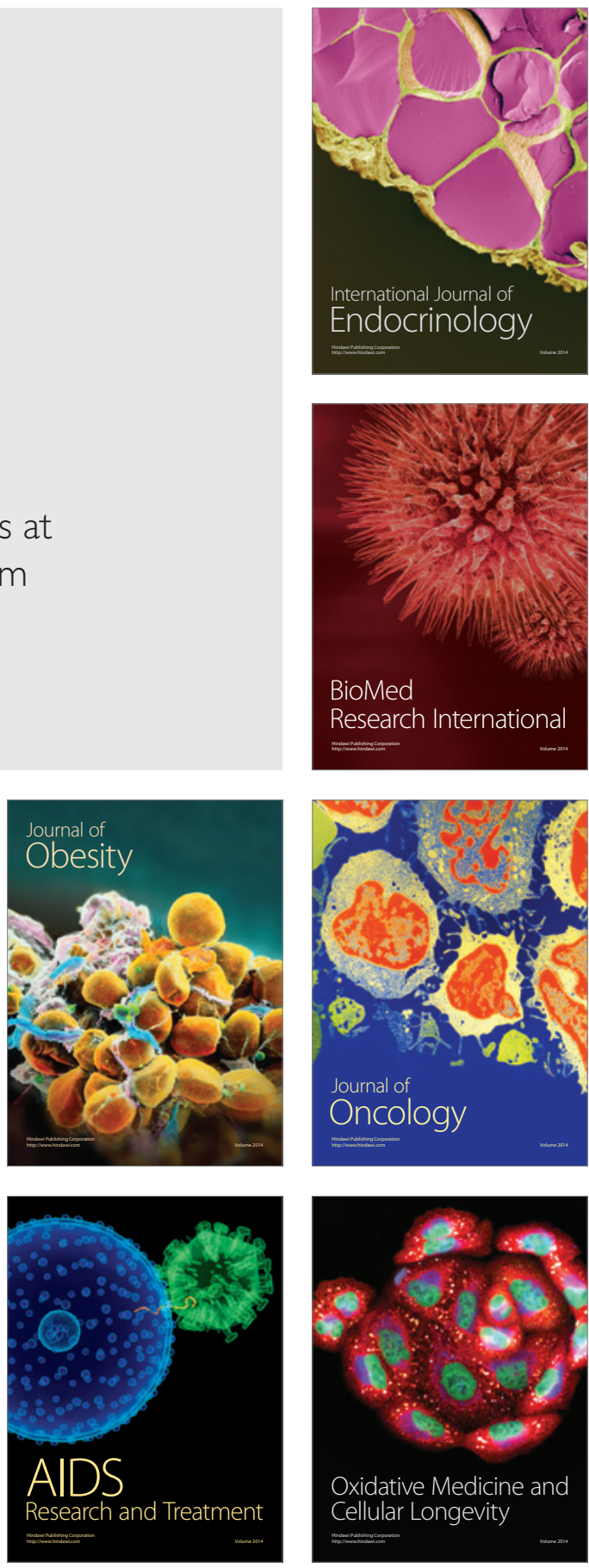